\title{
Electoral Competition: New Measures and Applications
}

\author{
By \\ James Splinter \\ A thesis submitted to the Faculty of Graduate and \\ Postdoctoral Affairs in partial fulfillment of the requirements \\ for the degree of Doctor of Philosophy in
}

Economics

Carleton University

Ottawa, Ontario 


\begin{abstract}
The thesis presents three papers on electoral competition. In the first chapter, a quantitative measure of political competition is computed for Canadian parliamentary elections over the history of the modern Canadian state from 1867 to 2011. The measure of political competition, electoral risk, measures the probability that the incumbent government will lose the next election. The extent to which the economic indicators can be used in an explanation of electoral success is investigated. Current measures of electoral competition are improved upon and demonstrated to be robust. Amongst conflicting recent literature, this paper offers evidence of the continued existence of the 'economic voter' in Canada.
\end{abstract}

In the second chapter, I examine the length of a Canadian parliament. The methodology employed uses survival analysis, allowing for the estimation of the dynamic probability that an incumbent government will call an election. The analysis incorporates principal components, along with other covariates, such as measures of political competition, to accurately estimate when an election is called. An optimal stopping rule is employed for the election decision and a Cox proportional hazard model is used to estimate the hazard function. The results show that Canadian governments engage in election timing and they are influenced by the prevailing level of electoral competition as measured by the probability of losing the next election.

In the third chapter, I examine several indexes of political competition. I consider these indexes as reflecting different dimensions of an underlying degree of competition using a multiple-indicators multiple-causes model (MIMIC). A variety of economic and socio-political causal variables are employed in the models and investigated for significance. The resulting index of political competition for Canada shows that competition was highest from the 1950s to the early 1980 s, before the level of competition decreased for 20 years until the early 2000s. In addition, the estimated indexes show that political competition has been elevated for the period of 2004 to 2015. 


\section{Acknowledgements}

I would like to thank Stephen Ferris, Roland Pongou, Lynda Khalaf, Hashmat Khan, and Patrick Coe for their valuable comments and suggestions. I would especially like to thank my supervisors Stanley Winer and Marcel-Cristian Voia for their guidance throughout the work on this thesis. Professor Winer's support and wisdom has been immeasurable and he has greatly helped me complete this journey.

On the administrative side, I am especially grateful to the graduate administrator of my department, Marge Brooks - she has helped me immensely throughout the program. I am also grateful to the other administrative staff of the department, who supported me during my tenure: Renee Lortie, Amanda Wright, Sabrina Robineau, Alison Daley, and Dawn Bjornson.

My family has been a constant source of support and inspiration; I could not have done this without them. I would like to draw special attention to my girlfriend, whose unending support and faith in me helped me complete my thesis.

Special thanks to the Carleton students who began this journey with me: Alex Maslov, Anderson Nzabandora, Tim Grieder, and Susan Bennet. I would also like to thank each of the upper-year and lower-year PhD students from Carleton and the University of Ottawa that made this journey unforgettable, with special thanks to Samira Hasanzadeh, who studied with me for countless hours.

Special thanks to the members of the Emperors Club, whose economic insights helped guide me every step of the way: Andrew Kwai, James Armbruster, John Mesman, Matthew Dick, and Dean Tester.

I am grateful to the members of the Economics Society who have made this process so memorable: Glen Barber, Scott Bacon, Andrew Kelly, Alicia Foster, Stephen van der Werf, and Nick Toller. 
Lastly, I am grateful to Troy Joseph and Vivek Dehejia, my professors of first year economics. They inspired my love for economics and they were the beginning of this journey. 


\section{Contents}

Chapter 1.

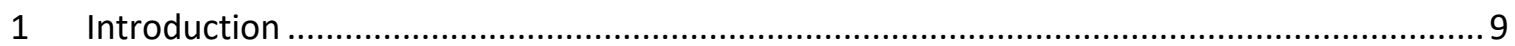

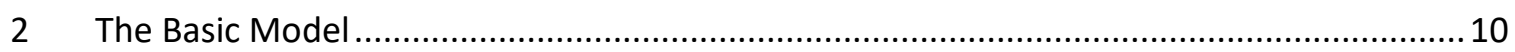

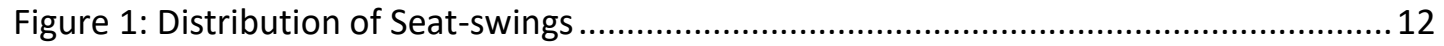

Figure 2:'Three Party' Pattern of Contestation Model Mixture, 1979 Canadian Election.....19

Figure 3:'Four Party' Pattern of Contestation Model Mixture, 1979 Canadian Election........20

Figure 3: Swing-ratios of Selected Parties over Time .........................................................22

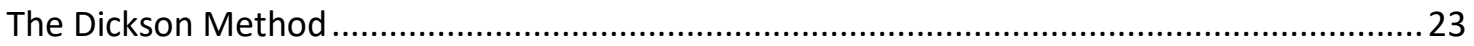

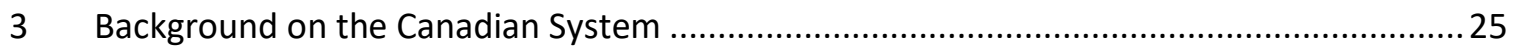

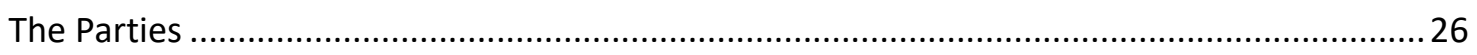

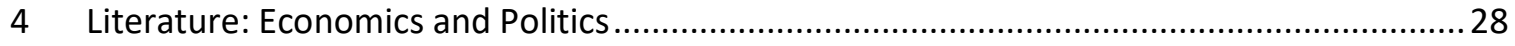

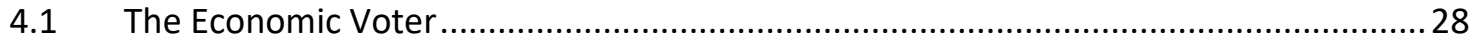

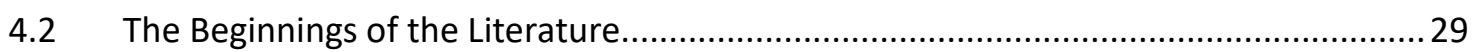

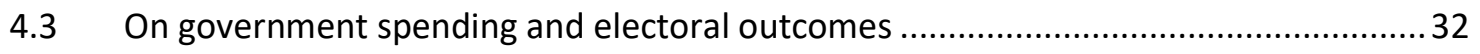

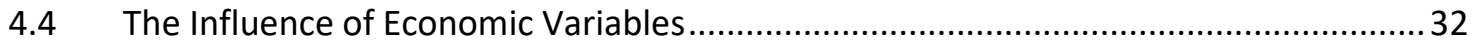

4.5 Concluding Literature on Economics and Politics ..................................................... 33

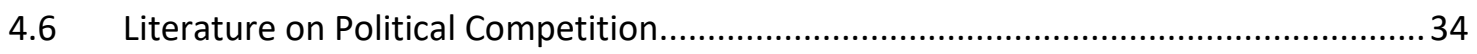

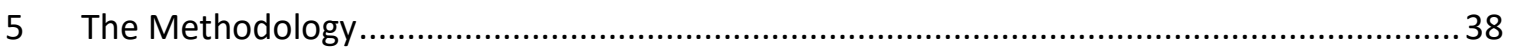

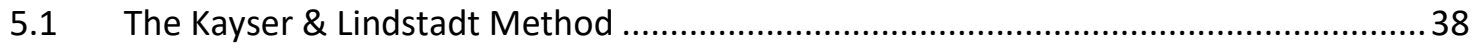

Figure 5: Kayser and Lindstadt (KL) and Historical LPRs Over Time.....................................42

Figure 6: All Kayser and Lindstadt LPRs Over Time .......................................................... 43

Figure 7: All Historical LPRs Over Time ……..................................................................... 44

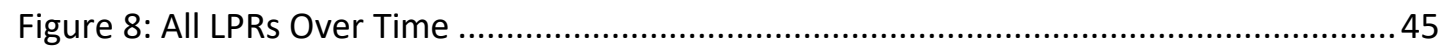

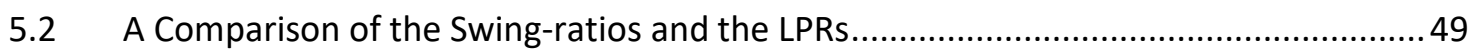

Figure 9: Swing-ratios of all Available Parties Over Time .................................................... 49

Figure 10: Swing-ratios of Top 3 Modern Federal Parties Over Time...................................50

Figure 11: LPRs and Swing-ratio of Liberals and Conservatives Over Time ..........................51

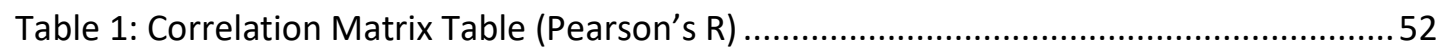

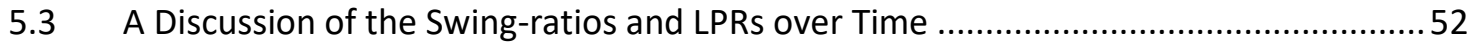

6 Robustness Test: Does Economics Drive Politics? ........................................................... 53 
Beta Regression

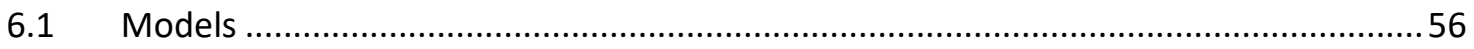

Table 2: Regression Results, Post World War 2, Canadian Variables ...................................58

Table 3: Regression Results, Post World War 2, American Variables ....................................59

Table 4: Regression Results, 1890-2011, Canadian Variables .............................................60

Table 5: Regression Results, 1890-2011, American Variables ..............................................61

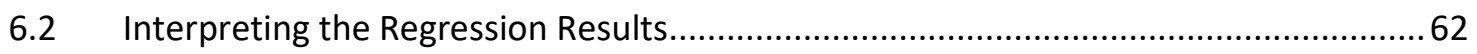

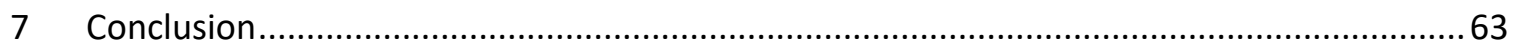

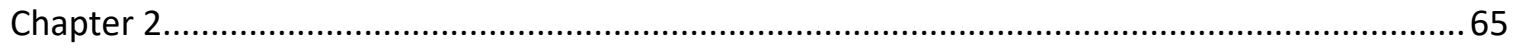

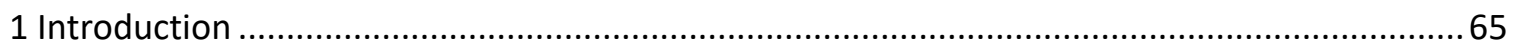

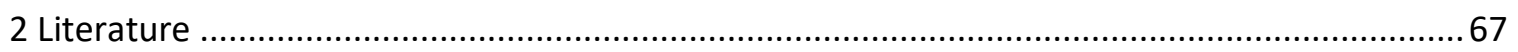

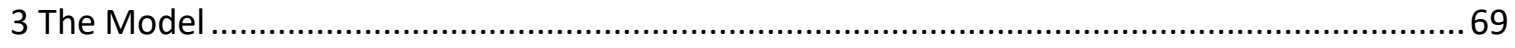

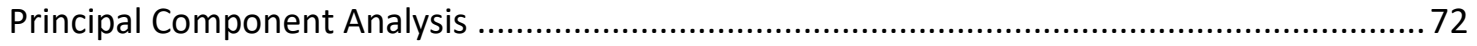

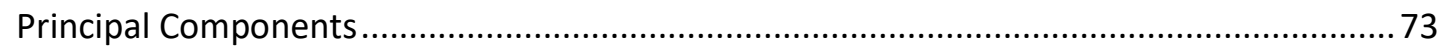

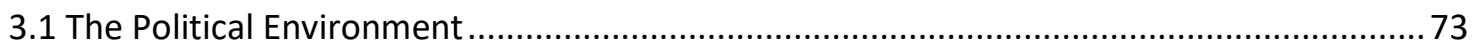

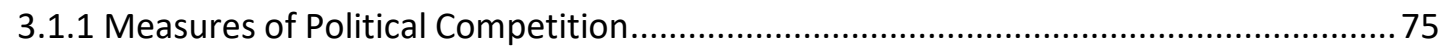

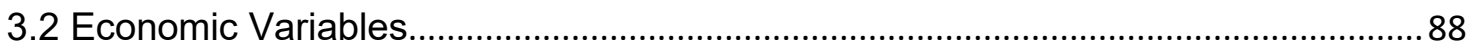

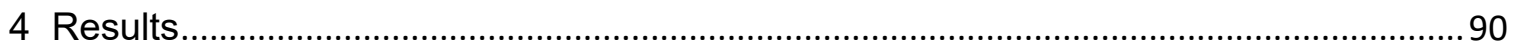

Figure 7: The Empirical Hazard Function .................................................................. 91

Table 1: Cox PH Results, $\exp \beta$ estimates (Robust Huber/White z values in brackets below

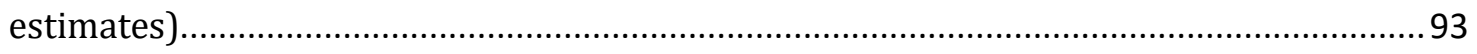

Table 2: Results from Combining Measures of Competition .............................................97

Figure 8: Estimated Hazard Functions of Model 5A and 5B ............................................ 98

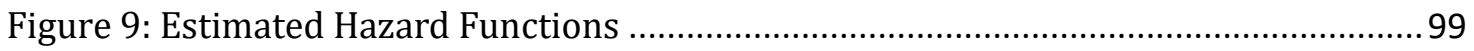

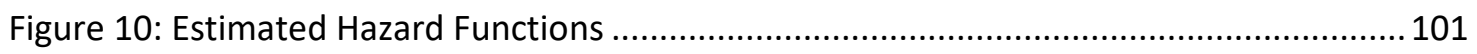

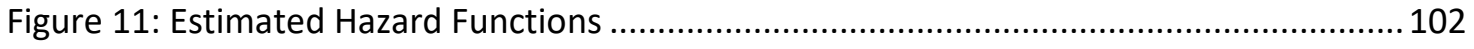

Table 3: Log-likelihood decomposition of Model 7 ............................................................ 103

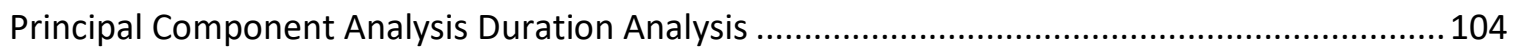

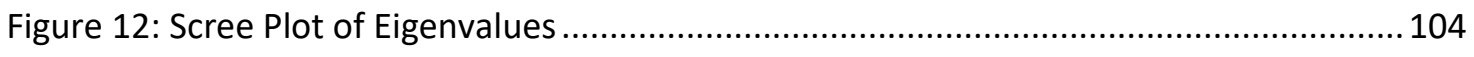

Figure 13: Percentage of Variance Explained ................................................................... 104

Table 4: Cox PH Results of PCA Models, $\exp \beta$ estimates (Robust Huber/White z values in

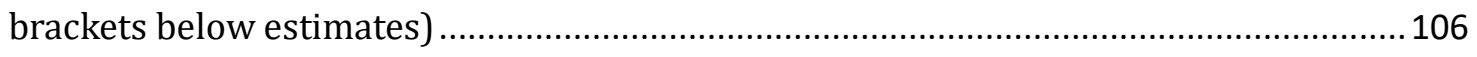




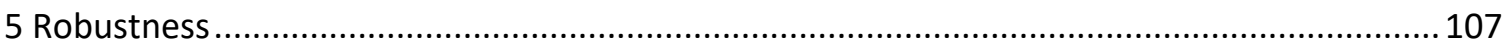

Figure 14: Goodness of Fit Using Cox-Snell Residuals for Model 1 .................................108

Figure 15: Goodness of Fit Using Cox-Snell Residuals for Model 7 .................................108

Table 5: Gompertz Results, $\exp \beta$ estimates (Robust Huber/White z values in brackets

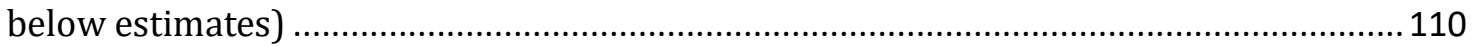

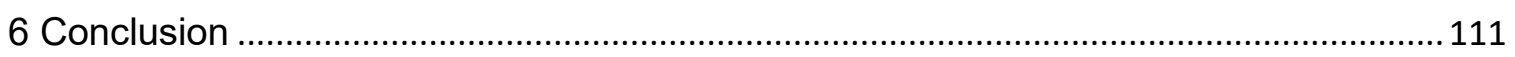

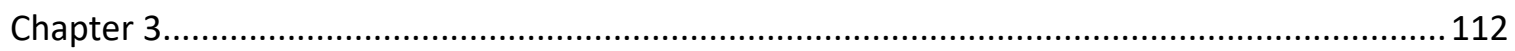

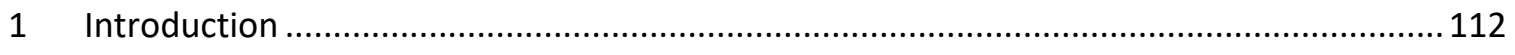

2 Contrasting Economic Competition with Political Competition ........................................113

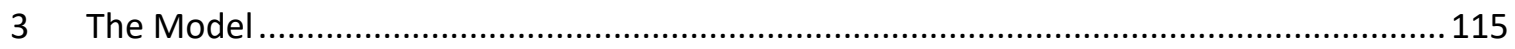

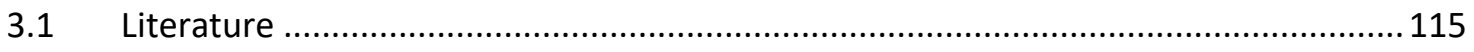

Figure 1: Hypothesized MIMIC path for estimating the shadow economy ..........................116

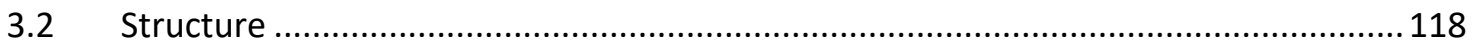

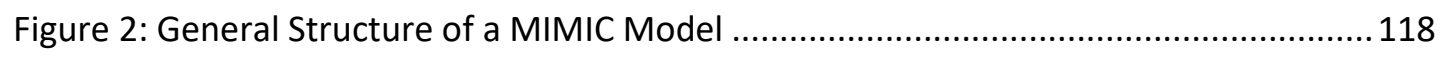

4 Applying the MIMIC Model: Political Competition ....................................................... 120

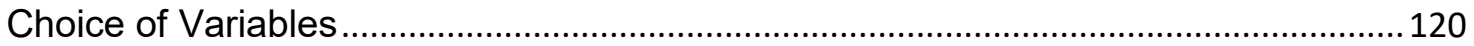

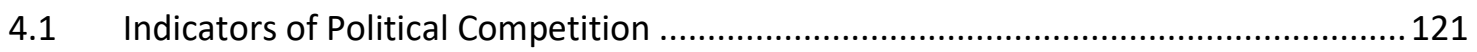

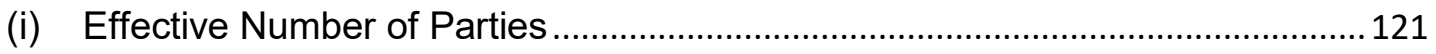

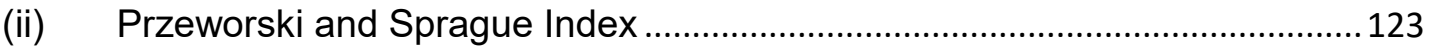

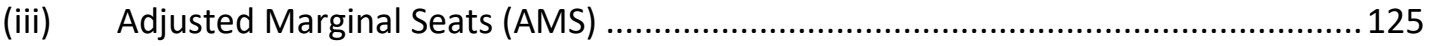

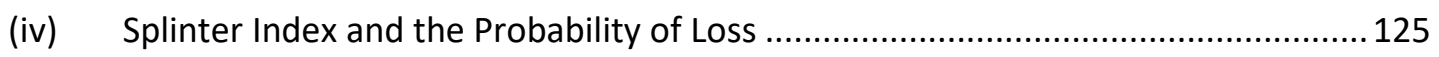

Figure 3:5 LPR from Distribution of Seat-Swings ......................................................... 126

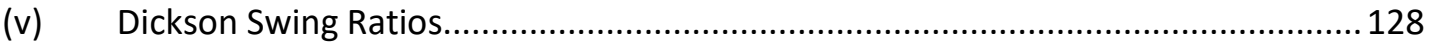

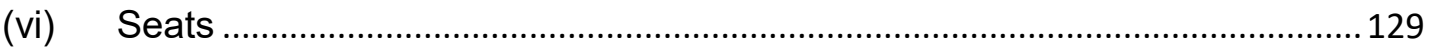

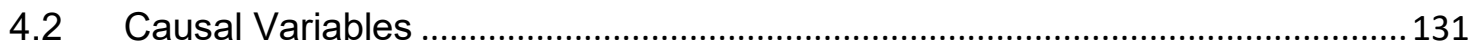

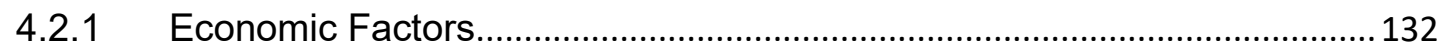

4.2.2 Demographic impacts on Competition ...................................................... 134

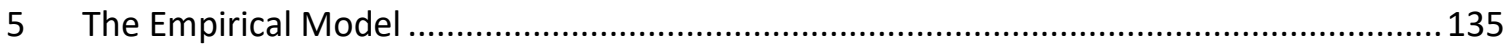

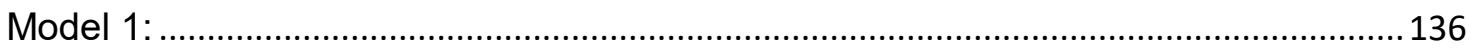

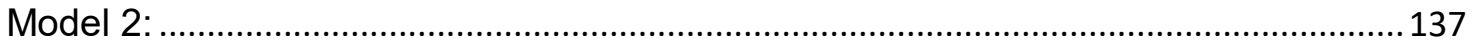

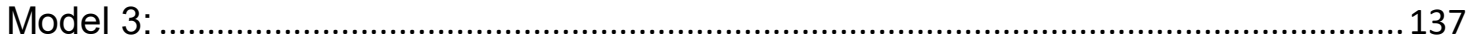

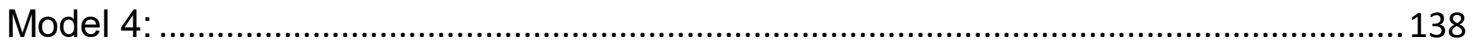


Model 5:

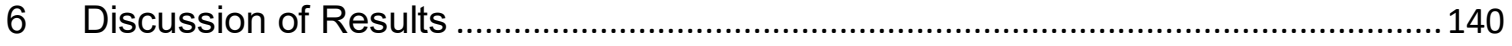

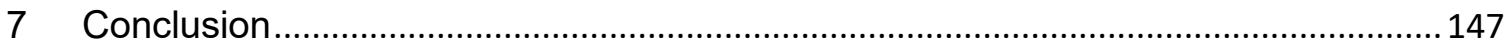

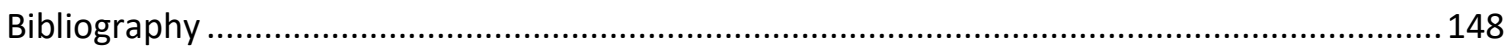

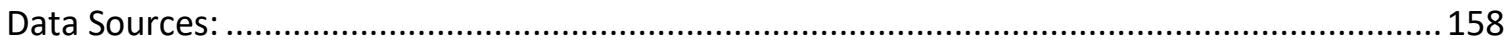

Appendix A: The Linzer (2012) method for calculating swing-ratios.......................................159

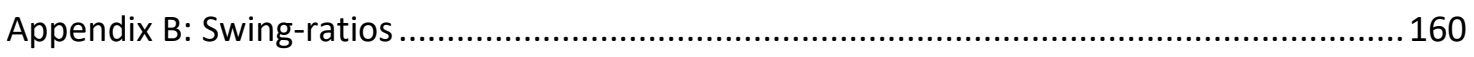

Appendix C: Correlation Matrix of the Measures of Political Competition .............................. 161

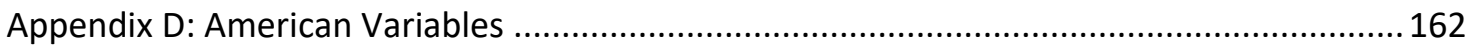

Table A1: American Variable Results, $\exp \beta$ estimates (Robust Huber/White $z$ values in

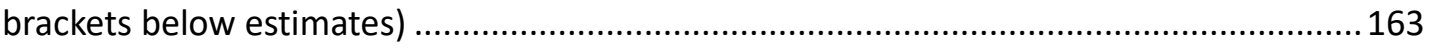

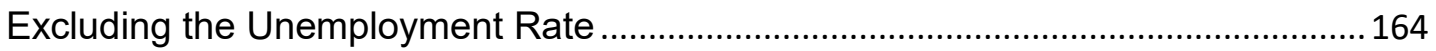

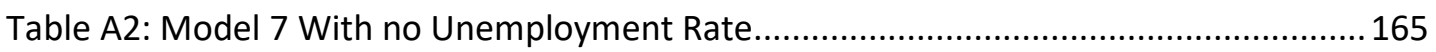

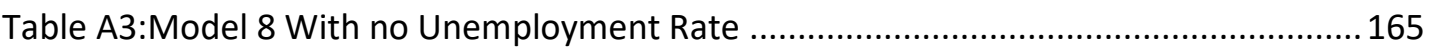

Appendix E: Error correction method (ECM) for the models to deal with potential cointegration 


\section{Chapter 1}

\section{Introduction}

\section{"When you think economics, think elections;}

When you think elections, think economics."

-Edward Rolf Tufte (Political Control of the Economy, 1978:65)

While the literature on political competition is flourishing, there are shortcomings in the theoretical descriptions of competition that need to be addressed. Notably, many measures of competition only capture one or two elements of a broader idea of competition. These measures of competition may also be limited in their applicability to different countries and different political systems. In this paper I develop a quantitative measure of electoral competition using the "probability of loss' of a future election. This measure of competition, defined as electoral risk, is a unique alternative that offers general applicability across political systems and countries. The proposed measure of competition, as it currently stands in the literature, is modified and updated in this paper and then tested for robustness.

The emphasis in this paper is to modify the measure of 'electoral risk' to incorporate more assumptions and demonstrate that the new measure has both predictive explanatory power and is also reflective of underlying changes in the economy. Motivation is provided for the existence of the economic voter, and the relationship between political competition and the economy is used as evidence for the economic voter's existence in Canada.

The model in this paper makes use of historical data to create a probability of the incumbent government losing the next election. Dynamic adjustments are made to reflect the changing political landscape and Beta regressions (Ferrari and 
Cribari-Neto, 2004) are used to show the significant relationship between the economic variables and electoral risk.

The measure of competition is developed by building off of Boyne (1998) and Kayser \& Lindstadt (2015). This paper proposes some improvements and examines political competition in Canada over time. While the literature relating economic variables with electoral success is vast, there has been no examination to test if Kayser and Lindstadt's measure of electoral competition can be explained by changes in economic indicators. This paper will be the first test of the measure's accuracy and also test the measure's robustness to changes in economic variables and how it applies to the Canadian context over time.

The paper is structured as follows. First I will examine the basic model and how it pertains to the literature on the relationship between economics and politics, and then continue by examining the more contextually narrow literature on electoral success and competition in the political sphere. Subsequently, the paper provides a background on the Canadian electoral system and how it relates to our chosen measure of electoral competition, electoral risk. The paper then examines the creation of a new measurement of electoral success and reviews in detail the implications, predictive power, and limitations of this measurement. The paper concludes with a test of the robustness of the different measures of the probability of electoral success to see if they correlate with the proposed economic variables.

\section{The Basic Model}

The calculation of electoral risk in this paper relies on two underpinnings: (i) the seats-votes relationship (known also as the swing-ratio) and (ii) the modelling of a distribution of past electoral outcomes. The electoral risk calculation uses estimated seats-votes relationships that are derived from the literature, including work by Taagapera (1986), King (1990), Calvo (2009), Dickson (2009), and 
Linzer (2012). The modelling of the past distribution of electoral outcomes was developed by Kayser \& Lindstadt (2015) and expanded in this paper.

Kayser \& Lindstadt define a 'seat-swing' as a net percentage change in seat shares between the party with the most seats and the party with the second most seats ${ }^{1}$. The seat-swing at time $t$ is:

$$
\text { Seat Swing }_{\mathrm{t}}=\% \Delta \text { Seats Share } \text { Incumbent }, t-\% \Delta \text { Seats Share } \text { Opposition }, t_{\text {S }}
$$

A seat-swing can be either positive or negative in value, but knowing only the value of the seat-swing does not tell us the resulting seat shares that are obtained by the incumbent or the opposition party. The seat-swing only reveals a relative change. Over the range of all possible seat-swings, there exists a subset of seat-swings which are large enough that the second-place party will replace the incumbent for any given seat distribution. From this subset, Kayser \& Lindstadt define the 'probability of loss' as: the probability that a seat-swing against the incumbent is sufficiently large enough such that the current opposition party becomes the party with the largest seat share (see Figure 1).

While it is theoretically possible that a non-opposition party ${ }^{2}$ becomes the new government, this has only happened in Canada once. In 2015, the previously third-place Liberals became the government. In addition to this event, the thirdplace party before the 1925 election was the Conservatives, who went on to win that election. It was the case, however, that through a technicality the Conservatives were the official opposition at the time. Outside of Canada, in Kayser \& Lindstadt's international sample, the third or lower place party unseated the incumbent only $2 \%$ of the time.

\footnotetext{
${ }^{1}$ In the Canadian context, the party with the second most seats is known as the official opposition.

${ }^{2} \mathrm{~A}$ non-opposition party: $\mathrm{A}$ third or lower place party, or a new entrant.
} 
To create a distribution of seat-swings to estimate the aforementioned probability of loss, Kayser \& Lindstadt propose a function, $g(s)$, that maps past estimated seat-swings, $\mathrm{s}_{\mathrm{n}}$, to a function, $f(s)$ :

$$
g:\left\{s_{n}\right\}_{1}^{t-1} \rightarrow f(s)
$$

Kayser \& Lindstadt use a kernel density function such that:

$$
g(s)=\frac{1}{n h} \sum_{i=1}^{n} K\left(\frac{s-s_{i}}{h}\right)
$$

where $\mathrm{h}>0$ is the bandwidth, $\mathrm{K}$ is the kernel function, which is Guassian, such that:

$$
K(u)=\frac{1}{\sqrt{2 \pi}} e^{-\frac{1}{2} u^{2}}
$$

Once the kernel density is known, calculating the probability of loss (known as the loss probability ratio, or LPR) is:

$$
L P R=\int_{-\infty}^{-d} g(s) d s
$$

where $d$ is the seat share gap between the incumbent and the opposition.

Figure 1: Distribution of Seat-swings

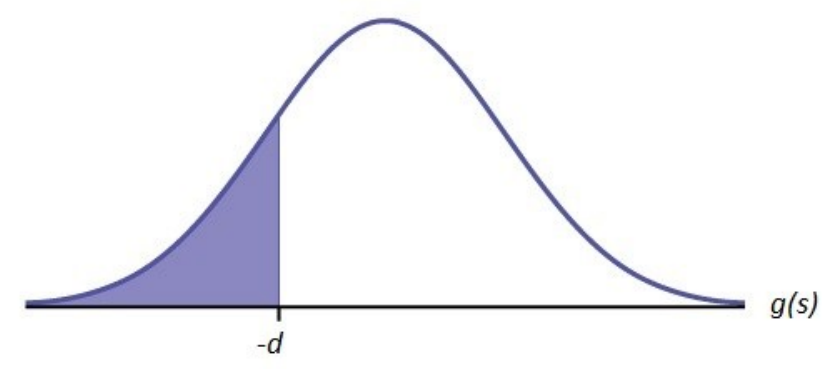

In figure 1, the shaded area represents the LPR.

To populate the distribution of past seat-swings, Kayser \& Lindstadt look at all the previous elections and use the Linzer-method to calculate a swing-ratio for 
each election ${ }^{3}$. They then use this swing-ratio to calculate a theoretical seatswing from the actual vote swings. All the estimated seat-swings that have happened against - or in favor of - an incumbent are included in the distribution of seat-swings. A continuous distribution is created by using the kernel density function to smooth the estimated distribution of seat-swings. Kayser \& Lindstadt tried different types of distributions in the kernel density estimator, and they demonstrate that the best suited distribution for the kernel density estimator is the Gaussian distribution.

The theoretical motivation for this process is that the incumbent prime minister is backwards looking. The prime minister looks at the current seat-share gap between their own party and the opposition party and estimates the probability of a loss. The seat-swings are calculated thus:

$$
s_{t}=\Delta v_{1} \tau_{1}^{*}-\Delta v_{2} \tau_{2}^{*}
$$

Where:

$s_{t} \quad$ : estimated seat-swing (as a share).

$\Delta v_{1} \quad$ : vote swing against/for the incumbent (as a share).

$\Delta v_{2} \quad$ : vote swing against/for the opposition (as a share).

$\tau_{1}^{*} \quad$ : estimated Linzer swing-ratio for the incumbent.

$\tau_{2}^{*} \quad$ : estimated Linzer swing-ratio for the opposition.

This method is based solely off past occurrences of estimated seat-swings and does not take into account any other information, such as polling data or any economic indicators. For these probabilities to be estimated there is a requirement for a populated distribution to exist. Kayser \& Lindstadt propose that

\footnotetext{
${ }^{3} \mathrm{~A}$ swing-ratio is a seats-votes elasticity that represents a $\mathrm{X} \%$ change in seats for a $1 \%$ change in votes.
} 
a minimum of 6 elections must have occurred before a distribution can be estimated with a kernel density estimator. Kayser \& Lindstadt increase the size of their populated distribution as time goes by and the number of elections increase. To illustrate this increasing distribution size, prior to the $40^{\text {th }}$ election, data from all previous 39 elections are included in the estimated distribution of seat-swings.

The $\tau$ in equation 6 above is the seats-votes elasticity, also known as the swingratio. The swing-ratio has been developed over many years and existed in many forms. The idea of the swing-ratio has been known since at least 1909 and was studied academically by Kendall and Stuart (1950) in their seminal paper, 'The law of the cubic proportion in election results'.

The swing-ratio, as an elasticity, is defined as the "percentage change in legislative seats associated with a 1\% change in legislative votes" (Niemi and Fett, 1986). In other words the swing-ratio is a measure of sensitivity between seats and votes. It has been demonstrated that swing-ratios can vary from country-to-country, over time, by different electoral rules, and by malapportionment ${ }^{4}$ (Gugdin and Taylor, 1979; Taagepera and Shugart, 1989).

Numerically, a swing-ratio is considered large if it is 3 or more $^{5}$. A swing-ratio more than 3 indicates a high level of sensitivity, which suggests that the respective party could be subject to a large increase or decrease in the number of seats they have in the legislature. It has been observed, and noted in this paper's data, that smaller regional parties tend to have lower swing-ratios. This demonstrates that regional parties are less sensitive to changes in national voteshares.

The seats-votes elasticity has been examined in several ways which have shown different outcomes. Taagapera (1986), King (1990), and Calvo (2009), all

\footnotetext{
${ }^{4}$ Malapportionment is the creation of electoral districts with unequal ratios of voters to representatives.

${ }^{5}$ Linzer (2012). Note that swing-ratios are a ratio of percentages and are analogous to the concept of elasticity in economics, hence this is a unit-less measure.
} 
developed their own measures of swing-ratios to examine overall responsiveness of an electoral system instead of developing separate and unique swing-ratios for individual parties like Linzer (2012) did. A number of papers have worked to tackle the problem of measuring swing-ratios for two-party systems but their work cannot be extended to systems that have more than two parties (Gelman \& King 1990, 1994; King \& Gelman, 1991; Jackman, 1994).

The seats-votes elasticity has been measured previously over time by including multiple years of electoral results (Niemi \& Fett 1986; Jackman 1994) but these papers have been criticized by Linzer (2012) because they require many years of data to be stable and develop a swing-ratio that applies to a group of years instead of an individual election. Linzer also criticizes this approach because the political parties may not remain stable over time, party platforms can vary substantially, and voter preferences do not remain constant.

Linzer (2012) makes note of four problems that exist in the literature on swingratios and provides a model that can handle all four problems.

1. The number of parties vary in different countries, i.e. contrary to what some models assume, the number of parties is often greater than two

2. Not all districts have the same parties competing for a seat. (This is referred to as a 'pattern of contestation', i.e. the parties or independent candidates competing for a seat in any given district may not be the same exact group of parties competing for a seat in a different district)

3. Malapportionment exists.

4. Socio-economic data may be required to build some models may not be available or exist.

The swing-ratios developed by Taagapera (1986), King (1986), and Calvo (2009) are all missing some element from the above list and only Linzer's swing-ratio satisfies a solution to the four problems.

A key distinction in Linzer's method is that his estimates can be constructed from only one election's worth of data. Each estimated swing-ratio is unique for each 
party and unique for each election - totally independent from all other elections. While it may seem counter-intuitive to not use prior elections' data, this approach creates the advantage of not requiring a minimum amount of time-series data to create swing-ratio; and also means the swing-ratios are not necessarily constant over a longer time period as other estimates design them to be.

Linzer coins the term 'pattern of contestation' to describe a group of districts (in Canada these districts are known as ridings) where each district in the pattern of contestation has the same parties competing for a seat. To illustrate, if only two parties existed and they both ran candidates in every riding, there would only be 1 pattern of contestation. Continuing with the illustration, if three parties exist, and one party chooses to run candidates in not-all of the ridings (i.e. the Bloc Quebecois in Canada), while the other parties run candidates in all the ridings, then there would now be two patterns of contestation. In reality, there often exists a case when a major party may not run a candidate in every riding, or where regional parties exist, or perhaps there are independents seeking office, and this results in there being many patterns of contestation. On average, there are about 4 useful patterns of contestation per election in Canada in modern times. The history of Canada is such that many parties used to compete in the early elections, and, over time, the number of parties that actively compete at the national level has shrunk considerably.

Since Linzer estimates swing-ratios election-by-election, the swing-ratios are dynamic and are regularly updated based off whatever changes that occur in the political environment. Since a party may only have electoral success for a few elections - for example, the Progressives, the Social Credit Party, or the Bloc Quebecois in Canada - a longer term estimate of a swing-ratio that was estimated over many elections would not be feasible or meaningful.

Linzer's method derives from the ridings up to the national level and hence each riding matters. This allows his method to address malapportionment. Malapportionment is the situation where certain ridings, while having equal voting weight (in the sense that each elect one Member of Parliament), contain 
noticeably different amounts of eligible voters. While there is some attempt to have each riding in Canada have somewhat-equal amount of voting citizens in it, there is actually a large degree of variance from the largest to the small riding in terms of the amount of eligible voting citizens that reside there.

Linzer uses a two-step approach for generating the swing-ratios. Linzer starts by using a method first developed by Gelman and King $(1990,1991,1994)$ to estimate a density function that captures the underlying joint distribution of vote shares and the number of votes cast for all districts. Linzer then employs a Monte Carlo simulation to generate alternative, hypothetical election outcomes that are consistent with the estimated density function. The simulations are repeated, which develops a relationship between seats won and votes cast. This is the basis for the estimated swing-ratios.

An important element of estimating the aforementioned density function is to capture the vote-trading relationship between the parties. There are observable trends of voters changing their vote preference from one party to another. The impact of a change in voting patterns results in a redistribution in the seats won by each party.

To create the desired density function, I estimate a joint distribution of variables using a finite mixture of multivariate normal densities. A multivariate normal density is estimated for each pattern of contestation.

In any election there are $M$ number of patterns of contestation, with $N_{m}$ number of ridings in the pattern of contestation, and $P_{m}$ number of parties in the pattern of contestation. For each riding, the vote-shares that the parties receive in a riding sum up to one, but this constraint can be removed by dividing each party's vote share by a reference party's vote share. The log is taken for each of these ratios to create continuous and unbounded variables. This transformation is a common approach to modeling compositional variables and it facilitates estimation of the statistical model using conventional distribution assumptions (Aitchison, 2003). 


$$
Y_{m}=\left(z, \lambda_{2}, \lambda_{3}, \ldots, \lambda_{P_{m}}\right)
$$

$Y_{m}$ is the $N_{m}{ }^{*} P_{m}$ matrix of election results for the $m^{\text {th }}$ pattern of contestation.

$\lambda_{i}$ is a $N_{m}{ }^{*} 1$ vector, the log of the ratio of vote share received by a party $i$ divided by a reference party.

$z$ is a $N_{m}{ }^{*} 1$ vector of $z_{i}$, which is the total amount of votes in the $i^{\text {th }}$ district.

The reference party selected in $\lambda_{i}$ is arbitrary. Obtaining the means $\left(\mu_{r}^{m}\right)$ and variances $\left(\sum_{r}^{m}\right)$, where $r$ is the number of components in the $m^{\text {th }}$ mixture, for each district in each pattern of contestation is required to run the election simulations. To better describe a mixture, multiple components can be used to capture the different dimensions in the variation.

The mixture model log-likelihood is:

$$
\ln L=\sum_{i=1}^{N_{m}} \ln \sum_{r=1}^{R_{m}} \pi_{r}^{m} f_{M V N}\left(Y_{i} ; \mu_{r}^{m}, \sum_{r}^{m}\right)
$$

The fitted mixture densities from equation 8 are then combined across patterns of contestation, in proportion to the share of districts observed in each group. The resultant density function is:

$$
F(Y ; \hat{\pi}, \hat{\mu}, \widehat{\Sigma})=\sum_{m=1}^{M^{c}} \frac{N_{m}}{D^{c}} \sum_{r=1}^{R_{m}} \hat{\pi}_{r}^{m} f_{M V N}\left(Y_{i} ; \hat{\mu}_{r}^{m}, \widehat{\sum}_{r}^{m}\right)
$$

$M^{c}$ is the number of contested patterns of contestation, a subset of $M$.

$D^{c}$ denotes the number of contested districts.

$\hat{\pi}_{\mathrm{r}}^{\mathrm{m}}$ is the weight assigned to each component and the weights sums to one. 
From this estimation, the resulting density function is an estimate of the underlying joint distribution of vote shares and district sizes across the entire set of contested electoral districts. The density estimate in equation 9 represents the likelihood of various riding-level election outcomes, given the conditions of that election. This distribution indicates how parties are expected to jointly trade-off voter support with each other.

Figure 2:'Three Party’ Pattern of Contestation Model Mixture, 1979 Canadian Election
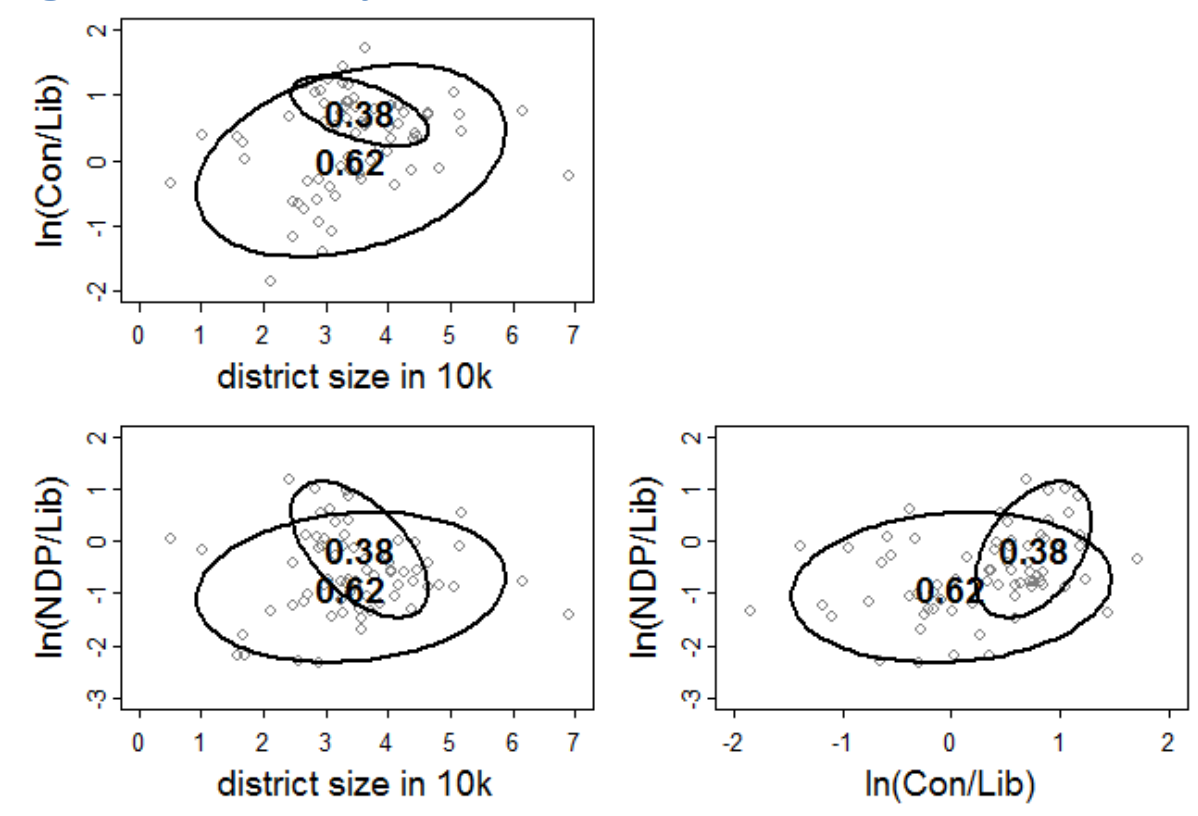
Figure 3:'Four Party' Pattern of Contestation Model Mixture, 1979 Canadian Election
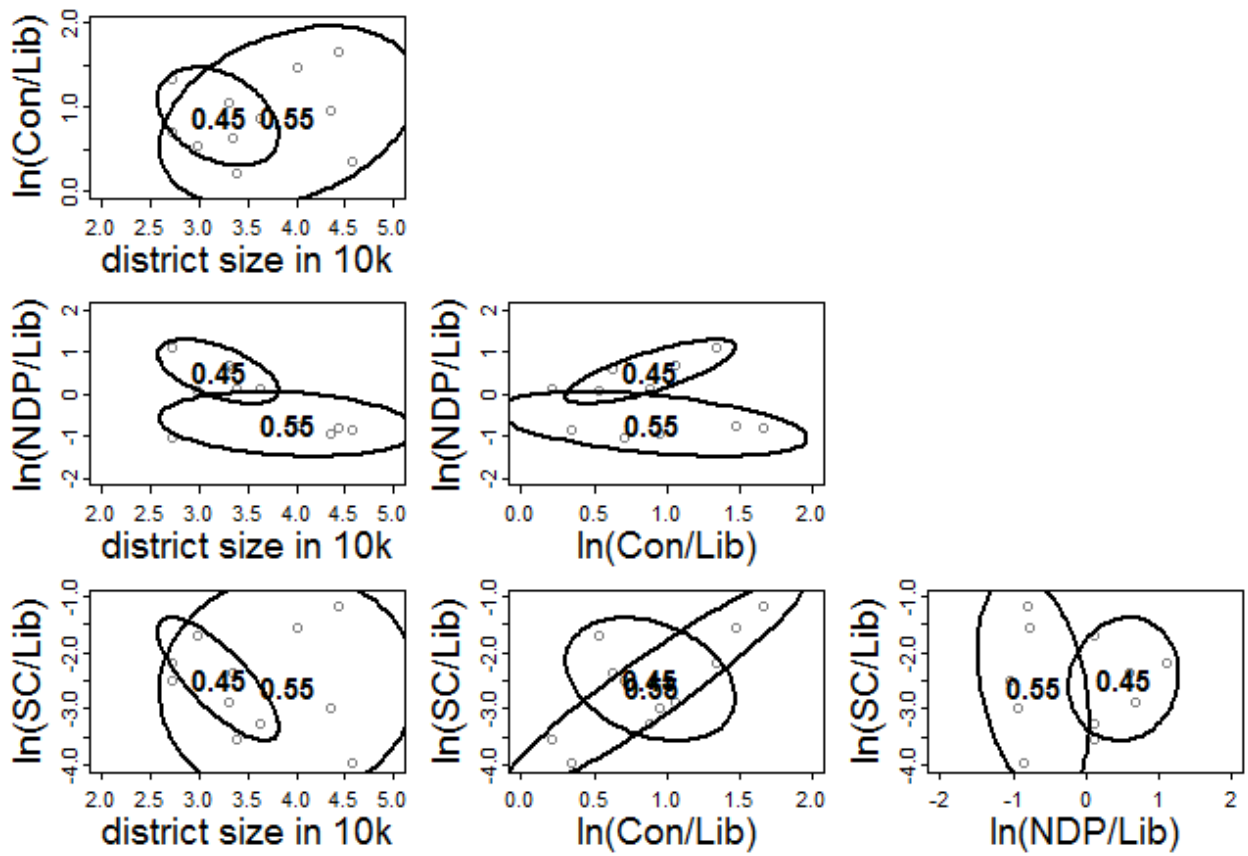

To illustrate, figures 2 and 3 provide estimates from the 1979 election in Canada and show the joint distributions of the log vote-share ratios. In both cases, the Liberal vote share is the denominator. Figure 2 is the pattern of contestation which is contested by the Liberals, PCs, and the NDP. Figure 3 shows the pattern of contestation that is contested by the Liberals, PCs, NDP, and the Social Credit party. The two ovals in each plot represent the distributions explained by two components, with the number inside the oval representing the weight of the component, $\pi$. In both figures 2 and 3 , the left-most column of charts is a relationship between the size of the district and the log of the voteshare ratio. The right-most columns are the joint distributions between the log of the vote-share ratios between the parties and how they trade off votes between each other. Each point on the graph represents a district.

In order to calculate the swing-ratio, Linzer adjusts the vote-shares for each party by $1 \%$, distributed across districts.

Linzer defines the vote-share that each party, $p$, actually won as 


$$
\bar{V}_{p}=\frac{\sum_{i=1}^{D^{c}} z_{i} v_{i p}}{\sum_{i=1}^{D^{c} z_{i}}}
$$

Where $v_{i p}$ is the vote-share won for party $p$ in district $i$, and $z_{i}$ is the total votes in district $i$.

Linzer employs Gelman and King's (1994) estimate a swing-ratio, $\tau_{p}$, for party $p$ as

$$
\tau_{p}=\frac{E\left(\tilde{s}_{p} \mid\left(\bar{V}_{p}+1 \%\right)\right)-E\left(\tilde{s}_{p} \mid\left(\bar{V}_{p}-1 \%\right)\right)}{2 \%}
$$

Where $\tilde{S}_{p}$ is the potential seats won by party $p$.

Equation 10 is the average per-unit change in seat share. Using the estimates from $\hat{\mu}_{r}^{m}, \widehat{\Sigma}_{r}^{m}, \hat{\pi}_{r}^{m}$ and the density function, equation 11 can be estimated computationally using Monte Carlo simulation. By resampling hypothetical district-level election outcomes, aggregating these simulated districts, and repeating the process thousands of times, a set of hypothetical seat-vote pairs are estimated. The seat-vote pairs then can be averaged to provide an average change in seats from a $1 \%$ change in votes, and hence a swing-ratio.

The detailed process used in the spirit of Linzer (2012) is in the appendix. 
Figure 3: Swing-ratios of Selected Parties over Time

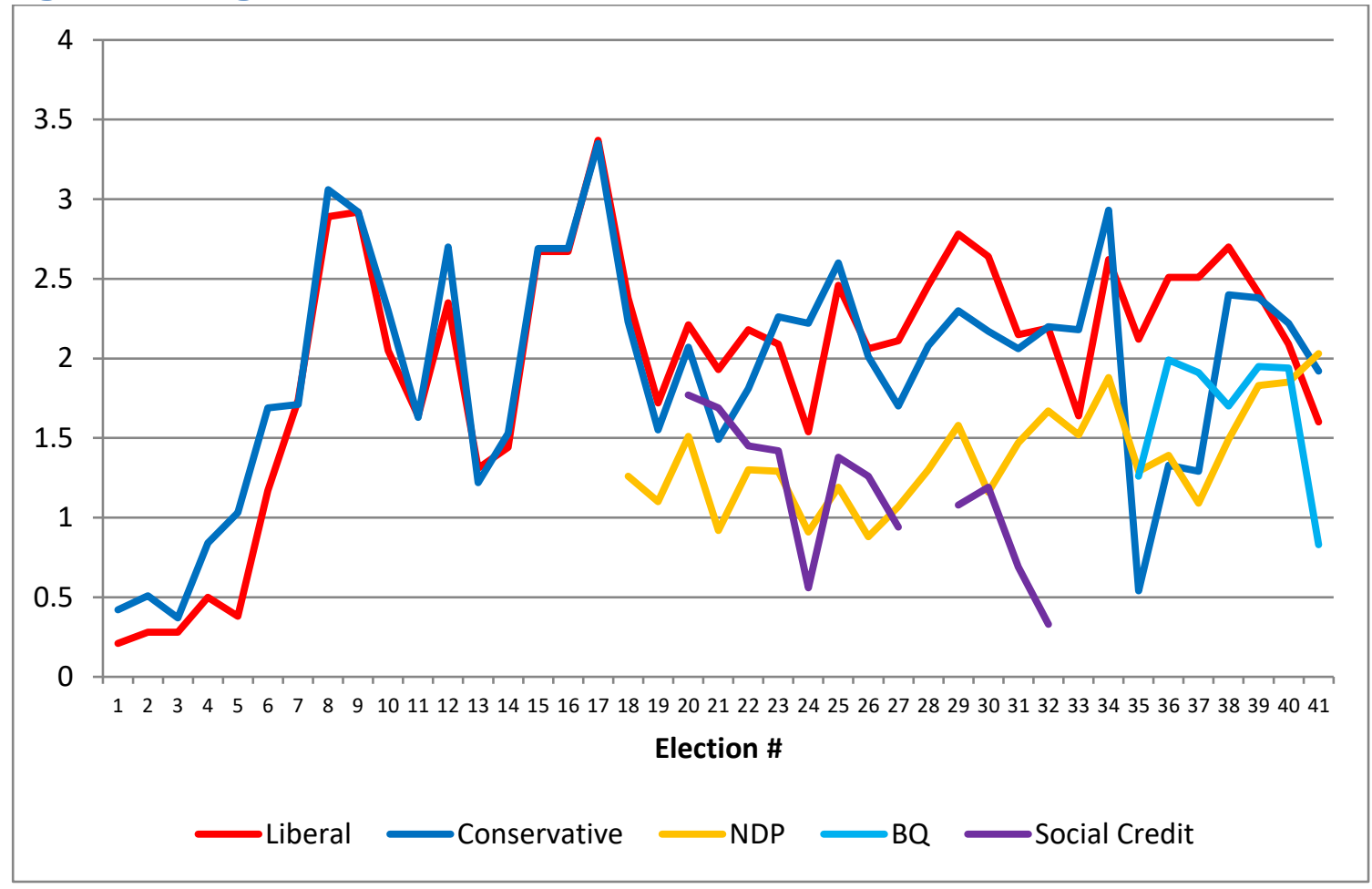

With a continued discussion in the next section, I will briefly comment on the calculated swing-ratios in this paper.

It is of special note that the swing-ratios of the Conservatives and the Liberals move in close tandem until the $21^{\text {st }}$ election. Their swing-ratios then move fairly closely together right until the $35^{\text {th }}$ election when the Conservative Party collapsed. Around the $21^{\text {st }}$ election is when the NDP and the Social Credit party began to win seats in parliament and when they started to become national or pseudo-national parties. As a result, a lowering of the swing-ratios for the Conservatives and the Liberals is observed. The Conservatives and Liberals consistently high swing-ratios - and the fact the swing-ratios move in tandem reflect that many voters interchanged between those two parties until new options came along. Canada has never seen the rise of far-left or far-right parties, and both the Conservatives and the Liberals have traditionally been relatively close to the center of the political spectrum, with the Liberals on the left, 
and the Conservatives on the right (Puddington, Piano, Eiss, \& Roylance, 2007). The lower swing-ratios for the NDP, the Social Credit Party, and the Bloc, are indicative of these parties' regionalism. The Social Credit Party never achieved much electoral success outside of Quebec; while the NDP originally existed mostly as a western-Canada party before appealing more broadly to socialistleaning and progressive Canadians. The Bloc Quebecois, a Quebec sovereignty party, has never run candidates outside of Quebec and has achieved all their electoral success in said province. A lower swing-ratio for the Bloc implies the party has difficulty with both winning and losing seats. Lower swing-ratios imply the seats the party wins are safe and the ridings where they lose are unattainable. It is of note that the rise of the NDP's swing-ratio in the $41^{\text {st }}$ election represents the first election that the NDP achieved major electoral success. In the $41^{\text {st }}$ election the NDP won over 100 seats in parliament and demonstrated national appeal. In that election, the NDP won most of their seats in Quebec, a province they historically struggled to gain any electoral success in.

\section{The Dickson Method}

A recent alternative to the Linzer method, which is employed in this paper, is the Dickson method. Dickson (2009) motivates his swing-ratio by describing districts with higher seats-votes elasticities as being more competitive, "... in the sense that sense that jurisdictions where seat shares are most responsive to vote share changes are more competitive...", and hence uses the swing-ratios themselves as an indicator of competition.

In equation 12, Dickson uses Thiel (1969) to describe a general relationship between seats $\left(\mathrm{S}_{\mathrm{i}}\right)$ and votes $\left(\mathrm{V}_{\mathrm{i}}\right)$ with an unknown parameter, $\alpha$.

$$
S_{i}=\frac{V_{i}^{\alpha}}{\sum_{1}^{n} V_{i}^{\alpha}}
$$

In the two-party case, equation 13 for the second (and only other) party would be 


$$
1-S_{i}=\frac{\left(1-V_{i}\right)_{i}^{\alpha}}{\sum_{1}^{2} V_{i}^{\alpha}}
$$

Equation 14 is obtained by dividing the equation from party one by the equation for party two, and then taking the logarithm.

$$
\ln \left(\frac{\mathrm{S}_{\mathrm{i}}}{1-\mathrm{S}_{\mathrm{i}}}\right)=\propto \ln \left(\frac{\mathrm{V}_{\mathrm{i}}}{1-\mathrm{V}_{\mathrm{i}}}\right)
$$

Equation 15 is the 'number of effective parties' equation.

$$
\text { ne }=\frac{1}{\sum_{1}^{\mathrm{n}} \mathrm{V}_{\mathrm{i}}^{2}}
$$

Taagepera (1986) combines these equations to obtain equation 16 after taking the derivative. This is a seats-votes elasticity measurement.

$$
\frac{\partial S_{i}}{\partial V_{i}}=\frac{\propto(n e-1)^{1-\alpha}\left[\left(\frac{1}{V_{i}}\right)-1\right]^{\alpha-1}}{V_{i}^{2}\left(1+(n e-1)^{1-\alpha}\left[\left(\frac{1}{V_{i}}\right)-1\right]^{\alpha}\right)^{2}}
$$

To obtain the 'cubic law rule' from Kendall \& Stuart (1950) set $\alpha=3$, and for the proportional representation, set $\propto=1$. The alpha value, $\propto$, is calculated for each province and in contrast to the Linzer method, $\alpha$ is estimated to be constant over time. Dickson notes that it is appropriate to estimate alpha for each province due to the provincial regional parties that exist, such as the Bloc Quebecois. Hence, to capture regional differences that would otherwise be smoothed-out with a national measure, the estimates must be done at the sub-national provincial level.

Dickson uses his estimated seats-votes elasticities for each province and government spending in the provinces from 1962-2002 to examine two ideas simultaneously. The first idea is that the government directs money towards high 
seat-vote elasticity provinces, where the payoff to an increase in votes is higher; secondly, that the government rewards loyal provinces for voting for them. These ideas may work together or against one another.

Dickson demonstrates that a relationship between swing-ratios and government spending, also showing that loyalty to the government is rewarded by more government spending. However, it is noted that too much loyalty, as measured by lower seat-vote elasticities will not be rewarded, as the benefit of doing so is lower. Dickson selects swing-ratios as a proxy for electoral competition. While Dickson contends that no paper has looked at seats-votes elasticities to explain federal spending, it's worth noting that this paper will examine the relationship between electoral success and government spending.

\section{Background on the Canadian System}

Canada is multi-party democracy where the party that wins the plurality of the seats in parliament has the first right to form a government. If the plurality is also the majority, then the party with the majority has the only right to form the government.

The seats in parliament are allocated from ridings, with each riding representing a geographical area. Each riding elects one Member of Parliament (MP). In the past, a small minority of ridings elected two members of parliament but this has not been the case since 1965 .

Canadian elections use a first-past-the-post (FPP) single member district (SMD) style where the candidate that receives the plurality of the vote is elected. Because this is not a proportional system, the numbers of votes received nationally will not necessarily be equal — or necessarily closely proportional - to the number of seats won in parliament.

The Canadian electoral system has remained mostly unchanged since Canadian Confederation in 1867, but the parties that seek office have undergone 
noticeable changes - this latter fact is especially noticeable when looking at the early years of Canada. Acclamations occurred about $25 \%$ of the time in first few elections, but there have been no acclamations in Canada since 1957. Since confederation, the number of parties has varied, but on average this number has fallen over time. This observation lends credence to Duverger's (Duverger, 1954) proposal that the number of parties competing in the same district will tend to 2 as time goes by.

As a final note on the Canadian electoral system, the only major changes to the system have been the granting women suffrage in 1917, the step-wise granting of suffrage to certain ethnic and religious minorities, and the lowering of the voting age from 21 to 18 in 1968.

\section{The Parties}

Canada has only ever been governed by two parties: the Liberals and the Conservatives. However, those two parties have not always existed in the exact same form as they do today. The Liberal Party of Canada (hereafter, the Liberals) has existed since confederation whereas the Conservative Party of Canada (hereafter, the Conservatives) has existed in slightly different iterations under a number of different names. The Conservatives were first known as the Liberal-Conservatives, then as the Conservatives, they then reverted to their old name. The Conservatives eventually settled on the name the 'Progressive Conservative Party of Canada'6 in 1942. During the 1990s the Progressive Conservatives (PCs) were split and challenged by the right-wing populist party, the Reform Party of Canada. Subsequently in the late 1990s the Reform Party of Canada merged with some PC members to form the Canadian Alliance. In early 2003, the merger between the Canadian Alliance and the remaining PC members of parliament was completed and the party was renamed the Conservative Party of Canada. A number of candidates have run under different names while still caucusing with the Conservatives or the Liberals. For example, in the early elections after confederation there were some candidates that ran

${ }^{6} \mathrm{At}$ this time known as the 'Conservatives' or the 'PCs' 
under the names 'Independent Conservative', 'Independent Liberal', or 'Labour Liberal'.

Over the years, various parties such as the Cooperative Commonwealth Federation, Social Credit Party, and the Progressives, have won a sizable amount of seats and occasionally held the balance of power. However, since the late 1970s, the Canadian electoral landscape has been defined by three national parties; the Liberals, the Conservatives, and the socialist-leaning New Democrat Party of Canada (NDP). Since the 1993 election, a regional party, catering to the needs and demands of the province of Quebec, was conceived as the Bloc Quebecois (known as the Bloc). The Bloc was made up of former Liberals and Conservatives operating with Quebec sovereignty as a main party platform. The Bloc has had varying degrees of success, achieving official opposition status in the 1993 election. Recently, the Bloc's electoral success has waned with the party only electing 10 members of parliament in the 2015 election. The Green Party of Canada, a national party focused on environmental issues has gained attention but limited electoral success in recent elections.

This paper focuses on 11 political parties that have won at least one seat in parliament more than once. In total, 12 parties are considered in the analysis, allowing for an 'Other' party to be an amalgamation of other parties that are not covered by the definitions laid out for the 11 parties. This amalgamation includes parties that have only won a seat once, and it is also an amalgam of votes, whether or not the votes translated into obtaining a seat. The 'Other' party serves as a catch-all for all remaining seats and votes that are received or obtained outside the 11 main parties. In recent elections, the 'Other' party has received very few votes as a percentage, but in the first few Canadian elections, using my definition, the 'Other' party received close to $30 \%$ of the vote, while electing only a handful of members.

The eleven parties considered are: the Liberals, the Conservatives, the Reform Party (which this paper combines with the Canadian Alliance), the New Democratic Party (which is combined with the Cooperative Commonwealth 
Federation), the Bloc, the Social Credit Party, the Raillement Creditiste Party, the Progressive Party, the United Farmers of Alberta, the National Party, and the Labour Party.

\section{$4 \quad$ Literature: Economics and Politics}

The intersection of politics and economics has been examined and studied for as long as each existed. While the academic literature has traditionally taken the relationship between economics and politics to imply that economic variables can be successfully used to help predict electoral outcomes, more recent literature calls that assertion into question.

In their highly cited paper, 'Economic Determinants of Electoral Outcomes' (Lewis-Beck \& Stegmaier, Economic Determinants of Electoral Outcomes, 2000), Lewis-Beck \& Stegmaier contend that economic conditions shape electoral outcomes. Lewis-Beck \& Stegmaier go further by asserting that good economic conditions lead to the incumbent holding power and bad economic conditions lead to the election of a new government. Lewis-Beck \& Stegmaier's review of the literature lets them assert that their statements are supported by a voluminous body of research.

Lewis-Beck \& Stegmaier examine the role of the 'economic voter', a voter that holds the government accountable for real and perceived economic conditions. Lewis-Beck \& Stegmaier even go so far as to claim that “... the explanatory vote functions establish that economic predictors rival, if not surpass, the political predictors in importance."

\subsection{The Economic Voter}

The idea of an 'economic voter', a citizen that behaves rationally and votes in favor of good economic outcomes raises a few contentions. Some questions regarding the economic voter are thus raised: 'Does the economic voter act based on current and past economic conditions? Or do they vote based of what 
they believe future economic conditions will be?' In the words of Alesina (Alesina, Londregan, \& Rosenthal, 1993), "Are ... voters naively retrospective, evaluating election-year economic growth, or do they prospectively 'focus only on that portion of growth likely to persist after the election?"

The literature examines if citizens can actually evaluate economic conditions as they exist objectively, or are the citizens' subjective opinions more meaningful when casting a vote. Furthermore, can the 'economic voter' accurately attribute economic variation objectively to the correct party? It has been demonstrated in (Rudolph, 2003), (Peffley, Feldman, \& Sigelman, 1987), (Peffley \& Williams, 1985), and (Basinger \& Lavine, 2005) that voters will attribute problem-solving, competency, and responsibility for good performance to the party they personally support and blame parties they don't support for inferior economic performance. Anderson and O'Connor (Anderson \& O'Connor, 2000) claim that "the translation of 'objective' economic conditions into voter motivations to reward and punish is anything but straightforward". On that note, much of the literature combines surveys of the citizens' views with actual economic condition information to explain electoral success.

Finally, it's asked, 'Does the economic voter react to national economic performance (sociotropic voting) or their own economic situation (egocentric voting)?' Each of these problems presented with regards to the economic voter demonstrates that it may be difficult to consistently find a relationship between economic variables and what happens in the political sphere. Furthermore, the relationships that exist may not be consistent over time, across countries, or even within countries. (Eulau \& Lewis-Beck, 1985)

\subsection{The Beginnings of the Literature}

A review of the literature suggests that after the Second World War, when the economic boom turned into a bust by the end of the 1960s and early 1970s, the academic study of the relationship between the economy and voters' behavior had begun to take off. The foundation of this area of study in political economy 
was laid by several seminal works, published in close succession, by Key (1966), Goodhart \& Bhansali (1970), Mueller (1970), Kramer (1971), Frey \& Garbers (1971), Stigler (1973), and Tufte (1975). Towards the end of the twentieth century, "the flow of scholarly papers on the topic had 'changed from a trickle to a torrent of over 300 articles and books on economics and elections' (Lewis-Beck \& Stegmaier 2000, p. 183) and covered virtually every democracy for which data on economics and elections were available" (Anderson C. J., 2007)

While seemingly intuitive, Key (1964) was one of the first to academically examine and discuss the idea that citizens will vote to keep incumbent governments if the economy is doing well, and vote them out if the economy is performing poorly. Looking at the United States - the most heavily researched country in the literature - Lewis-Beck \& Stegmaier (2000) argue that economic voting research in the United States really began in the congressional sphere, with the seminal work of Kramer (1971). Kramer's paper states that when congressional voters believed economic performance to be satisfactory, they voted for the party of the incumbent president; however if the voters judged the economic performance to be less than satisfactory they voted for the opposition (Kramer 1971). To test his theory, Kramer examined the effects of the macroeconomic indicators of inflation, unemployment, and income on the United States House of Representatives (known as the House) election outcomes in aggregate time series models (1896-1964, excluding 1912, 1918, 1942, and 1944). Kramer found that income has a statistically significant impact and showed that a $1 \%$ decline in real per capita personal income produced a $0.5 \%$ fall in the House vote-share of the incumbent party (Kramer 1971). As a rebuttal, prominent economists attacked Kramer's findings with the belief that it made little sense for voters to think about the political-economy sphere in this fashion (Stigler 1973, Arcelus \& Meltzer 1975). Kramer responded by carrying out further analysis and arrived at an even stronger result that "all three economic variables do influence congressional elections" (Goodman \& Kramer 1975). Another early paper in the field, Tufte $(1975,1978)$ also found strong economic effects on the American congressional vote. Tufte theorized that the House elections held 
between presidential terms were pseudo-referenda on both the political and the economic performance of the president. Hence, this notion that the populace expressed their sentiment about their perceived economic situation by voting, while intuitive, was also coupled with powerful empirical results. Tufte's work helped early research on numerous aggregate time series models featuring economic indicators and conditions and how they relate to congressional elections.

Over time, Kramer's (1971) findings have been subject to both criticism and confirmation.

"... regardless of the construction of alternative data series for GNP and unemployment, and regardless of the particular specification that was employed, a century of economic and political data uphold Kramer's basic findings: electoral support for congressional candidates of the incumbent party increases along with income and job growth, and decreases with higher rates of inflation" (Kiewiet \& Udell 1998).

Reading the literature, one can't escape the idea that citizens do not view the economy purely objectively. Citizens cannot make their decisions only on the objective information available on the economy as measured by their income or the unemployment rate, but rather, citizens must make their decisions based off what they believe the economic conditions are. While it is not unreasonable to think that the citizens' beliefs regarding the economic performance are correlated with actual economic performance, this belief should be taken into account when possible. Deviation between perceptions and reality may occur and this phenomenon has been studied. Much of the literature on the topic of this deviation uses surveys and polls to gauge the perceptions that citizens hold. Consequently, as surveys have improved over time, and the data on surveys has expanded with each year, the literature on subjective opinions of the economy is more biased towards recent years.

Rather than explain electoral success at election time, as this paper does, some of the earliest literature simply tried to find a relationship between government 
popularity (as it was polled) and macroeconomic variables. Goodhart \& Bhansali (1970:45) modeled government popularity, measured from a public opinion time series on vote intention as a function of macroeconomic indicators in addition to electoral trends. Goodhart \& Bhansali found government popularity was significantly correlated with the inflation rate and the unemployment level. Their confirmation of the political-economy relationship sparked other papers, some of which supported them: Frey \& Schneider (1978), Pissarides (1980), Whiteley (1986), and some of which did not: Miller \& Mackie (1973), Mosley (1978), Chrystal et. al. (1981).

\subsection{On government spending and electoral outcomes}

Wright (1974) found that 'New Deal' spending in the United States from the federal government was higher in states that displayed higher voter volatility, suggesting that these states were trying to be won-over by the federal government with spending. Further research (Anderson and Tollison 1991, Couch and Shughart 1998, Larcinese et al. 2006) found that loyalty to the president (i.e. the state voted for the sitting president) resulted in the state receiving more federal funding. This results in conflicting evidence on the question of whether loyalty or competitiveness is 'rewarded' with more funding. Voia \& Ferris (2013) investigate the very existence of a political business cycle and find that there is a lack of evidence for one in Canada. Voia and Ferris find that there are sequential steps where an election is likely to follow a peak in the business cycle. Furthermore, Voia and Ferris find that it is the change in real variables that precipitates the election rather than the other way around - this also disproves the case for simultaneity. Hence, this suggests that the government witnesses economic conditions and assumes voters feelings regarding these conditions and it is the government who then makes their decision on when to call an election from these observations of the economy.

\subsection{The Influence of Economic Variables}

Most papers have attempted to explain electoral success using a combination of both economic and political variables. To explain American electoral success, the following papers have used economic variables. My motivation for selecting 
variables comes from the literature, where real income (real GDP per capita), the unemployment rate, inflation, and government spending are selected.

\begin{tabular}{|c|c|}
\hline Paper & Economic Indicators Examined \\
\hline Tufte (1978:122) & Income, candidate evaluation \\
\hline Fair (1978:168) & GNP, time, incumbency \\
\hline Hibbs (1982:394) & Personal income \\
\hline \multicolumn{2}{|l|}{ Lewis-Beck \& Rice } \\
\hline$(1984)$ & Presidential popularity, GNP \\
\hline Abramowitz (1988) & Presidential popularity, GNP, incumbency \\
\hline Erikson (1989) & Income, candidate evaluation \\
\hline \multicolumn{2}{|l|}{ Campbell \& Wink } \\
\hline$(1990)$ & Presidential trial-heat, GNP \\
\hline \multicolumn{2}{|l|}{ Lewis-Beck \& Rice } \\
\hline (1992) & Popularity, GNP, House vote \\
\hline Campbell (1996) & Presidential trial-heat, GDP \\
\hline Abramowitz (1996) & Popularity, GDP, time in office \\
\hline Norpoth (1996c) & Past votes, GNP, inflation \\
\hline \multicolumn{2}{|l|}{ Lewis-Beck \& Tien } \\
\hline$(1996)$ & Popularity, GNP, peace and prosperity \\
\hline \multicolumn{2}{|l|}{ Wlezien \& Erikson } \\
\hline$(1996)$ & Leading indicators, presidential popularity \\
\hline Holbrook (1996b) & Presidential popularity, personal finances \\
\hline
\end{tabular}

\subsection{Concluding Literature on Economics and Politics}

While older ideas from the likes of Watt (1968) argue that throughout all of political history the success of the incumbent's economic policy was indeed the determining factor in electoral success, Anderson (2007) puts forward in his analysis on the intersection of economics and politics a more balanced approach by weighing both sides of the opposing ideas, "Over the years, the notion that voters judge democratic governments by how well they manage the economy 
has taken on the ring of an incontrovertible social scientific fact... The trouble with these claims...is that they are only intermittently borne out by the facts... In particular, these newest findings of conditional economic effects on government support have had the unintended consequence that the reward-punishment thesis-which has guided most of the work in the area of economics and elections and which makes economic voting such an appealing explanation for how elections come out-has been systematically challenged."

\subsection{Literature on Political Competition}

"Despite its frequent theoretical use, no valid measure of electoral competitiveness exists that applies across different electoral and party systems. We argue that one particular type of electoral competitiveness electoral risk - can be estimated across institutional contexts and matters most for incumbent behavior." (Kayser \& Lindstadt, 2015)

A rich literature exists on the topic of electoral competition. A review from Kayser \& Lindstadt (2015) showed that among prominent political science journals - the American Political Science Review, American Journal of Political Science, and Journal of Politics, over the period of 2010 to 2015, a paper on electoral competition appeared, on average, in every second journal publication.

The literature suggests that electoral competition has been difficult to define and proposed measures of electoral competition have been heavily criticized. Boyne (1998) stated, "... the conceptualization of party competition in most of the empirical studies is flawed, and the measures of competition are weak." Elkins (1974) has noted that electoral competition measurements between parties has "obscured the nature of party competition". Kayser and Lindstadt (2015) attempt to rectify the missing measurements in the literature by proposing a measurement of electoral competition that can be generalized to cases of multiple parties - not just a 2-party system - and across different electoral systems, such as single member district (SMD) and proportional representation (PR). 
Different measures of electoral competition exist and have been extensively studied. Strom (1989) looks at "contestability", which is the ease of entry for new parties into the political sphere; "conflict of interest", defined as how the government is composed and how it relates to electoral reforms; and "performance sensitivity", a measure of sensitivity of the change in electoral outcome as it relates to a change in voting patterns.

Similar to performance sensitivity, electoral competition could be measured by responsiveness. That is to say, responsiveness is how the public policy changes as a response to a change of interest by the electorate (Golden \& Min, 2013). An idea that has been used as a measurement of electoral competition has been put forward by Laasko \& Taagepera who developed the aforementioned idea of the 'effective number of parties' which builds off a similar idea to the HerfindahlHirschman Index. The effective number of parties equation proposed by Laasko \& Taagepera is:

$$
E N P_{t}=\frac{\sum_{j=1}^{J} E N P_{j t}}{J}
$$

Where $E N P_{j t}=1 / \sum_{i=1}^{I} v_{i j t}^{2}$ with $v_{i j t}$ as the vote share of candidate $i$ in constituency $j$ in election $t$. Hence, the effective number of parties (ENP) is only equal to the number of parties running if they all have equal weight. In reality, certain parties win a lion's share of the votes, while smaller parties obtain relatively smaller shares of the votes. In these typical situations, the ENP tends to be lower than the actual number of parties running.

In economics, a sector with more firms generally characterizes a situation of more competition - and a similar interpretation could be made here in the political realm. It is suggested, as the ENP grows, the amount of competition grows. However, this may go against the idea of the aforementioned Duverger's Law and imply that competition may in fact be lacking. 
The political science literature purports that uncertainty of an electoral result is a proxy for electoral competitiveness. Recent literature (Grofman \& Selb, A fully general index of political competition, 2009), building off the work of Mayhew (1974), suggest that a highly competitive election is one in which the winning vote-margin is small. Hence, an uncertain election with a small margin of victory is indicative of competitive election. Conversely, a small margin of victory, but within a very stable vote distribution would not be a sign of electoral competition.

Ferris, Winer, and Grofman (2016) propose that by combining the idea of Duverger's Law, with Demsetz's (1968) theory of competition around natural monopolies, a new measure of electoral competition can be constructed. Ferris et. al. (2016) creates a measure, which they coin as the 'Duverger-Demsetz' perspective, which states that fewer, and not more, effective ${ }^{7}$ parties competing in a district is a demonstration of electoral competition.

Demsetz (1968) proposes that the threat of competition can drive natural monopolies towards lower prices than the natural monopolies would otherwise chose in the absence of the credible threat of competition, and hence, this drives prices and quantities towards to a more surplus-maximizing equilibrium. This is because a natural monopoly that is trying to maximize profits will be concerned about a new entrant entering the market and hence the incumbent firm will strategically lower prices to dissuade the new entrant from entering the market.

The analogue in the political sphere is that competition and good governance can be induced from the incumbent and other parties, but only if there exists a credible alternative to the incumbent government. Ferris et. al. note that as the number of parties increase, the likelihood of any of the smaller parties getting elected - in a first past the post single member district system — reduces. As this likelihood reduces, the credible threat diminishes. Likewise, as the number of parties tends towards two, the credibility of the threat towards the incumbent increases, and hence this induces competition and good governance.

\footnotetext{
${ }^{7}$ From the Laakso and Taagepera (1979) theory of the 'effective number of parties'.
} 
Building off the work of Endersby, Galatas \& Rackaway (2002) and Przeworski \& Sprague (1971), Ferris et. al. compare and evaluate the Duverger-Demsetz perspective to a variety of indexes that measure competition. Ferris et. al. look at volatility adjusted vote-margins as a measure of how asymmetrically the seats are distributed among the major parties, which can be employed as a correction for the number of marginal seats ${ }^{8}$.

Kayser and Lindstadt (2015) propose that a desirable measurement of electoral competition satisfies six criteria;

(A) Conceptual clarity

(B) Robustness to the number of parties

(C) Parties as the unit of analysis

(D) A direct connection to the loss of power

(E) Interval-level scale

(F) Congruence with the executive's perspective on their political security

Kayser and Lindstadt then propose that electoral risk satisfies all six conditions and that electoral risk can be measured as the probability of loss. Kayser and Lindstadt define the probability of loss as "the expected probability that the plurality party in parliament loses its plurality in the next election". The intuition behind this is that when the probability of losing for the incumbent is at very high or at a very low levels, the incumbent party is less likely to be responsive to the electorate. At a very low probability of loss, the incumbent would behave more similarly to a dictatorship, and at very high loss probabilities, the incumbent party is similar to a 'lame duck'.

\footnotetext{
${ }^{8}$ A marginal seat is defined by Ferris et al (2016), building off the work of Lovinck (1973) and Bodet (2014), in mathematical terms. They use slightly different variations of a general idea; a marginal seat is a seat that has a vote-margin that lies in the tail-end of a distribution of seatmargins.
} 
Kayser \& Lindstadt's measure of electoral risk is a function of two elements: "the expected variability in nation-level part vote share; and the manner in which changes in a party's vote share produce changes in its legislative seat share." The second element mentioned is in fact the previously defined seats-votes elasticity.

\section{The Methodology}

This paper will use the Kayser \& Lindstadt (2015) method as a base and improves upon its accuracy and meaningfulness. Kayser \& Lindstadt use the Linzer (2012) method for calculating swing-ratios in their calculation for a probability of loss for the incumbent. The probability of loss (known as the Loss Probability Ratio or LPR) is then used a proxy measurement of the level of electoral competition.

The theoretical underpinning for this idea is that consistently low probability of loss implies that the incumbent is very secure and hence the electoral environment is not competitive. The opposite also holds; if the probability of electoral loss is high, this implies the incumbent can be replaced regularly and the level of competition is high. Since we are only using a probability of loss, it is not required that the incumbent actually loses the election, merely that the probability exists to a sufficient degree. From this, one can infer that a very low probability is synonymous with low competition in the electoral environment, and an extremely low probability is indicative of a one-party state.

\subsection{The Kayser \& Lindstadt Method}

Recognizing the value of Linzer's new approach, Kayser and Lindstadt incorporated the Linzer method when they created their measure of electoral competition. Their measure of electoral competition, which they dub 'electoral risk', is the probability that the incumbent party will lose office in the next election, 
known as the loss probability ratio. Further details for the Kayser \& Lindstadt methodology are discussed in the Basic Model section.

This paper improves on the Kayser \& Lindstadt method by suggesting that using election results from 1867 or other early elections is not relevant for calculating the LPR in $21^{\text {st }}$ century elections, and indeed, including early election data in the distribution of seat0swings may even be misleading or incorrect. Where Kayser \& Lindstadt use estimates of seat-swings, this paper also investigates whether using actual historical seat-swings may be more accurate. I think that historical seat-swings is a more valid theoretical model, as I see little reason to estimate alternative historical values when the true historical values are otherwise known. The known values are a more realistic way of creating a past distribution to sample from to predict future election outcomes. Furthermore, using historical values means there is no requirement to justify the estimated values, or to make assumptions regarding the validity of the estimated values.

This paper develops a version of the Kayser \& Lindstadt approach where the number of elections in the distribution does not grow over time but rolls along, adding a new election as time goes by, and dropping the most distant election from the distribution. This is known as the 'add one and drop one' approach and creates a rolling dynamic distribution as the new information comes along ${ }^{9}$. The LPR estimates are created by using $8,9,10$, and 11 , elections worth of data by always using the most recent election data ${ }^{10}$. The estimates for the LPR are

\footnotetext{
${ }^{9}$ Developed with, and originally suggested by, Professor Stanley L. Winer, Carleton University, http://http-server.carleton.ca/ winers/

${ }^{10}$ This is the first time that this rolling distribution has been created in this context. The numbers of 8 through 11 are based off a minimum required, which Kayser \& Lindstadt suggest to be 6 , and 4 iterations of increasing the rolling distribution by 1 additional election. I decided to use a size that was slightly larger than the minimum to generate a more meaningful distribution. The upper bound for this approach is the total number of elections available. Using a heuristic approach, the proposed theory is that after 11 elections - which is close to 40 years of data the political scene will have changed sufficiently that there is no advantage to including more elections. Empirically, the numbers from the rolling distribution including 11 elections often look similar to those numbers that were generated using all elections.
} 
estimated using both the estimated seat-swings suggest by Kayser \& Lindstadt and the actual historical seat-swings. The LPRs are estimated using both approaches and evaluated to see which performs better. Later, in the test for robustness section, each method is examined to see which is more robust to being influenced by economic indicators. In that section, each method is tested to see which has a better ability to predict elections using back-testing.

To make the 'add one and drop one' improvement, equation (2) becomes

$$
g:\left\{s_{n}\right\}_{t-r}^{t-1} \rightarrow f(s)
$$

Where $r$ is equal to $8,9,10$, or 11 . This is likewise taken into account for equation (3).

Using the actual historical seat-swings instead of the Linzer-based estimated seat-swings results in changing equation (1) to the seat-swing that actually happened in that election.

It is of note that Kayser \& Lindstadt use their calculated LPR as an independent variable in their regression to test changes in the real price levels, but do not explicitly test their LPR to see how accurately it predicts elections. To test the accuracy of the models, a 'Count R-Squared' method is used. This method counts the number of times the probability of loss was above a threshold of $50 \%$, and checks to see if the incumbent actually lost that election. Over certain time frames, and certain versions of the model, the method has an accuracy of over $80 \%$. However, using the entire time frame, the models' accuracies vary from $58 \%$ to $50 \%$, leaving room for improvement. A switch from using the estimated historical seat-swings, as Kayser \& Lindstadt do, to creating the distribution using the actual historical seat-swings, boosts the accuracy of the model from $52 \%$ to $58 \%$, suggesting that adopting this paper's suggested method is an improvement on the existing model. However, using the 'add one and drop one' method over 
the range of 8 to 11 elections shows both increases and decreases in accuracy - suggesting a certain level of spuriousness.

Both models tend to be biased towards a low probability of loss. The Kayser \& Lindstadt method is particularly biased; which is to say, the models under-predict losing elections. There is a possibility that the models may improve their accuracy by recalibrating. This paper examined this possibility by increasing the Count R Squared threshold from $50 \%$ to $75 \%$. The theory being that a probability in the range of $100 \%$ to $75 \%$ of loss should carry more confidence and should be more accurate than an estimated LPR from $50 \%$ to less than $75 \%$. The models perform well by increasing the threshold, and under the more 'confident' criteria, they are accurate over $80 \%$ of the time. This suggests there exists validity to this approach and these models, but they must be improved and recalibrated to successfully predict election results. 
Figure 5: Kayser and Lindstadt (KL) and Historical LPRs Over Time

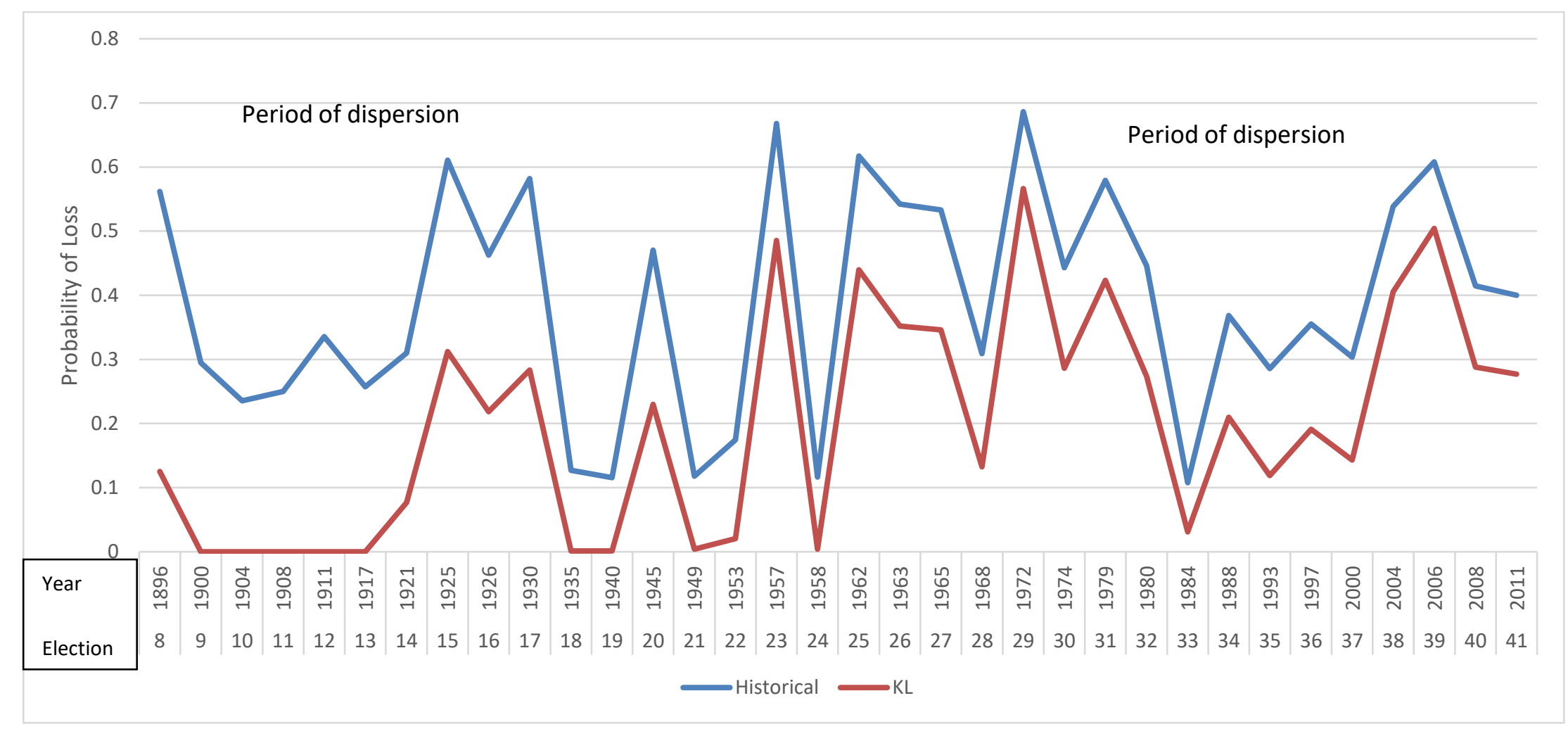


Figure 6: All Kayser and Lindstadt LPRs Over Time

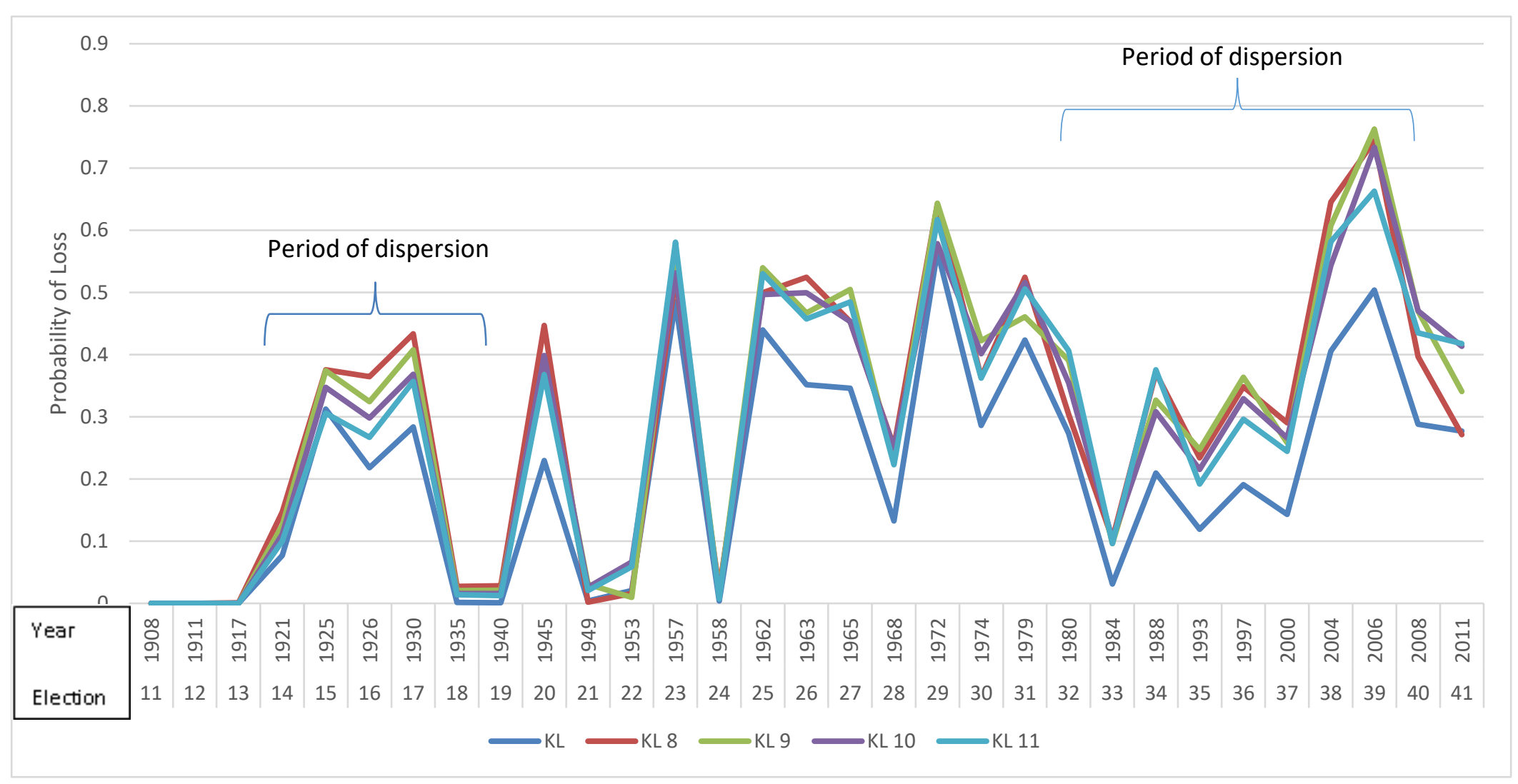


Figure 7: All Historical LPRs Over Time

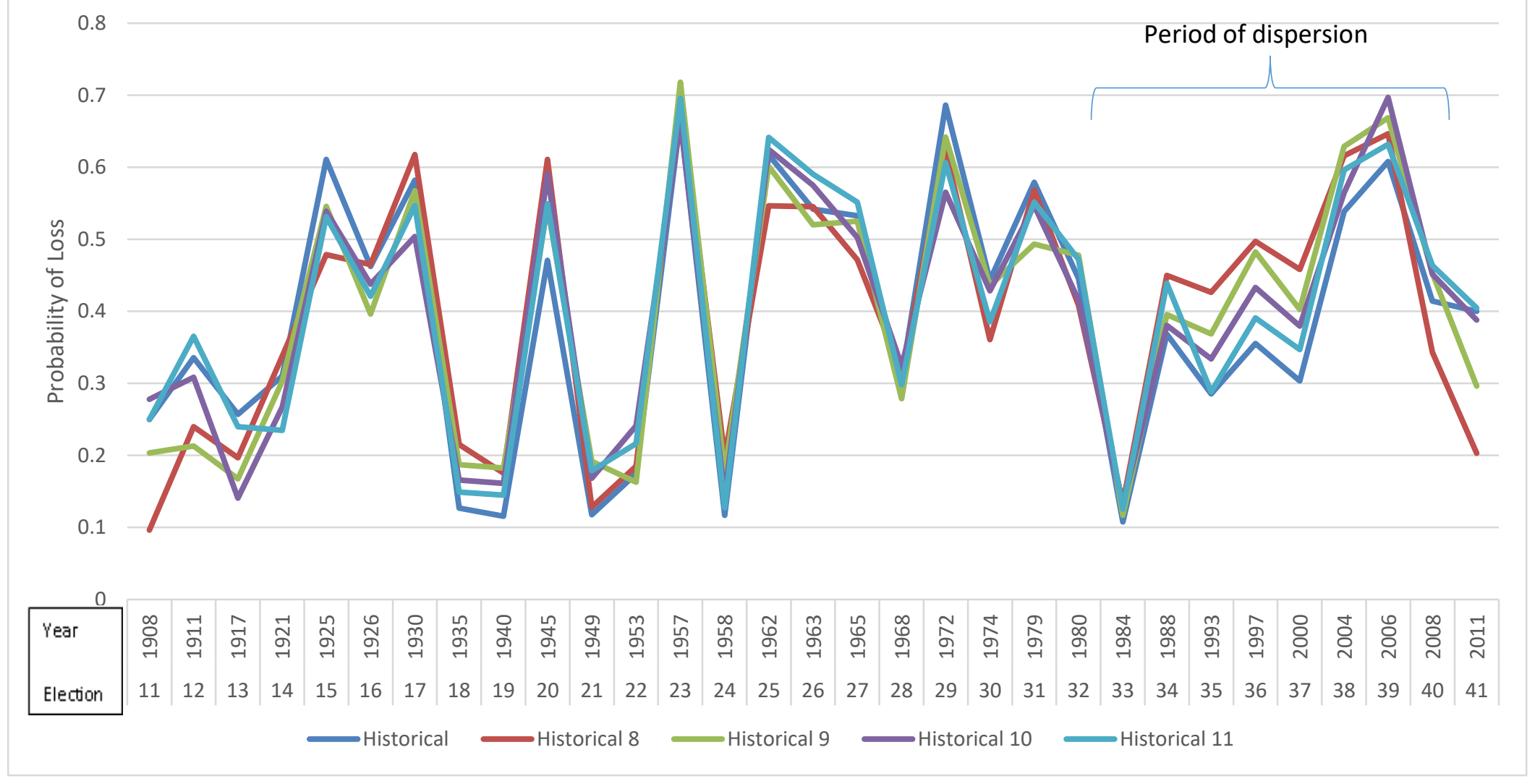


Figure 8: All LPRs Over Time

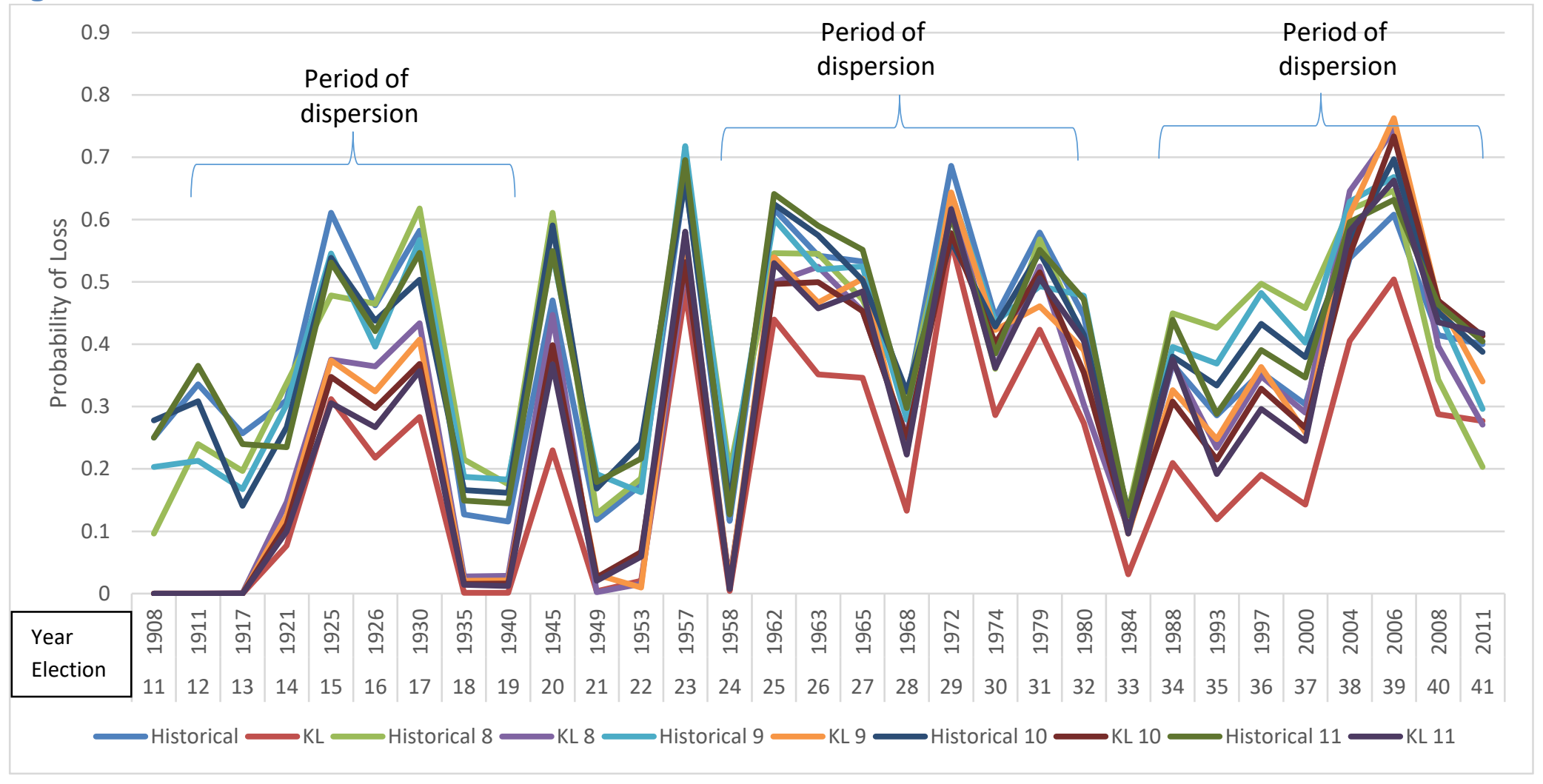


There are several takeaways from the presented LPRs over time. It is observed in figure 5 that both measures of the LPR move consistently together and both show noticeable variance and little persistence with respect to time. The Kayser Lindstadt LPRs are consistently lower than the Historical LPRs; and the Kayser Lindstadt LPRs noticeably give an estimate of 0 probability of loss for several elections in a row. In figure 5, both sets of LPRs are moving in tandem for most of the time period, but differentiate themselves noticeably over two sub-periods. Labeled as 'periods of dispersion', it is observed that from 1896 to 1930, the difference in the two LPRs is about $25 \%$. The two LPRs then move closely together until the 1988 election, when they disperse by about $10 \%$ up to the year 2000 election.

Following intuition, as observed in figures 6 and 7 , and as the number of elections added in the 'add one and drop one' version of the LPRs, the LPRs tend towards the models that include all the election results. Because of this, the difference should be highest as the LPRs approach modern times, and this is indeed the visually observed case.

It is of note, that while figure 6 shows two periods of dispersion, figure 7 shows only one period of major dispersion. In figure 7, the period of 1921 to 1930 seems to show all of the LPRs moving relatively more closely in tandem.

Since the LPRs are constructed solely from swing-ratios and past election results, it implies they are not directly influenced by other events, such as: the two world wars, the introduction of women's suffrage in 1917, the Great Depression, or any economic event. However, the LPRs can be indirectly influenced by these results, and perhaps affected through a lag. As serious events might affect a large swing in seats or votes, these events get built into the distribution after they happen. As such, it is observed that there is large increase in the LPRs after 1917 for several elections, and during the 1945 election. It is suggested the reader look closely at figure 7 during the period of 1988 to $2000-$ when the lowest LPR is the Kayser \& Lindstadt $(\mathrm{KL})$ method that includes the entire election history of Canada; and the highest LPR is the Historical 8 , which 
only includes in its distribution the last 8 elections, and the actual seat-swings that had occurred. It was during this period that the previous 8 elections saw the Conservatives decimate the Liberals and win two large majorities (with the Liberals suffering, at the time, their largest loss of seats ever), and the 1993 election which saw the largest collapse in Canadian electoral history, when the Conservatives went from 156 seats to 2 . As a result, as this time the distribution for the 'Historical 8' was then biased towards large swings and hence increased estimated LPRs.

The LPRs tend to increase slightly over time, implying that the Canadian electoral system maintains a healthy amount of competition. A possible explanation for this comes from the 'Duvergian' idea that the number of parties competing in the same district approaches two over time as each party tries to capture more of the left-right political spectrum. In our Canadian context, it has been observed that the number of parties fall over time from well over a dozen to 3 major parties competing at the national level. It would be difficult for a major party to be removed from government if their opposition is scattered amongst many smaller parties, and hence one could argue that this is a less competitive environment. As evidence for this, during the 1990s and early 2000s, the Liberals won 4 elections in a row, and three of those victories came when the Liberals ran against 2 major parties that were right-of-center. This was followed by the Conservative party winning 3 elections in a row, defeating 2 federal parties that were center or left-of-center (the Liberals and the NDP), and 2 additional parties that were left-of-center (the Bloc Quebecois and the rising Green Party).

Witnessing the LPRs over time and their similarities - and having demonstrated the improved accuracy of this paper's alternative model - this paper seeks to examine if the LPRs are robust to variation with respect to economic indicators. Thus far, the LPR has only been used in the literature as an explanatory variable, but it will be tested here to see if the LPRs can be explained by variations in the economic sphere. While supported by the aforementioned literature, it is contended that a probability of losing an election should show some correlation 
to changes in economic variables and these variables are used as part of a test of robustness for the Kayser Lindstadt measure and this paper's proposed improvements. 


\subsection{A Comparison of the Swing-ratios and the LPRs}

Figure 9: Swing-ratios of all Available Parties Over Time

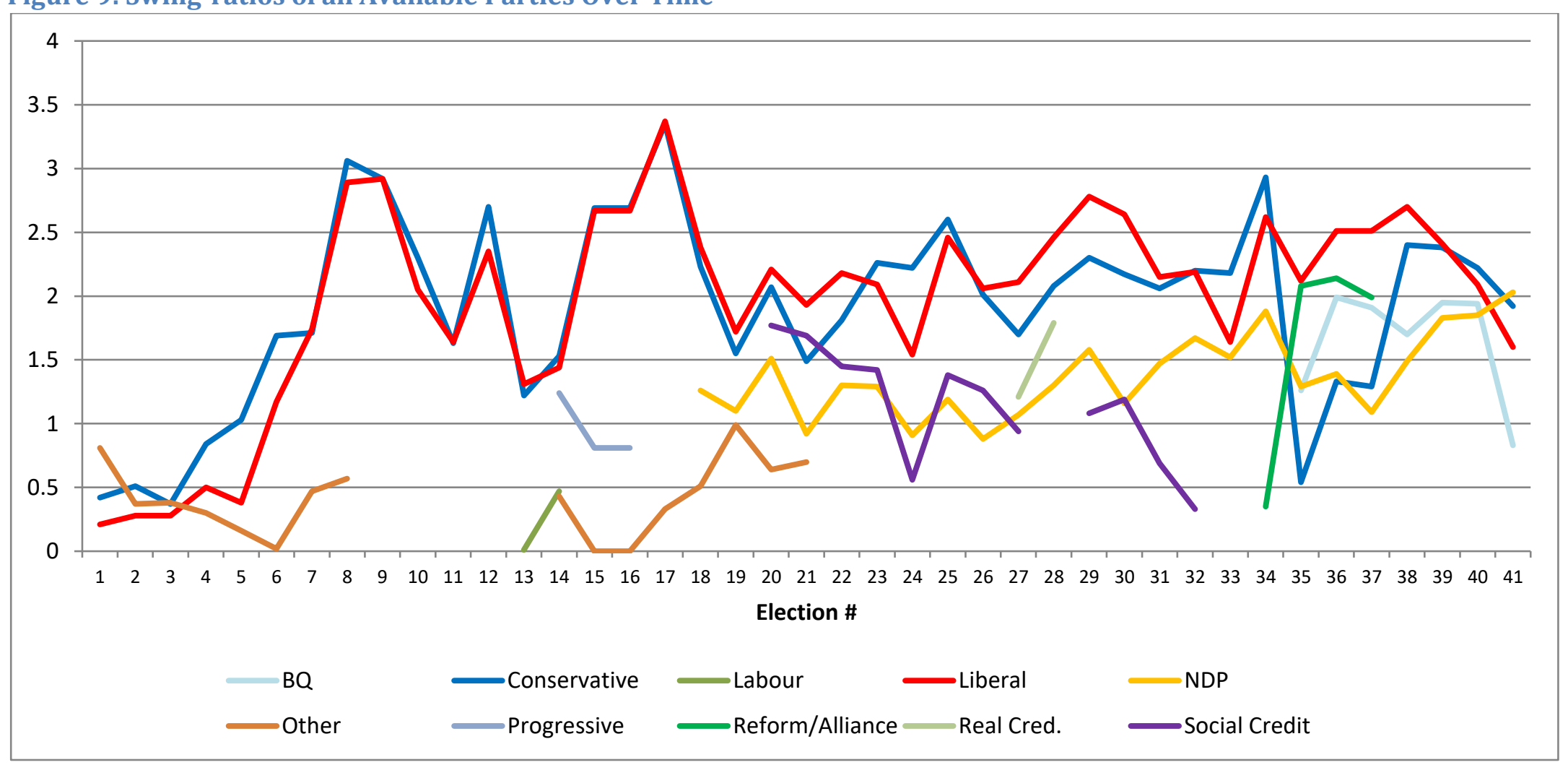


Figure 10: Swing-ratios of Top 3 Modern Federal Parties Over Time

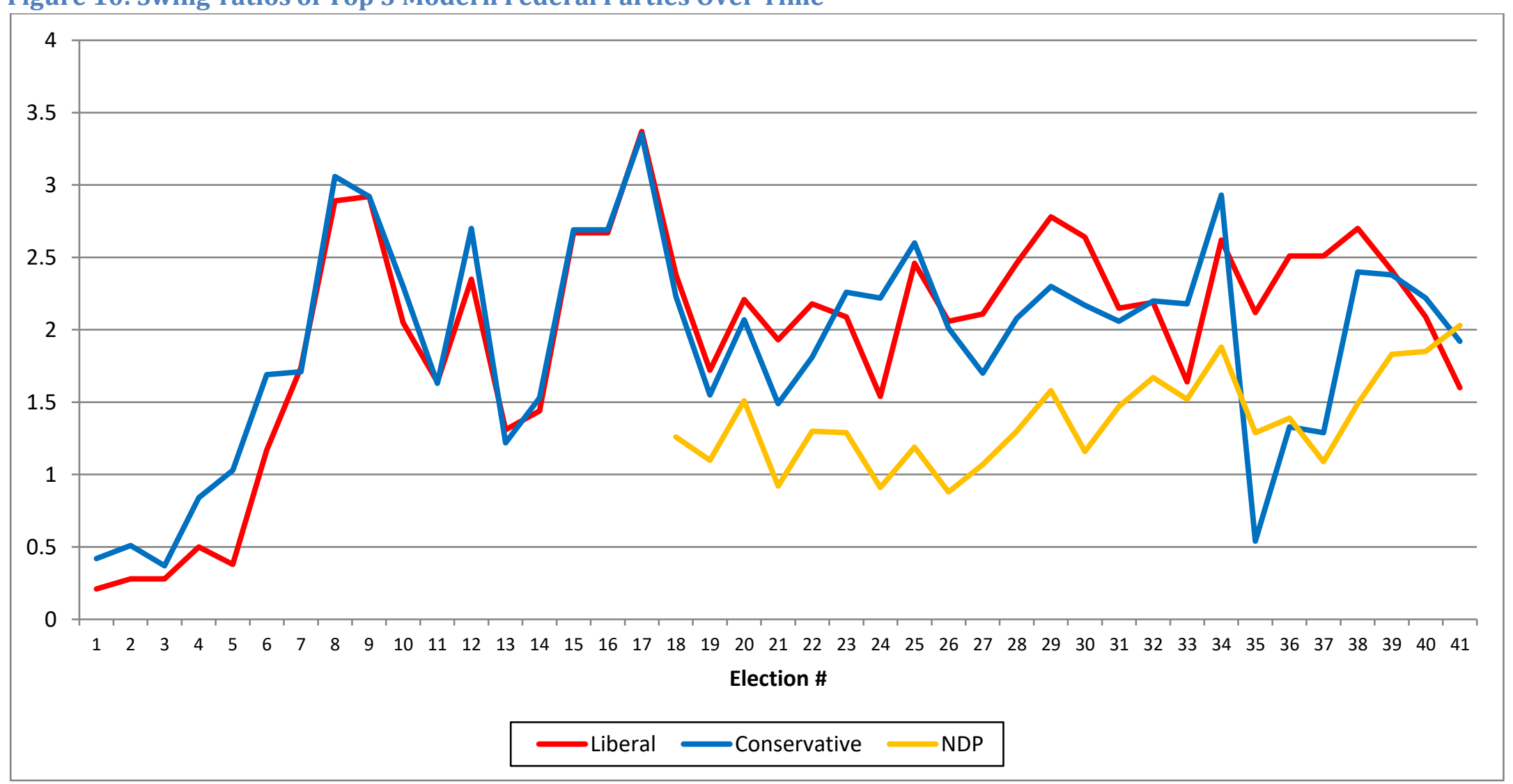


Figure 11: LPRs and Swing-ratio of Liberals and Conservatives Over Time

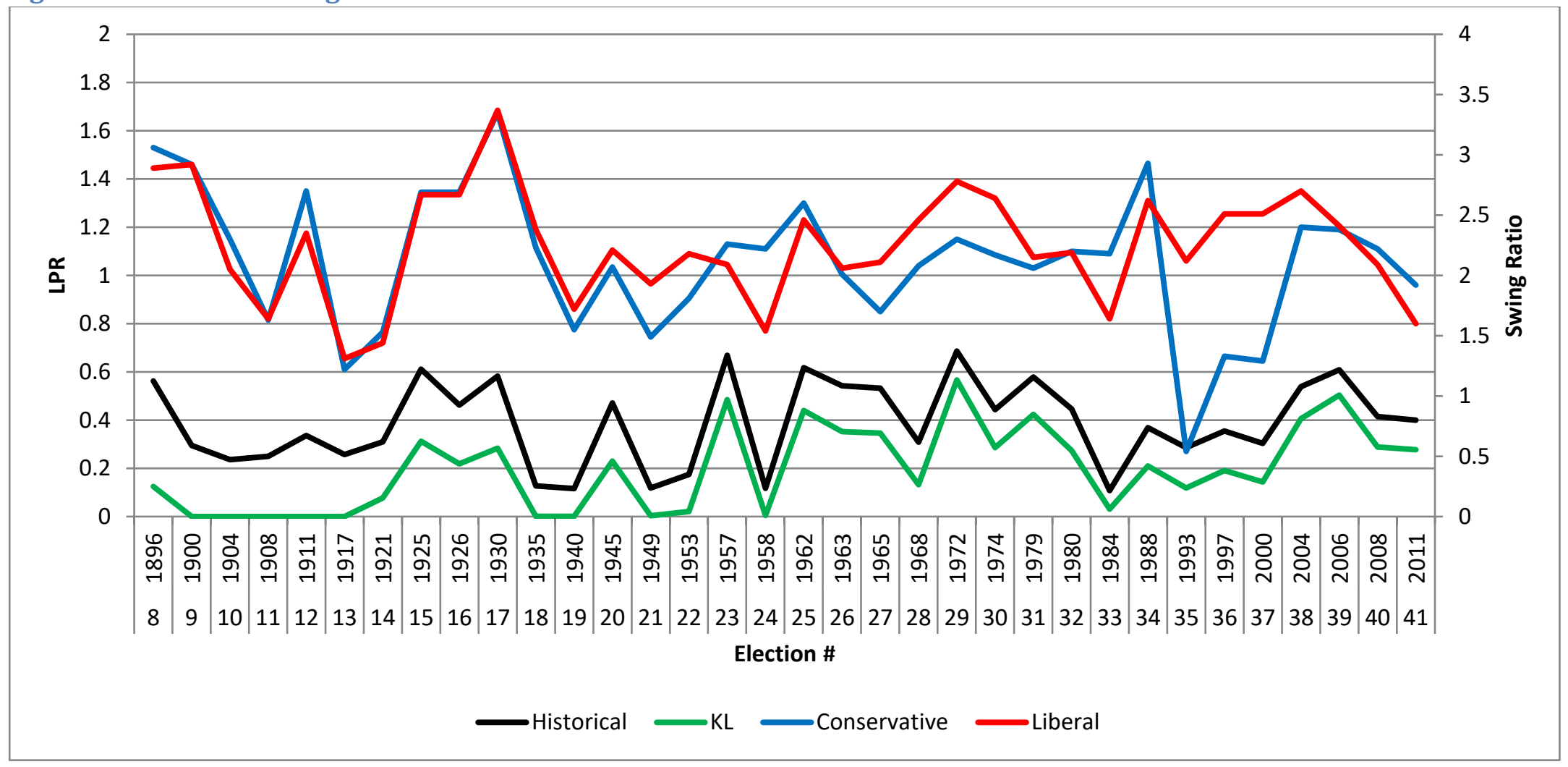


Table 1: Correlation Matrix Table (Pearson's R)

\begin{tabular}{|c|cccc|}
\cline { 2 - 5 } \multicolumn{1}{c|}{} & Historical & $\mathrm{KL}$ & Conservative & Liberal \\
\hline Historical & 1 & & & \\
KL & 0.9013 & 1 & & \\
Conservative & 0.4237 & 0.2504 & 1 & \\
Liberal & 0.5193 & 0.3733 & 0.6244 & 1 \\
\hline
\end{tabular}

\subsection{A Discussion of the Swing-ratios and LPRs over Time}

From figure 9 it is observed that in the first several elections the LPRs for the parties examined are quite low - implying very low competition. Indeed, during the first few elections, the major parties were uncoordinated ${ }^{11}$ and many smaller parties and independents vied for seats. This allowed for the Conservatives and the Liberals to safely win many seats. After the $6^{\text {th }}$ election, the LPRs for the Conservatives and the Liberals rise and then the LPRs stay somewhat steady in the range of 2 to 2.5. The relationship between a higher swing-ratio and electoral success can be observed. It is of note that an increasing swing-ratio - whilst the swing-ratios of the other parties decreases - is indicative that a party will gain seats in parliament. The swing-ratios of the Liberals and the Conservatives seem to trend to 2 after the rise of stable alternative parties. The Liberals and Conservatives have remained substitute parties, in the sense that voters will go from one party to the other more likely than a third party. However the rise of successfully third parties, like the NDP and the Bloc Quebecois, have seemingly increased the dispersion between the Liberals and the Conservatives swingratios and lowered the swing-ratios for those two parties closer to two. This may be indicative of increased party loyalty or partisanship. Figure 11 and table 1 show the LPRs and the swing-ratios over time graphically and a correlation matrix demonstrating how all measures are correlated. The historical distribution based LPR, proposed first in this paper, shows a higher correlation with the

\footnotetext{
${ }^{11}$ It is of historical note that the Liberals ran their first two elections without an official party leader.
} 
swing-ratios of the two major parties compared to the Kayser \& Lindstadt proposed measure.

\section{Robustness Test: Does Economics Drive Politics?}

Kayser \& Lindstadt looked at how their measure of electoral competition, electoral risk, could explain real prices across countries and over time. However, they did not try to look at how electoral risk could itself be explained by any other variable. This paper examines the LPRs to see if the probability of losing can be explained by economic variables.

Motivated by the literature, it is contended here that the unemployment rate, real income, the inflation rate, and government spending could all influence the outcome of an election and these variables should correlate statistically with the estimated LPRs.

The data used in this paper on the inflation rate, real income, and government spending goes back to the 1890s, but quality information on the unemployment rate was only available for both the US and Canada for the post-Second World War period. This paper tests a series of models from the 1890s to the 2011 election using the first 3 mentioned variables, and tests a series of models for the post-Second World War period with all the variables including the unemployment rate.

It is proposed that citizens care about changes in their real income, changes in government spending, and changes in the unemployment rate; instead of caring about levels of these variables. The inflation rate, which is already a measure of change, is not altered in anyway. Real income, government spending, and the unemployment rate are all included in the model as percentage changes from the previous year - this is also referred to as a growth rate. To address the problem that much of the data exists on a year-by-year basis, but elections occur within 
the year, variables were included for both the election year and the previous year. It is contended that voters are most heavily influenced by recent economic conditions and that economic changes that occurred more than 1 to 2 years in the past carry much lower weight.

There are 10 different ways to estimate the LPR — and thus 10 dependent variables used in the regressions - along with 12 possible independent variables. After examining the data, four economic variables, their prior year values, and two dummy variables for breaks in time were selected. A dummy for post-Second World War is included in the regression analyses that span from 1890 to 2011 and a dummy for pre-1979 is included for the post-Second World War analyses that include the unemployment rate.

In this paper, steps are taken to address the endogeneity and simultaneity problem that exists when using political-economic variables. Feedback loops may exist between the political sphere and the economic sphere, and variables in both spheres may simultaneously respond to outside factors. To address use the American counterparts for each variable as instrumental variables. Theoretically it would be very difficult for the Canadian incumbent to influence or cause variation in the American variables that are used in this context.

It's been recognized that the effects between economics and electoral success may work in both directions. Changes in policy, taxation, and spending at the government level can explain differences in economic effects (Eulau \& LewisBeck 1985, Lewis-Beck 1988, Voia \& Ferris 2013). To address this endogeneity problem, American counterparts ${ }^{12}$ for each variable are used as instrumental variables in addition to running the Canadian variable regressions.

\footnotetext{
${ }^{12}$ The American counterpart variables were all sufficiently correlated to the Canadian variables with the exception of the change in the unemployment rate, which showed no correlation, and the change in the government spending during the election year. However, the change in government spending during the election year was correlated with the Canadian change in government spending, just not to a sufficiently high degree. The $F$ value obtained from the regression was 3.14 , which does not meet the rule-of-thumb threshold of 15 . It is of note that the unemployment
} 


\section{Beta Regression}

Ordinary least squares (OLS) regressions should not be employed in this instance because the dependent variable is not free to take on any value and, because it is a probability, the dependent variable is restricted to be a real number between 0 and $1^{13}$. The predicted value from such a regression using OLS may "... yield fitted values for the variable of interest that exceed its lower and upper bounds" (Ferrari \& Cribari-Neto, 2005). The dependent variable is assumed to follow a beta distribution, hence the name 'beta regression'.

Originally developed by Ferrari \& Cribari-Neto (2005), the beta regression has advantages because it uses the real values of the data, instead of transformed values of the dependent variable that many previous authors proposed as a solution to bounded data. One of the beta regression's advantages is that the underlying beta density can assume a number of different shapes, including left and right skewed data.

The beta density is expressed as:

$$
\begin{aligned}
& \mathrm{f}(\mathrm{y} ; \mathrm{p}, \mathrm{q})=\frac{\Gamma(\mathrm{p}+\mathrm{q})}{\Gamma(\mathrm{p}) \Gamma(\mathrm{q})} y^{p-1}(1-y)^{q-1} \\
& 0<y<1
\end{aligned}
$$

And $p, q>0$ and $\Gamma($.$) is the gamma function.$

Ferrari \& Cribari-Neto propose the alternative specification by setting $\mu=p /(p+q)$ and $\varphi=p+q:$

$$
\mathrm{f}(\mathrm{y} ; \mu, \varphi)=\frac{\Gamma(\varphi)}{\Gamma(\mu \varphi) \Gamma((1-\mu) \varphi)} y^{p \varphi-1}(1-y)^{(1-\mu) \varphi-1}
$$

rates between the US and Canada are sufficiently correlated, and it is only the year-over-year percentage changes for unemployment that do not show correlation.

\footnotetext{
${ }^{13}$ If the dependent variable also assumes the extremes 0 and 1 , a useful transformation in practice is $(y \cdot(n-1)+0.5) / n$ where $n$ is the sample size (Smithson and Verkuilen 2006).
} 


$$
0<y<1
$$

With $0<\mu<1$ and $\varphi>0$

Since $\mathrm{y} \sim \beta(\mu, \varphi)$, then $\mathrm{E}(\mathrm{y})=\mu$ and $\operatorname{Var}(\mathrm{y})=\frac{\mu(1-\mu)}{(1+\varphi)}$.

General version of the model, let $y=\left(y_{1}, \ldots, y_{n}\right)^{T}$ be a random sample, where $y_{i}$ $\sim \beta\left(\mu_{i}, \varphi_{i}\right), \mathrm{i}=1, \ldots, \mathrm{n}$

The beta regression model is defined as

$$
\begin{aligned}
& \mathrm{g}\left(\mu_{i}\right)=x_{i} \\
& \beta=n_{i}
\end{aligned}
$$

Where $\beta=\left(\beta_{1}, \ldots, \beta_{k}\right)^{T}$ is a $k \times 1$ vector of unknown regression parameters $(\mathrm{k}<$ $\mathrm{n}), x_{i}=\left(x_{i 1}, \ldots, x_{i k}\right)^{T}$ is the vector of $\mathrm{k}$ regressors and $n_{i}$ is a linear predictor (i.e. $\left.n_{i}=\beta_{1} x_{i 1}+\cdots+\beta_{k} x_{i k}\right)$. In this case, $\mathrm{g}():.(0,1) \mathrm{g}():.(0,1) \rightarrow \mathbb{R}$ is a link-function, which is strictly increasing and twice differentiable.

\subsection{Models}

\section{For the post-war period:}

$$
\begin{aligned}
& L P R_{t}=\alpha+\beta_{1} * U R_{t}+\beta_{2} * U R_{t-1}+\beta_{3} * U R G R_{t}+\beta_{4} * \\
& U R G R_{t-1}+\beta_{5} * G_{t}+\beta_{6} * G_{t-1}+\beta_{7} * Y_{t}+\beta_{8} * Y_{t-1}+\beta_{9} * \\
& \pi_{t}+\beta_{10} * \pi_{t-1}+\beta_{11} * D 1979_{t}+e_{t}
\end{aligned}
$$

Where; $L P R_{t}$ is one of the 10 measures of the LPR.

$U R_{t} \quad:$ the unemployment rate.

$U R G R_{t} \quad$ : the year-over-year percentage change of the unemployment rate. 
$G_{t} \quad:$ the year-over-year percentage change of per capita government spending.

$Y_{t} \quad$ : the year-over-year percentage change of per capita real GDP.

$\pi_{t} \quad$ : the inflation rate measured from the Consumer Price Index.

$D 1979_{t} \quad$ : a dummy for all years prior to 1979.

$e_{t} \quad:$ the error term.

\section{For the post-1890 period:}

$$
\begin{gathered}
L P R_{t}=\alpha+\beta_{1} * G_{t}+\beta_{2} * G_{t-1}+\beta_{3} * Y_{t}+\beta_{4} * Y_{t-1}+\beta_{5} \\
* \pi_{t}+\beta_{6} * \pi_{t-1}+\beta_{7} * D W W 2_{t}+e_{t}
\end{gathered}
$$

Where; $L P R_{t}$ is one of the 10 measures of the LPR.

$G_{t} \quad:$ the year-over-year percentage change of per capita government spending.

$Y_{t} \quad$ : the year-over-year percentage change of per capita real GDP.

$\pi_{t} \quad$ : the inflation rate measured from the Consumer Price Index.

$D W W 2_{t} \quad$ : a dummy for all years prior to and including the Second World War.

$e_{t} \quad:$ the error term. 
Table 2: Regression Results, Post World War 2, Canadian Variables

\begin{tabular}{|c|c|c|c|c|c|c|c|c|c|c|c|}
\hline & \multicolumn{10}{|c|}{ Regression } \\
\hline & & \multicolumn{2}{|c|}{ All } & \multicolumn{2}{|c|}{ Eight } & \multicolumn{2}{|c|}{ Nine } & \multicolumn{2}{|c|}{ Ten } & \multicolumn{2}{|c|}{ Eleven } \\
\hline & & Historical & $\mathrm{KL}$ & Historical & $\mathrm{KL}$ & \begin{tabular}{|l|} 
Historical \\
\end{tabular} & $\mathrm{KL}$ & Historical & $\mathrm{KL}$ & Historical & $\mathrm{KL}$ \\
\hline Coefficient & Intercept & 0.872 & 0.683 & 0.596 & 0.559 & 0.623 & 0.917 & 0.598 & 0.554 & 0.773 & 0.792 \\
\hline P Value & & 0.001 & 0.004 & 0.000 & 0.000 & 0.000 & 0.001 & 0.000 & 0.000 & 0.002 & 0.005 \\
\hline Sig. Indicator & & $* * *$ & $* *$ & $* * *$ & $* * *$ & $* * *$ & $* * *$ & $* * *$ & $* * *$ & $* *$ & $* *$ \\
\hline Coefficient & UR & -20.645 & -20.630 & & & & -26.752 & & & -26.068 & -29.245 \\
\hline P Value & & 0.009 & 0.008 & & & & 0.003 & & & 0.002 & 0.002 \\
\hline Sig. Indicator & & $* *$ & $* *$ & & & & $* *$ & & & $* *$ & $* *$ \\
\hline Coefficient & UR_Prev & 16.408 & 17.033 & & & & 22.220 & & & 23.610 & 25.997 \\
\hline P Value & & 0.018 & 0.014 & & & & 0.005 & & & 0.004 & 0.006 \\
\hline Sig. Indicator & & $*$ & $*$ & & & & $* *$ & & & $* *$ & $* *$ \\
\hline Coefficient & URGR & & & -0.507 & -1.030 & -0.852 & & -0.865 & -0.949 & & \\
\hline P Value & & & & 0.073 & 0.003 & 0.004 & & 0.002 & 0.003 & & \\
\hline Sig. Indicator & & & & & $* *$ & $* *$ & & $* *$ & $* *$ & & \\
\hline Coefficient & URGR_Prev & & & & -0.270 & & & & & & \\
\hline P Value & & & & & 0.186 & & & & & & \\
\hline Sig. Indicator & & & & & & & & & & & \\
\hline Coefficient & G & 0.715 & 0.866 & & 1.048 & 0.855 & 1.171 & & & 0.427 & 0.803 \\
\hline P Value & & 0.195 & 0.118 & & 0.075 & 0.088 & 0.061 & & & 0.374 & 0.159 \\
\hline Sig. Indicator & & & & & . & & . & & & & \\
\hline Coefficient & G_Prev & -0.486 & -0.389 & & & & -0.984 & & & -0.868 & -0.858 \\
\hline P Value & & 0.382 & 0.475 & & & & 0.117 & & & 0.098 & 0.148 \\
\hline Sig. Indicator & & & & & & & & & & . & \\
\hline Coefficient & Income & -5.010 & -5.385 & -3.850 & -6.959 & -6.303 & -6.495 & -6.059 & -6.548 & -7.308 & -7.767 \\
\hline P Value & & 0.096 & 0.073 & 0.177 & 0.049 & 0.027 & 0.052 & 0.013 & 0.025 & 0.023 & 0.033 \\
\hline Sig. Indicator & & & . & & $*$ & $*$ & . & $*$ & $*$ & $*$ & $*$ \\
\hline Coefficient & Income_Prev & -1.683 & -2.099 & & & & -3.127 & & & -2.156 & -3.332 \\
\hline P Value & & 0.492 & 0.388 & & & & 0.249 & & & 0.331 & 0.200 \\
\hline Sig. Indicator & & & & & & & & & & & \\
\hline Coefficient & Inflation & 0.025 & 0.022 & 0.024 & & & 0.018 & 0.020 & 0.028 & 0.011 & 0.017 \\
\hline P Value & & 0.171 & 0.213 & 0.191 & & & 0.337 & 0.156 & 0.102 & 0.460 & 0.342 \\
\hline Sig. Indicator & & & & & & & & & & & \\
\hline Coefficient & INFLATION Prev & -0.039 & -0.038 & -0.044 & -0.025 & -0.027 & -0.032 & -0.039 & -0.046 & -0.017 & -0.023 \\
\hline P Value & & 0.146 & 0.156 & 0.110 & 0.191 & 0.103 & 0.258 & 0.066 & 0.076 & 0.458 & 0.394 \\
\hline Sig. Indicator & & & & & & & & & & & \\
\hline Coefficient & pre1979 & & & & & & & 0.121 & 0.089 & 0.170 & 0.113 \\
\hline P Value & & & & & & & & 0.055 & 0.229 & 0.145 & 0.385 \\
\hline Sig. Indicator & & & & & & & & & & & \\
\hline Adj. R-Squared & & 0.3937 & 0.3599 & 0.1468 & 0.3281 & 0.3161 & 0.4765 & 0.4651 & 0.4199 & 0.5253 & 0.4959 \\
\hline Model P & & 0.07675 & 0.09655 & 0.178 & 0.05557 & 0.04374 & 0.04031 & 0.01397 & 0.02305 & 0.03708 & 0.04735 \\
\hline
\end{tabular}

\section{Significance Indicator}

$* * *$

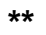

\section{Alpha Level}

$<0.001$

$<0.01$

$<0.05$

$<0.1$

All variables suffixed with 'prev' are the previous year's values. 
Table 3: Regression Results, Post World War 2, American Variables

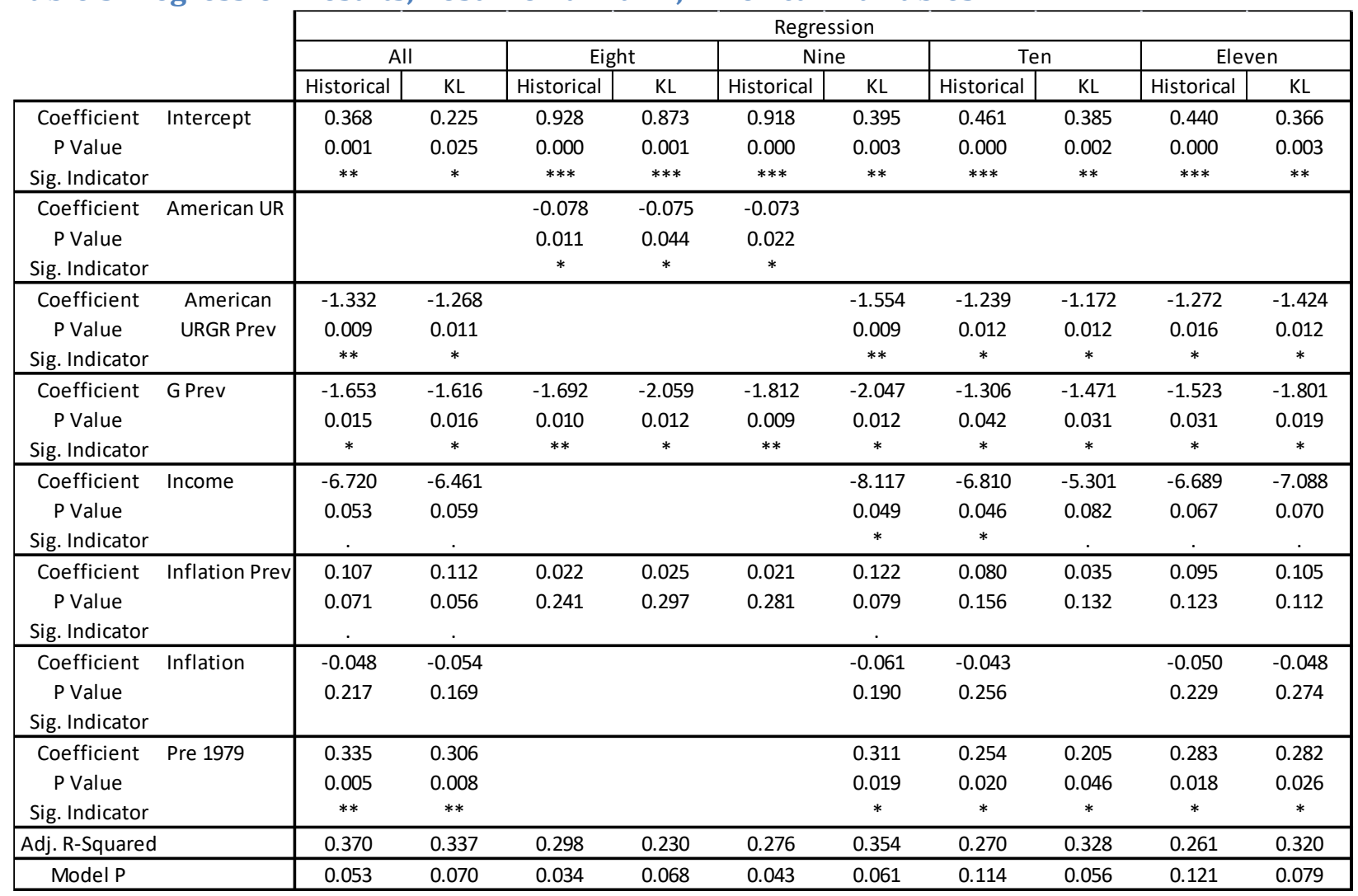

Significance Indicator

***

**

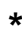

\section{Alpha Level}

$<0.001$

$<0.01$

$<0.05$

$<0.1$ 
Table 4: Regression Results, 1890-2011, Canadian Variables

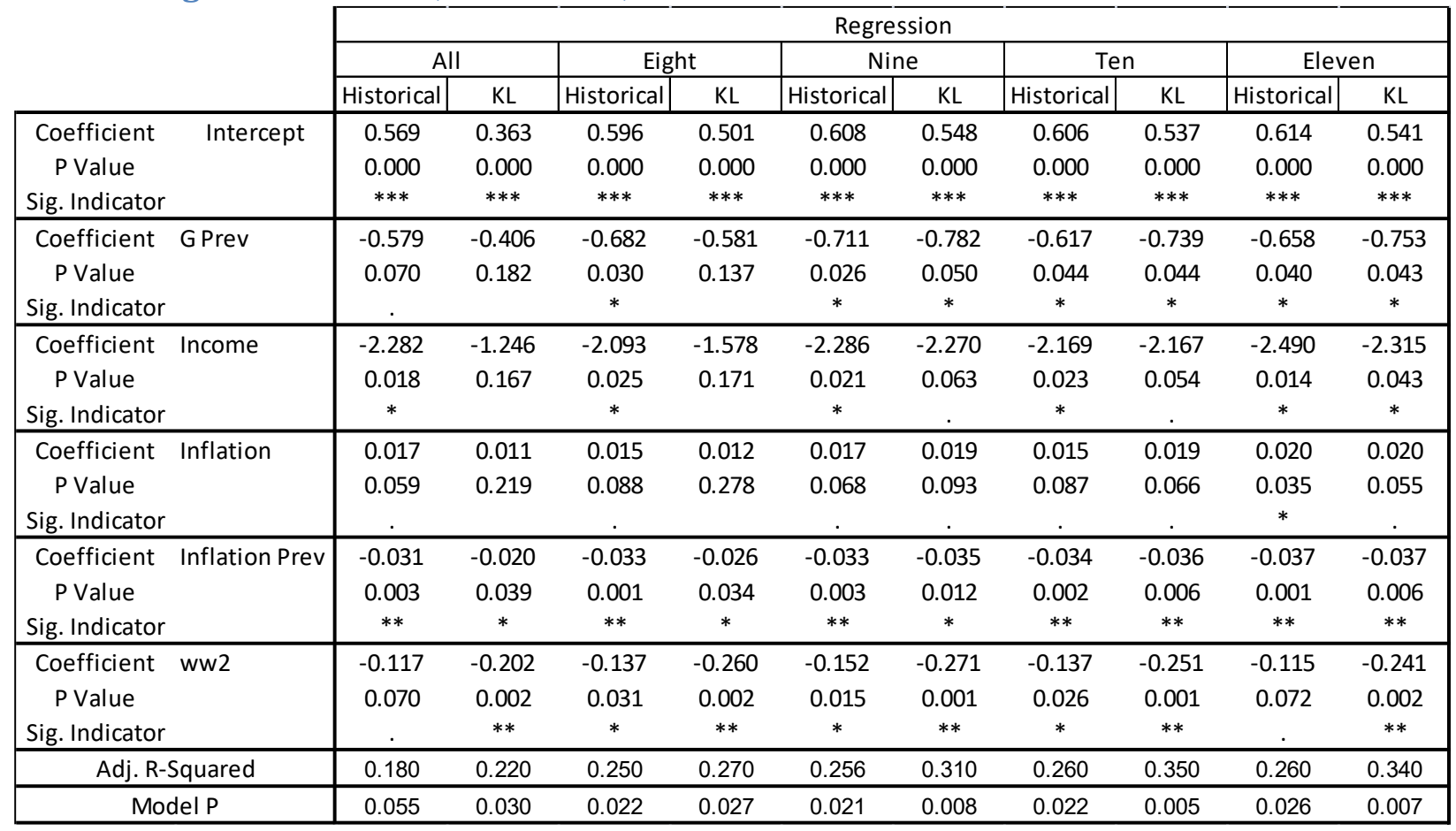

Significance Indicator

***

**
Alpha Level

$<0.001$

$<0.01$

$<0.05$

$<0.1$ 
Table 5: Regression Results, 1890-2011, American Variables

\begin{tabular}{|c|c|c|c|c|c|c|c|c|c|c|}
\hline & \multicolumn{10}{|c|}{ Regression } \\
\hline & \multicolumn{2}{|c|}{ All } & \multicolumn{2}{|c|}{ Eight } & \multicolumn{2}{|c|}{ Nine } & \multicolumn{2}{|c|}{ Ten } & \multicolumn{2}{|c|}{ Eleven } \\
\hline & Historical & $\mathrm{KL}$ & Historical & $\mathrm{KL}$ & Historical & $\mathrm{KL}$ & Historical & $\mathrm{KL}$ & Historical & $\mathrm{KL}$ \\
\hline Coefficient (Intercept) & 0.533 & 0.344 & 0.529 & 0.435 & 0.554 & 0.504 & 0.532 & 0.482 & 0.536 & 0.478 \\
\hline P Value & 0.000 & 0.000 & 0.000 & 0.000 & 0.000 & 0.000 & 0.000 & 0.000 & 0.000 & 0.000 \\
\hline Sig. Indicator & $* * *$ & $* * *$ & $* * *$ & $* * *$ & $* * *$ & $* * *$ & $* * *$ & $* * *$ & $* * *$ & $* * *$ \\
\hline Coefficient GUS & -1.494 & -1.179 & -1.460 & & -1.379 & -1.640 & -1.946 & -2.258 & -1.747 & -2.247 \\
\hline P Value & 0.059 & 0.103 & 0.071 & & 0.070 & 0.074 & 0.016 & 0.016 & 0.043 & 0.018 \\
\hline Sig. Indicator & . & & . & & . & . & $*$ & $*$ & $*$ & $*$ \\
\hline Coefficient G US Prev & -0.473 & -0.412 & -0.334 & -0.483 & -0.421 & -0.651 & -0.080 & -0.407 & -0.171 & -0.367 \\
\hline P Value & 0.257 & 0.283 & 0.433 & 0.347 & 0.312 & 0.197 & 0.839 & 0.373 & 0.686 & 0.427 \\
\hline Sig. Indicator & & & & & & & & & & \\
\hline Coefficient Income US & -0.352 & & -0.595 & -0.204 & -0.931 & -0.663 & -0.769 & -0.579 & -0.921 & -0.616 \\
\hline P Value & 0.634 & & 0.472 & 0.837 & 0.247 & 0.490 & 0.306 & 0.501 & 0.259 & 0.483 \\
\hline Sig. Indicator & & & & & & & & & & \\
\hline Coefficient Inflation Prev US & -0.016 & -0.010 & -0.012 & -0.018 & -0.015 & -0.017 & -0.008 & -0.011 & -0.012 & -0.010 \\
\hline P Value & 0.268 & 0.450 & 0.410 & 0.273 & 0.315 & 0.337 & 0.585 & 0.504 & 0.445 & 0.536 \\
\hline Sig. Indicator & & & & & & & & & & \\
\hline Coefficient Inflation US & 0.026 & 0.021 & 0.021 & 0.006 & 0.022 & 0.030 & 0.024 & 0.035 & 0.026 & 0.035 \\
\hline P Value & 0.043 & 0.076 & 0.108 & 0.566 & 0.084 & 0.052 & 0.050 & 0.016 & 0.052 & 0.019 \\
\hline Sig. Indicator & $*$ & . & & & - & $\cdot$ & $*$ & $*$ & $\cdot$ & $*$ \\
\hline Coefficient ww2 & -0.039 & -0.141 & -0.051 & -0.218 & -0.088 & -0.192 & -0.037 & -0.137 & -0.023 & -0.130 \\
\hline P Value & 0.583 & 0.038 & 0.488 & 0.014 & 0.207 & 0.027 & 0.603 & 0.099 & 0.768 & 0.130 \\
\hline Sig. Indicator & & $*$ & & $*$ & & $*$ & & . & & \\
\hline Adj. R-Squared & 0.07237 & 0.1919 & 0.03528 & 0.1148 & 0.1086 & 0.2486 & 0.1654 & 0.3159 & 0.09554 & 0.2981 \\
\hline Model P & 0.2401 & 0.06308 & 0.3358 & 0.1344 & 0.1735 & 0.03252 & 0.1001 & 0.01391 & 0.2117 & 0.02089 \\
\hline
\end{tabular}

Significance Indicator

***

**

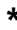

Alpha Level

$<0.001$

$<0.01$

$<0.05$

$<0.1$ 


\subsection{Interpreting the Regression Results}

The results show, as expected, that, ceteris paribus, the Canadian variables offer more explanatory power than the American variables. As noted, the Canadian variables may suffer from endogeneity and simultaneity. As table 2 shows, it is possible to consistently create a model that is significant, offers explanatory power, and correlates with many of the economic variables and the selected LPRs. This suggests that the KL measure of the LPR, as shown in the column 'KL' under the column heading 'All', passes a test of robustness.

Table 2 shows that income - as measured as a percentage change in real per capita GDP - and the unemployment variables are consistently significant, while other variables offer less explanatory power. The income coefficients are consistent with intuition, which is to say, as income increases the probability that the incumbent will lose decreases, thus implying the populace are satisfied with the government.

Table 3 tells a slightly different story. Looking at the American variables, it is observed that government spending influences the LPR and the pre-1979 dummy variable offers some significant explanatory power. The American variable regressions are less likely to be significant at the alpha ${ }^{14}$ level of 0.05 . Where Table 3 shows that the adjustments made to the Kayser \& Lindstadt model by rolling the elections in the distribution using the 'add one drop one' approach offer mixed results in improving explanatory power, whereas table 2 demonstrates that the adjustments to the model improve significance and explanatory power of the model.

Curiously, the percent growth of the unemployment rate in all cases has a negative coefficient. This implies that if the unemployment rate increases over the previous year, the probability that the incumbent will lose goes down. This is a non-intuitive result. In the cases where the level of the unemployment rate is used, it is shown to be significant in both the current and previous period, with

\footnotetext{
${ }^{14}$ The probability of committing a Type-1 error.
} 
opposite signs. It is observed that the current periods have a negative coefficient, and the previous periods have a positive coefficient for the level of the unemployment rate. This confirms the percentage change in the unemployment rate coincides with the data. This author's only explanation for such a result is that because the unemployment rate operates only in a band (in other words, cannot be less than zero, and functionally cannot be above 100 , and historically operates on a much narrower band), that a decreasing unemployment rate is behaving as a proxy or instrument for previous higher levels of unemployment, and hence dissatisfaction with the incumbent government.

In tables 4 and 5 , it is observed that it is much easier to construct statistically significant models to explain the LPR - albeit with fewer significant variables. The explanatory power, as measured by the adjusted R-Squared, is noticeably smaller without the unemployment rate variables included. The significance of the models in table 5 with the American variables is noticeably less than the Canadian counterpart. However, here it appears that using the Kayser \& Lindstadt proposed estimated seat-swings offers more explanatory power, instead of using the historical seat-swings to estimate the distribution.

It is of note that when the unemployment rate is present in the model, inflation does not offer much explanatory power, but in the absence of the unemployment rate, inflation is shown to consistently significant.

\section{Conclusion}

A measure for political competition, estimated by electoral risk, has been applied to the Canadian data set for all elections from 1867 to 2011 and has been shown to offer successful predictive power in back testing. The measure proposed by Kayser \& Lindstadt has been tested for the first time and proven to be accurate and robust to its correlation with economic variables. Improvements made to the model in this paper can offer further explanatory power. 
It has been demonstrated that the Kayser \& Lindstadt LPR can be improved upon with recalibration; and further model development in this area is predicted to outperform existing models in terms of accuracy.

Finally, evidence from this paper points to the continued existence of the 'economic voter' and the value of economics in predicting political outcomes. 


\section{Chapter 2}

\section{Introduction}

The extensive study of economics, politics, and the intersection of these two academic disciplines has led to some fascinating theories and conclusions. The impacts of public policies on economic growth and economic distribution have been studied broadly. Likewise, prevailing economic conditions have been studied for their influence on political success.

In this paper I focus on constructing a hazard-based duration model to estimate the length of a Canadian parliament. This model uses economic, socio-political, and principal component explanatory variables. For the political variables, this paper will pay close attention to the impact of political competition on election timing, using indicators of political competition developed in my first chapter and others (Przerworksi, 1971; Ferris, Winer, \& Grofman, 2016).

Knowing the date that the federal election will be held can have an impact on decisions that citizens, businesses, and sub-national governments make. Elections in a competitive democracy introduce inherent uncertainty. Uncertainty regarding the future of government policies causes businesses to potentially delay investment decisions and focus more on the short term - potentially to the detriment of consumers and shareholders. Some businesses, for example, legal cannabis growers and distributers, were directly and significantly affected by the federal Canadian government's 2015 decision (and prior to that, the Liberal Party of Canada's policy platform) to legalize recreational cannabis. Citizens, whose lives depend on policies that may be changed under a new government, may, ceteris paribus, also alter their behavior as a result of an election. Some examples of this altered behavior include delaying a purchase of a new house, undergoing a house renovation to take advantage of an expiring tax credit, or 
delaying taking a new job as a result of uncertainty regarding new sector or policy decision.

In constructing the hazard function to estimate the probability of an election being called, I build on the previous work by Ferris \& Voia (2009) ${ }^{15}$, Voia \& Ferris (2013), Smith (1996), Kayser (2005), Box-Steffensmeier \& Jones (1997), and Ferris, Winer, \& Grofman (2016). In this paper I differ from previous work by employing principal components to represent meaningful variable groups, use new variables, and some different periods of reference in order to determine and examine the variables that influence the length of a Canadian parliament.

Canada has existed as a multi-party majoritarian and democracy, with essentially unchanged political institutions since 1867 . This period provides ample timeseries data and allows for the investigation of the influence of economic and political conditions on electoral timing. Under Canada's Westminster-style system, the party that obtains the most seats in an election has the first right to gain the confidence of the House and form a government ${ }^{16}$.

When any new government takes office, they can govern for a maximum of a 5 year period. Parliament can be ended sooner than 5 years if the government decides to dissolve the parliament and begin an election process ${ }^{17}$. Alternatively,

\footnotetext{
${ }^{15}$ A subtle, but meaningful, difference in my work compared to that of Ferris \& Voia (2009) is my interpretation of the final 6 months of a government before an election must be called. A technical note, discussed in further detail later, is the use of censored data in duration analysis. By looking at each election in detail, I came to the conclusion that there is evidence that every election after 1945 was called before that maximum time allotted, and hence there was no censored data.

${ }^{16}$ While parliament is composed of three parts - the House, the Senate, and the Governor General - it is the House that plays the dominant role. When referring to Canadian parliament, colloquial parlance makes little distinction between the Parliament and the House. This paper will focus solely on the election and governing duration of the House and will interchangeably refer to the House as Parliament.

${ }^{17}$ Bill C-16 of the $39^{\text {th }}$ Canadian Parliament changed the maximum amount of time of a Parliament to 4 years. While the bill specified a fixed-election date, the Constitution still allows for a parliament to be dissolved early and an election called before the specified date.
} 
parliament is dissolved if the controlling government has lost the confidence of the house and no other alternative government/coalition has been formed. Since the majority of parliaments in Canada last fewer than 5 years, this allows for a sizeable data set to examine the causes of early termination of parliament. Historically, only $12 \%$ of Canadian parliaments lasted their maximum duration. Parliaments lasting a full five-year term were more common before the Second World War, where about a quarter of Canadian parliaments lasted the full duration. However, since 1945 no Canadian parliament has lasted the full fiveyear term.

This paper is organized as follows; there is a literature discussion in section 2, the formal model of duration is presented in section 3 along with motivation for the variables, section 4 is the results, robustness checks are in section 5 , and section 6 concludes. Additional results and the data are in the appendix.

\section{Literature}

The literature on the political economy is vast and has been discussed in many review articles. In constructing the models and selecting variables to include, many papers were referenced, which often build off each other (Lewis-Beck \& Stegmaier, 2000; Dewan \& Shepsle, 2011; Grofman, 2016; Przeworski, 2016).

Duration analysis has become a popular form of statistical examination in the political science literature. Duration analysis has been used to estimate political processes - most notably by Smith (1996), Kayser (2005), Box-Steffensmeier \& Jones (1997), and Ferris \& Voia (2009) for the Canadian example. Some articles on the topic are explaining the length of coalitions (King, Alt, Burns, \& Laver, 1990), cabinet reshuffles (Kam \& Indridason, 2005), the factors precipitating the dissolution of individual parliaments (Lupia \& Strom,1995; Strom \& Swindle, 2002; Ferris \& Voia, 2009), and the stability of ministerial tenures (Berlinski, Dewan, \& Dowding, 2007; Huber \& Martinez-Gallardo, 2008). Analysts have looked across countries to examine differences in parliamentary institutions in order to test various timing hypotheses. Other analysts chose to look within 
countries at the time series presented by successive parliamentary governments, such as Inogushi (1981) and Ito (1990) for Japan, Smith $(1996,2003)$ for the UK, and Chowdury (1997) for India.

As duration modeling has become more common, the modeling process has become more rigorous and nuanced for different possible applications. In this paper, when the government decides to call an election, I explain this decision as the outcome of a decision process that features an 'optimal stopping rule' (Balke, 1990; Kayser, 2005; Ferris \& Voia, 2009). I treat 'optimal stopping' as the ideal time to take an action to maximize an expected benefit or to minimize an expected loss. In the case of an election, both ways of viewing optimal can be applied. The incumbent government is minimizing the probability of their loss in the upcoming election - at a yet undetermined time - while trying to maximize the seats they obtain and also the rent they obtain by being in government. As discussed in more detail later, the government can be thought of as an actor that extracts a rent by governing. In that case, the government tries to maximize the expected total rent when making their decision about electoral timing.

One of the first papers to examine the length of a Canadian parliament using duration analysis, Ferris \& Voia (2009) examine if the length of parliament can be explained by economic circumstances, policy decisions, and whether or not these factors affect different parties distinctively (along the lines of Nordhaus (1975), Rogoff \& Sibert (1988), and Belsey \& Case (1995)). In this paper I expand the analysis by including voter-observable variables such as inflation ${ }^{18}$, the number of consecutive elections in a row a government has won, the unemployment rate, and several measures of electoral competition. My analysis makes use of principal components to create theoretical variables that are designed to capture economic sentiment. By including the unemployment rate in my models, and variables derived from the unemployment rate, , some of my analysis occurs over a distinctly different time period than that of Ferris \& Voia

\footnotetext{
${ }^{18}$ Inflation as measured by the change in the consumer price index (CPI)
} 
(2009). This is because the unemployment rate only became available in its current estimation in 1948.

\section{The Model}

In order to model the election date, I assume that the probability that the incumbent government will call an election, $F($.), in year $\boldsymbol{d}$ of its mandate, depends upon two sets of factors, and on the time spent in office, $\boldsymbol{t}$. The first set of factors is denoted $\boldsymbol{c}$; these are characteristics that exist in the political environment, such as the level of political competition. Also included in $\boldsymbol{c}$ are characteristics specific to the party in power, such as their political persuasion and the party's level of political capital.

The second set of factors, denoted as $x(t)$, varies over time. This set of factors is based on the prevailing economic conditions. We see that the variables behave as proxies for how the representative economic voter feels about the government and how the economic voter decides their voting decision.

The model is similar to the model presented in Ferris \& Voia (2009), which also employs the concept of optimal stopping. I assume that the incumbent government claims responsibility for the prevailing economic conditions. Hence, the economic voter seeks to reward the incumbent for good economic outcomes and punish the incumbent for bad economic outcomes. While it is reasonable to assume that the government has control - to some extent - over the economy, it's also possible that much of the variation observed in economic outcomes is, in-fact, not in the incumbent's control and the economy behaves more stochastically. If we accept that some of the economic conditions are out of the government's control, I can then assume that there is a theoretically describable distribution of possible economic events. It is from this distribution that an event can be drawn in each period. A good event, which is defined as an event that is above the expected value ${ }^{19}$, makes the government appear favorable to the

\footnotetext{
${ }^{19}$ The expected value is the average growth rate, about which the economy varies.
} 
voters. A bad event, defined as an event below the expected value, makes the government appear incompetent. I assume that all draws are independent and hence not influenced by past economic circumstances - nor do current events have the ability to influence future economic circumstances.

The cumulative probability of drawing an economic event, $x$, where $x \in$ $\left(x_{\min }, x_{\max }\right)$ is denoted as $G(x)$, and $g(x)$ is the frequency associated with a particular $x$. The expected value of the economic event can be calculated thus: $E(x)=\int_{x_{\min }}^{x_{\max }} x g(x) d x$. It can then be deduced that it is the value $x(t)-E(x)$ that influences the probability of the incumbent government continuing to hold office.

Given the above, we see that the probability that the incumbent government will win can then be defined as,

$$
F(x(t), c, d)=\int_{x_{\min }}^{x(t)} f(x(t), c, d) d x
$$

Governing parties are said to accrue a rent ${ }^{20}$ while they are in office and, hence, by winning an election they gain more rent. By calling an election early, the governing party believes that the expected rent from winning the election is larger than the potential rent accrued by continuing to stay in office. The key concept is that because parliaments last 5 years or less, there is an incentive to call an election early if the government believes that they can win the next election and then govern for at most another five years. As a result of this, the government is seeking an opportune time to extend their governing duration.

The optimal stopping problem can be described thus,

\footnotetext{
${ }^{20}$ Rent is not necessarily a monetary concept, rent can be thought of in terms of influence, favors, or political capital - this in addition to any monetary value the government may be able to obtain. As motivation, Downs (1957) claims, "We assume that (the government) act solely in order to attain the income, prestige, and power which come from being in office."
} 


\section{Net Value(election at d)}

$$
=R E(n) F(x(t) ; c, d)-R \int_{d}^{5}[1-H(x(t), c, d) d d
$$

where $R$ is rent, and $E(n)$ is the expected number of years ${ }^{21}$ the party can expect to govern after winning office and $H($.) is the election hazard so that $1-H($.$) is the$ probability of surviving year $d$ given that the government has survived thus far. The first part of the right hand side is the expected gain from being in office. The second part of the right hand side is the expected loss; this is obtained by integrating the conditional survival across all remaining years and multiplying that by the rent from continuing to be in office. In the expected loss, the area under the integral falls as $d$ approaches 5 . It follows that, as time goes by, the minimum necessary economic conditions required for the net value to be positive falls. In other words, it becomes more and more likely that the government will call an election as time goes by if economic conditions are good, and, ceteris paribus, the threshold for calling an election falls over time. It is these two predictions that form the foundation for how I evaluate election timing in this paper.

My paper uses the Cox semi-parametric proportional hazard (Cox $\mathrm{PH}$ ) model to test the predictions of several theoretical models. The process uses a sequential decision rule which employs a measure of economic variables to select an ideal time to call an election.

Using the Cox PH model, Ferris \& Voia (2009) assume that the probability of the election being called depends on 3 sets of factors - in addition of the length of time the parliament has been in power. Ferris \& Voia examine characteristics of the electoral system, such as party fractionalization; in addition to this particular measure, my paper will include the measures of competition developed in my first chapter and others (Przerworksi, 1971; Ferris, Winer, \& Grofman, 2016). Fractionalization is used by Ferris \& Voia (2009) as a proxy for competition in the political system. However, the recent literature is broader and allows for some

\footnotetext{
${ }^{21}$ This number may be thought of as 5 or less.
} 
aforementioned other measures of competition to be taken into account and examined.

\section{Principal Component Analysis}

While more frequently used in other social sciences, principal component analysis (PCA) allows for the dimension of a set of variables to be reduced while maintaining most of the variation found in the whole set of variables. A set of variables can undergo an orthogonal transformation where the newly constructed variables are linearly uncorrelated variables known as principal components. PCA is often used as part of exploratory data analysis, where PCA is used to find correlations amongst the underlying variables.

PCA deals with two main issues: it removes collinearity between variables by replacing the variables with a newly constructed principal component, and, at the same time, PCA reduces the number of dimensions in the model. The reduction in dimensionality has the potential to increase the significance of the model and remove any confounding factors.

The literature has few examples of using PCA in hazard models. Principal components have been used to a degree for variable selection, but the only example of using PCA-generated covariates in a Cox proportional hazard model is an operational research paper on condition-based maintenance (Lin et al., 2006).

The value of PCA in my model is its potential to reduce the number of variables and increase the degrees of freedom while offering a potentially more holistic and theoretically consistent estimate of voter's preferences. The constructed variables, known as the 'economic outlook' variables, are developed from the economic variables in the model: the growth rate of income, inflation, change in government spending, and the unemployment rate. In the models not employing

principal components, up to three lags could be included for each economic 
variable, allowing for a maximum of 16 variables. Using PCA allows for the reduction of the number of variables used - which could increase the strength of each estimate in the model - without sacrificing much of the explanatory power of the model.

\section{Principal Components}

Represented by $\boldsymbol{x}=\left(x_{1}, x_{2}, \ldots, x_{n}\right)$, a vector of $\mathrm{n}$ random variables, PCA allows there to be a set of $n$ uncorrelated linear combinations of $n$ random variables such that the $i^{\text {th }}$ linear combination had the $i^{\text {th }}$ largest variance among all possible (normalized to one) linear combinations, where $i=1,2, \ldots, n$. Most of the variation can be captured by the first $j$ linear combinations (where $j<n$ ). This allows the $j$ linear combinations, known as principal components, to explain most of the variation observed in the $n$ variables.

\subsection{The Political Environment}

The characteristics that exist in the political environment are expected to affect the hazard rate of an election call in different ways ${ }^{22}$. Many studies have examined the particulars of a parliamentary system and how they influence electoral results. These particulars have been researched for cross-country examination, with studies such as King et al. (1990), Strom and Swindle (2002), Persson and Tabellini (2003), and for country-specific examination, with studies such as Inogushi (1981) and Ito (1990) in Japan, and Smith (2003) for the UK.

The characteristics that affect the political environment included are (i) partisanship, (ii) the number of times the incumbent government has consecutively held government, (iii) the degree of fractionalization of the parliament, (iv) the political affiliation of the party, and (v) the level of competition that exists in the political environment.

\footnotetext{
${ }^{22}$ In the model formulation in the next section, the characteristics that exist in the political environment are denoted as ' $c$ '.
} 


\section{Partisanship}

Throughout Canada's history, a number of parties have achieved electoral success, but only two parties have ever governed: the Liberals, and the Conservatives. The Liberal Party of Canada (hereafter, the Liberals) has existed since Confederation, while the Conservative Party of Canada (hereafter, the Conservatives) has existed in somewhat different forms and under a number of different names.

When the Conservatives were first formed in 1854 they were known as the Liberal-Conservatives. The party changed its name to the Conservative Party in 1873, and then in 1922 the party reverted to their previous name. After 1942, the party adopted the name 'Progressive Conservative Party of Canada'23 . During the 1990s the Progressive Conservatives (PCs) splintered; members left the party to join the Bloc Quebecois and the Reform Party of Canada. By 2003, the Canadian Alliance Party merged with what remained of the PCs and formed the present day iteration of the Conservatives, 'the Conservative Party of Canada'. This amorphous history of the Conservative Party becomes relevant for my analysis when I measure partisanship between the two major parties over time. A variable called 'Liberal' is used as a dummy variable and is equal to one when the Liberal party is in office. Since the Conservatives are the only other party to hold power, when this variable is equal to zero, it captures all iterations of the Conservative Party.

\section{Consecutive Elections}

The trend observed in Canadian politics is that the governing party typically changes after three consecutive elections ${ }^{24}$. While the number of consecutive times the incumbent government has governed is not directly causal on an election being called early, time in office from previous elections may indeed be a convenient proxy for voter satisfaction and sentiment. Overtime, voters become

\footnotetext{
${ }^{23}$ Known colloquially as the 'PCs' or simply, 'the Conservatives'.

${ }^{24}$ After 41 elections, the median is amount of elections won consecutively is 3 . This is, however, skewed, and the mean number is 2.78 .
} 
increasingly dissatisfied with the government and the voters' desire for a change of government increases. A newly elected government begins their initial term with a theoretical stock of political capital, and with each misstep or scandal, the incumbent loses some of their political capital. Hence, the number of consecutive prior governments could be used as an instrumental variable that captures many other underlying voter sentiments.

If one assumes that scandals are randomly and equally distributed across time and across parties, then the expected total number of scandals under a government would grow over time. If the voters have a negative disposition which results in them biasedly remembering scandals more distinctively than they remember any good actions of a government, then, ceteris paribus, we would expect voter favorability towards the governing party to fall over time. Hence, the probability of a government change tends to increase with each consecutive government. For these reasons, I include a variable in the duration analysis that measures the number of parliaments for which the incumbent has consecutively been in office.

\subsubsection{Measures of Political Competition}

Electoral competition is an important institution for ensuring that government policy is aligned with the desires of the electorate (Wittman 1995, Breton 1996). Competition is also observed in spatial voting models including Coughlin (1992), Hettich and Winer (1999), Adams, Merrill \& Grofman (2005), and Shofield \& Sened (2006). In these models, competition induces parties to choose policy platforms that cater to the interest of various voter blocs and balance their competing interests.

While the reader may have an intuitive understanding of electoral competition, defining the concept in a rigorous and academic fashion has proven to be difficult. Political competition is complex and multidimensional; it includes entry 
and exit, competition in elections and competition between elections. Many competing definitions exist, with each definition having their own merits ${ }^{25}$. Boyne (1998), takes a critical standpoint, and puts forth that “... the conceptualization of party competition in most of the empirical studies is flawed, and the measures of competition are weak." This paper uses several measures of competition which I think are both academically sound and distinct enough from one another to capture a unique element of competition.

\section{Effective Number of Parties (ENP)}

A method that is employed in my paper to examine the level of competition is to examine the number of parties running in any given district. Ferris, Winer, \& Grofman (2016) argue that a long run deviation above 2 effective parties is a signal of low competition. To measure the number of parties, Ferris, Winer, \& Grofman (2016) use the idea of the 'effective number of parties (ENP)' that was developed by Laakso \& Taagepera (1979).

The ENP uses the idea of the Herfindahl-Hirschman index $(\mathrm{HHI})$ to provide an idea of how many parties have sufficient market share to be considered legitimate contenders for government. Laakso and Taagepera define the ENP for the constituency as,

$$
E N P_{j t}=\frac{1}{\sum_{i}^{I} v_{i j t}^{2}}
$$

\footnotetext{
${ }^{25} \mathrm{~A}$ rich and constantly expanding literature exists on electoral competition. In Kayser and Lindstadt's (2015) review they mentioned that in prominent political science journals, such as the American Political Science Review, American Journal of Political Science, and Journal of Politics, over the period of 2010 to 2015, a paper on electoral competition appeared in every second journal publication on average.
} 
where $v_{i j t}$ represents the vote share of candidate $i$ in constituency $j$ in election $t$. The ENP for the whole system is defined as,

$$
E N P_{t}=\frac{\sum_{j=1}^{J} E N P_{j t}}{J}
$$

The ENP will be equal to the number of parties running in the constituency when the vote share of each party is the same. When many parties run, but only a few parties obtain the majority of the votes, the ENP will be smaller than the total number of parties running.

The analogue to the ENP in economics is to look at the number of firms in an industry. Generally speaking, the more firms that exist in the industry then the more competitive the industry is. Likewise, as Ferris, Winer, \& Grofman (2016) note, it is common in the literature to say that as the ENP increases, the competition in the political environment increases. However, this line of reasoning comes under scrutiny as it seemingly contradicts Duverger's Law ${ }^{26}$ (1954) which states that over time the number of parties competing in any district should tend to two. A violation of Duverger's Law implies something - possibly a lack of competition - is occurring that is pushing the parties away from Duverger's predicted equilibrium. A long term deviation above 2 is interpreted as a sign of lower competition.

Ferris, Winer, \& Grofman (2016) create a measure of competition based on what they refer to as the 'Duverger-Demsetz perspective'. This measure of competition combines Duverger's Law with Demsetz's (1968) theory of competition regarding

\footnotetext{
${ }^{26}$ Duverger claimed that moderate parties will merge together to defeat the possibility of a radical party gaining power. Parties will try to increase market share by moving towards the center of the political spectrum. Fringe parties will get fewer votes and over time until only two parties will remain.
} 
natural monopolies ${ }^{27}$. Ferris, Winer, \& Grofman (2016) propose that - similar to a monopolist trying to discourage a new entrant - a government that holds power in a low-competition state will still try to behave somewhat competitively to discourage another party from unseating them. The idea exists in parallel with governments that are in a completely non-competitive state. These one-party states or dictators will still try to behave in such a way that the likelihood of political insurrection or an equivalent event is minimized. So long as a credible threat exists, good governance can be induced from the incumbent government.

\section{Figure1: Effective Number of Parties over Time}

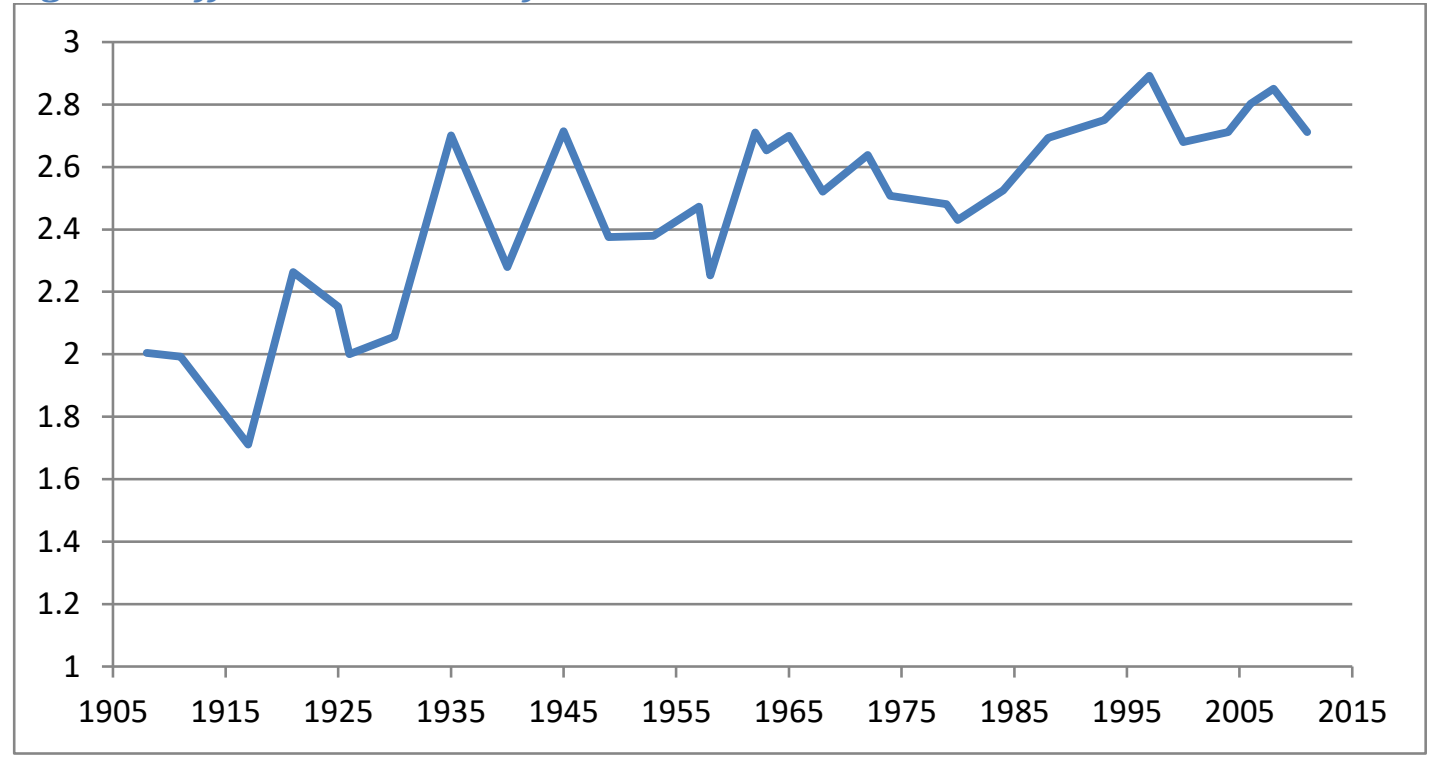

Since 1908 the effective number of parties has risen, deviating away from two and closer to three ${ }^{28}$. This deviation-from-two represents the electoral success of

${ }^{27}$ Demsetz theorized that a more competitive outcome could be achieved from monopolies than otherwise expected if the monopolies were trying to discourage incumbents. The monopolist, rather than only maximizing current profit, will instead choose a lower price that discourages any competitor from joining the market, subsequently increasing the firm's long term expected profit. Consumers benefit from this lower price as long as the monopolist believes there exists a credible threat from a new entrant.

${ }^{28}$ One of the measures of competition uses 11 previous elections to be calculated. The 1908 election in Canada was the $11^{\text {th }}$ federal election. The year of 1908 is used to graph each measure of competition over the same time period. 
many different Canadian political parties ${ }^{29}$ that have tried to break the politicalpower duopoly held by the Liberals and the Conservatives.

\section{Fractionalization}

The fractionalization of parties is the degree to which there are dominant versus insignificant parties. Fractionalization of political parties can be measured analogously to measuring competition amongst firms. Rae (1971) was one of the first researchers to apply the Herfindahl-Hirschman index $(\mathrm{HHI})^{30}$, to the political sphere. Ferris \& Voia (2009) note that fractionalization represents the difficulty of political coordination and maintaining coalitions. Fractionalization at time $t$ is calculated as

$$
\text { Fractionalization }_{t}=\sum_{j=1}^{J} \text { vote }_{\text {share }}^{2} \text {, }
$$

where $\mathrm{J}$ is the total number of effective parties as measured by the ENP.

Along a similar vein, if the $\mathrm{HHI}$ is applied to only the opposition parties (in other words, $\mathrm{J}-1$, where $\mathrm{J}$ is the number of political parties) and excludes the incumbent, the $\mathrm{HHI}$ would then measure how fractionalized the opposition is. The incumbent can then use this measure of fractionalization as a cue for political opportunism. Two possible competing theories may prove to be valid; firstly, a highly fractionalized opposition, ceteris paribus, would likely lead to electoral success for the incumbent. The incumbent may react by taking advantage of the situation and calling an election, but, on the other hand, the incumbent

\footnotetext{
${ }^{29}$ The NDP, Social Credit Party, the Reform Party, the Canadian Alliance Party, and the Bloc Quebecois have all had meaningful electoral success at one time or another since the 1970s.

${ }^{30}$ Herfindahl-Hirschman index is an index that ranges from 0 to 10000 , which is calculated as a sum of the squared market shares of each firm in the industry. As the industry goes towards a monopoly, the index approaches 10000 .
} 
government may also see no threat of electoral loss and chose to continue to govern, being confident that they will win the future election when it arises.

$$
\text { Fractionalization of Opposition } t=\sum_{j=1}^{J-1} \text { vote }_{t} \text { share } e_{j t}^{2}
$$

\section{The Przeworski and Sprague Index (1979)}

The Przeworski and Sprague index is a multi-party index of political competition at the constituency level. The index measures the volatility adjusted vote margin. The vote margin is the difference between the vote total of the winner and the second place party/candidate. A district is said to be 'closer' the more narrow the margin is, and the more 'close' an election is the more competitive the election is said to be. Vote margins can be examined both at the district level but also at the national level.

Przerworksi and others (Przerworksi, 1971; Elkins, 1974; Bartolini, 1990; Ferris et al., 2016) note that the winning vote margins themselves cannot be used independently as a measure of election closeness without first taking into account the vote-volatility that exists in each of the districts. If there are very stable vote outcomes, then a small margin of victory will not necessarily indicate a close election. However, if there is high variance in the vote patterns, then a close margin of victory could be interpreted as a very competitive result. This idea motivated Przeworski \& Sprague, and those after them, to make adjustments to the vote margins in order to take into account district level variability.

To define the party-based PS competition index, the leading vote deficit, $h_{p j}^{t+1}$, is computed for each party, $p$, in constituency, $j$, and election $t+1$ : 


$$
h_{p j}^{t+1}=\frac{\left(v_{1 j t}-v_{p j t}\right)}{\text { Volatility }_{t i}}
$$

Recognizing that not all parties or districts remain the same over time, Ferris et al. (2016) make some adjustments to then aggregate up to a national measure of competition.

$$
h_{p j}^{t+1}=\left\{\begin{array}{c}
1 \text { if } 0 \leq h_{p j}^{t} \leq 1 \\
\frac{1}{h_{p j}^{t}} \text { if } h_{p j}^{t}>1
\end{array}\right.
$$

Ferris et al. (2016) note that for a highly competitive party, $c=1$ in equation (9) because the vote deficit for that party is less than the portion of the electorate that switched parties in the previous election.

The calculated measurement can then be aggregated across all the parties in each constituency :

$$
C_{j}^{t+1}=\sum_{p=1}^{P} c_{p j}^{t+1} v_{p j t}
$$

When $C_{j}=0$, this indicates there is no competition in the constituency. National average competitiveness is then defined as

$$
C_{N J}^{t+1}=\sum_{j=1}^{J} a d j_{-} v w_{j t+1}
$$

Where $a d j_{-} v w_{j t+1}$ is the adjusted vote weight for each constituency. 
Figure 2: Przeworski and Sprague Index over Time

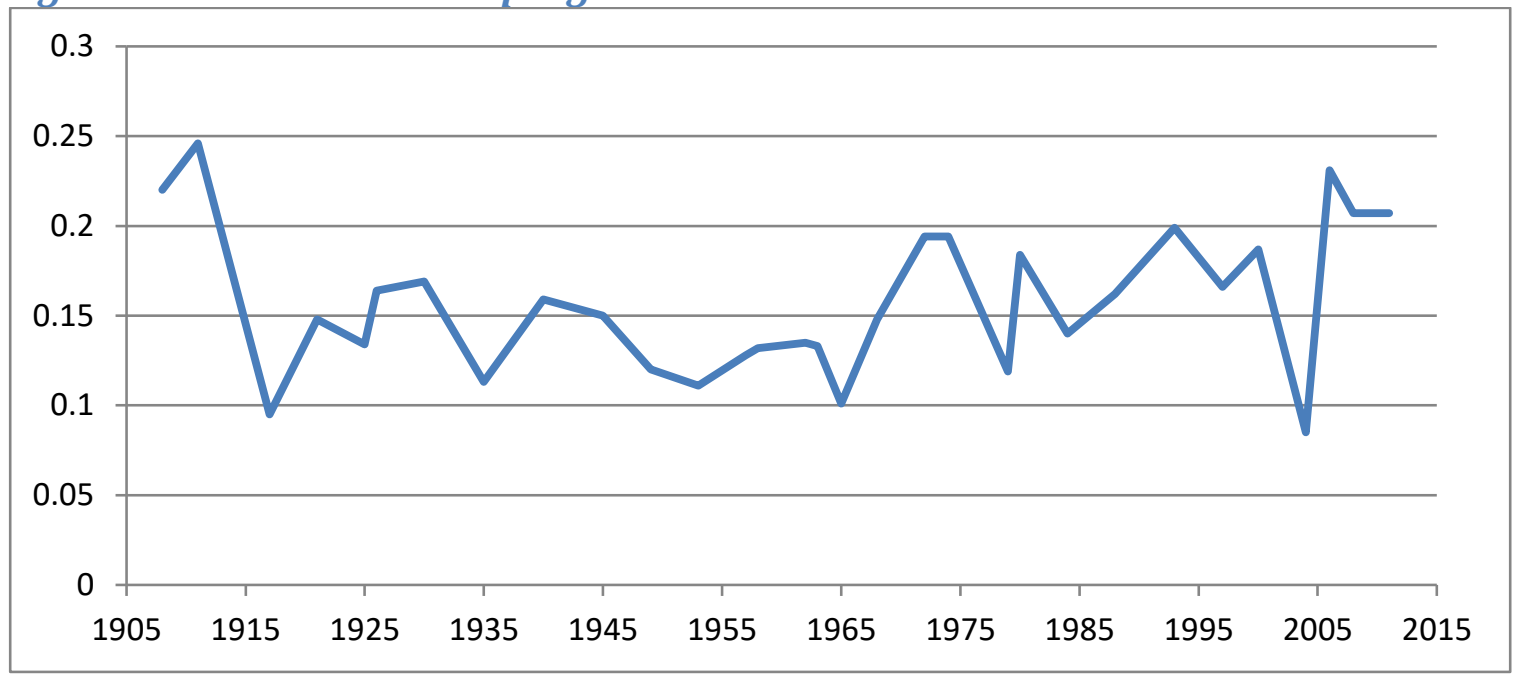

\section{Seats}

In the spirit of Ferris et al. (2016), I use the percentage of seats won by the governing party as an indicator of how competitive the previous election was. As the percentage of seats won by the governing party increases, ex-post, we say the more dominant the victory was and the relatively less influence the opposition was able to gather. Very large wins in terms of percentage seats won would then be indicative of a low competition environment. This is a narrow but intuitive interpretation of competition. This interpretation can exist in contrast to other interpretations; for example, competition could be viewed as the voters having many available alternatives, such as in the 1993 Canadian election, when two new major parties came to the electoral forefront (the Reform Party of Canada and the Bloc Quebecois). However, when many parties were available for voters to choose from, vote-splitting - among other factors - led the Liberal Party of Canada to a large majority. In this case, using the percentage seats suggests, ex-post, that the election was not competitive from the point of view of the Liberal party. 
Figure 3: Proportion of Seats Won by the Government

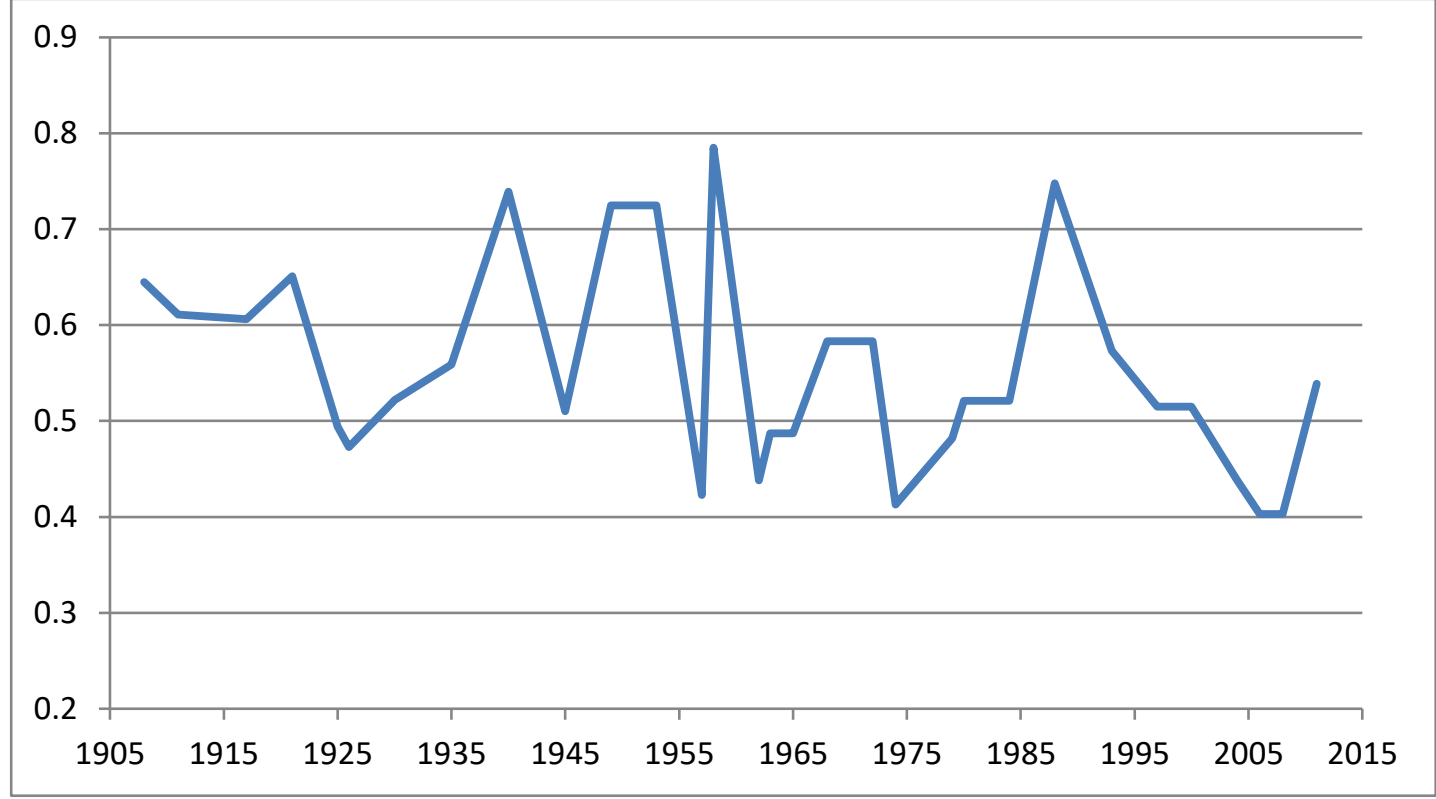

Figure 4: Proportion of Seats Won by Government and LPR over Time

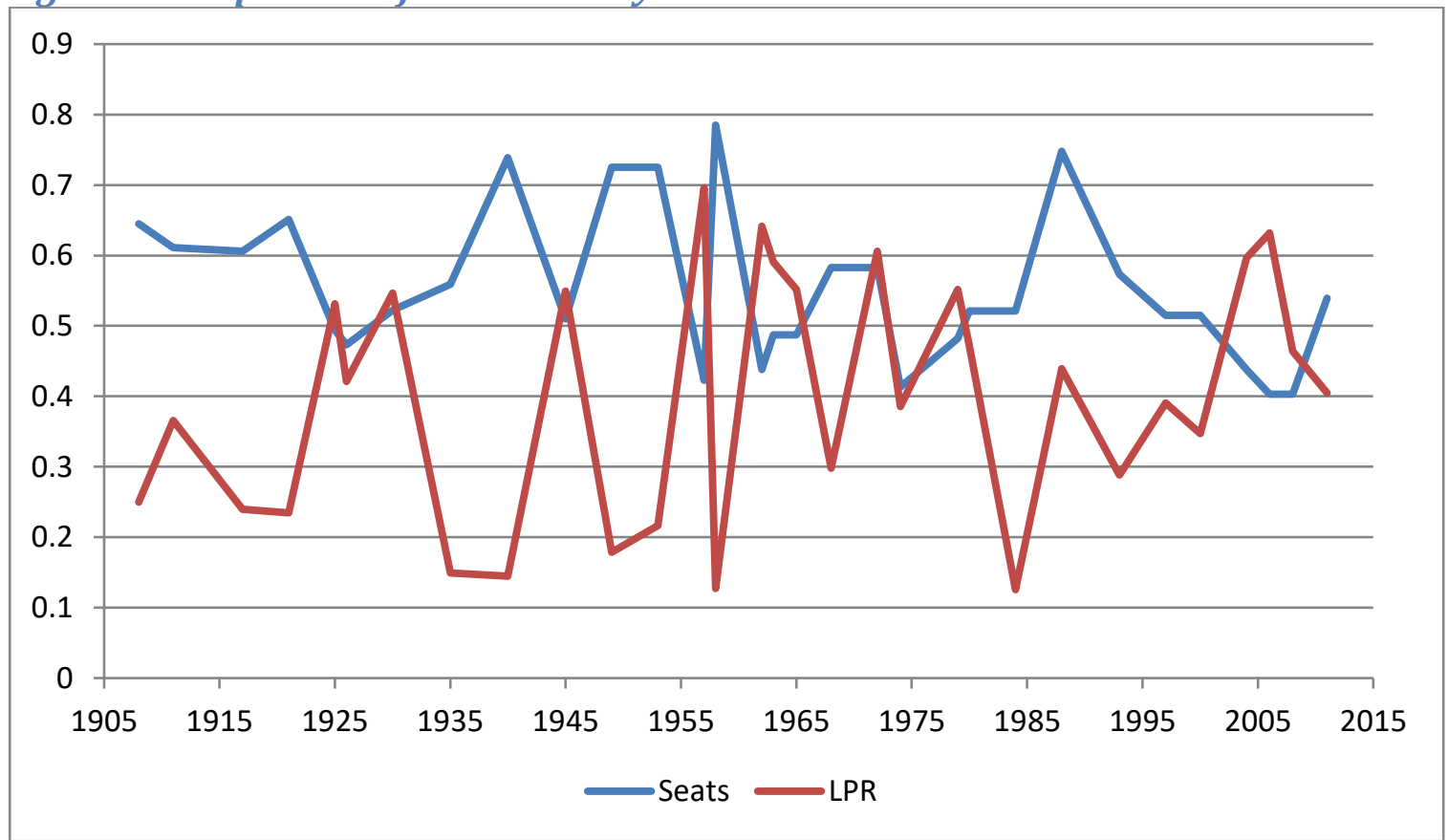

Figure 4 shows the seats won by the government and the loss probability ratio (LPR) over time and there is a clear negative relationship between the two. The correlation between the two variables as measured by Pearson's $R$ is -0.69 . The 
LPR, discussed shortly, is constructed from the seat-gap, which itself is influenced by the seats won by the government. The intuitive explanation is: the higher the amount of seats the government has, the less likely they are to lose the next election.

\section{Adjusted Marginal Seats (AMS)}

Hartle (1985) makes note that not all districts are equal. Some districts are more likely to vote in a partisan fashion, and some districts demonstrate more malleability in their preferences. Hartle calls districts that historically demonstrate changes in preferences 'marginal'.

Hartle goes on to say that a marginal constituency is a district that cannot be ignored by the incumbent, in the sense that economic rents cannot be taken from the district without a risk that the incumbent will lose the constituency. To deal with the difficulty in implementing this definition, alternatives have been put forward by Bodet (2014) to define a 'safe' seat. Bodet defines a safe seat as a seat that lies in the safe side of a tail on a distribution of historical vote margins. Ferris et al. (2016) calculate safe seats by obtaining the volatility adjusted vote margins from the previous 3 elections. The tails are constructed using 2 standard deviations. The relative proportion of safe seats can be calculated when the number of marginal seats in known. The proportion of marginal seats, defined on a party by party basis, is used as a measure of competition.

Ferris et al. define the historical volatility adjusted margin for incumbent party, $p$, in constituency, $j$, in election, $t$, as:

$$
\text { Vol. Adjusted Vote Margin }=\frac{\left(v_{1 p j t-1}-v_{2 j t-1}\right)}{\text { Volatility }_{t}}
$$

Using this measure, a distribution of constituencies is created by using the constituencies' volatility adjusted vote margin. The proportion of safe seats is $\psi_{t}$. Which leads to the proportion of marginal seats, $M S_{t}$, where 


$$
M S_{t}=1-\Psi_{t}
$$

Ferris et al. noted that the distribution of safe seats was not symmetrical and created an adjustment to correct for this. The motivation for this is thus; an election where only one party has the majority of the safe seats is not as competitive as an election that has a more equal distribution of safe seats.

The adjustment for asymmetry builds from Gaines and Taagepera's measure of 'D2', and defines the Euclidean deviation from a three party equal sharing of safe seats as:

$$
\phi 3_{t}=\sqrt{\frac{3}{2}} * \sqrt{\left(\frac{1}{3}-S_{p 1 t}\right)^{2}+\left(\frac{1}{3}-S_{p 2 t}\right)^{2}\left(\frac{1}{3}-S_{p 3 t}\right)^{2}}
$$

Where $S_{p k t}$ is the seat-shares in Parliament of the party in the $\mathrm{k}^{\text {th }}$ place in terms of seats. $\phi 3_{t}$ is equal to zero if the safe seats are symmetrically distributed, and equal to one if one party has all the safe seats.

Combining (10) and (11) creates the measure of asymmetrically adjusted marginal seats.

$$
A M S_{t}=1-\left\{\Psi_{t} \phi_{t}\right\}
$$




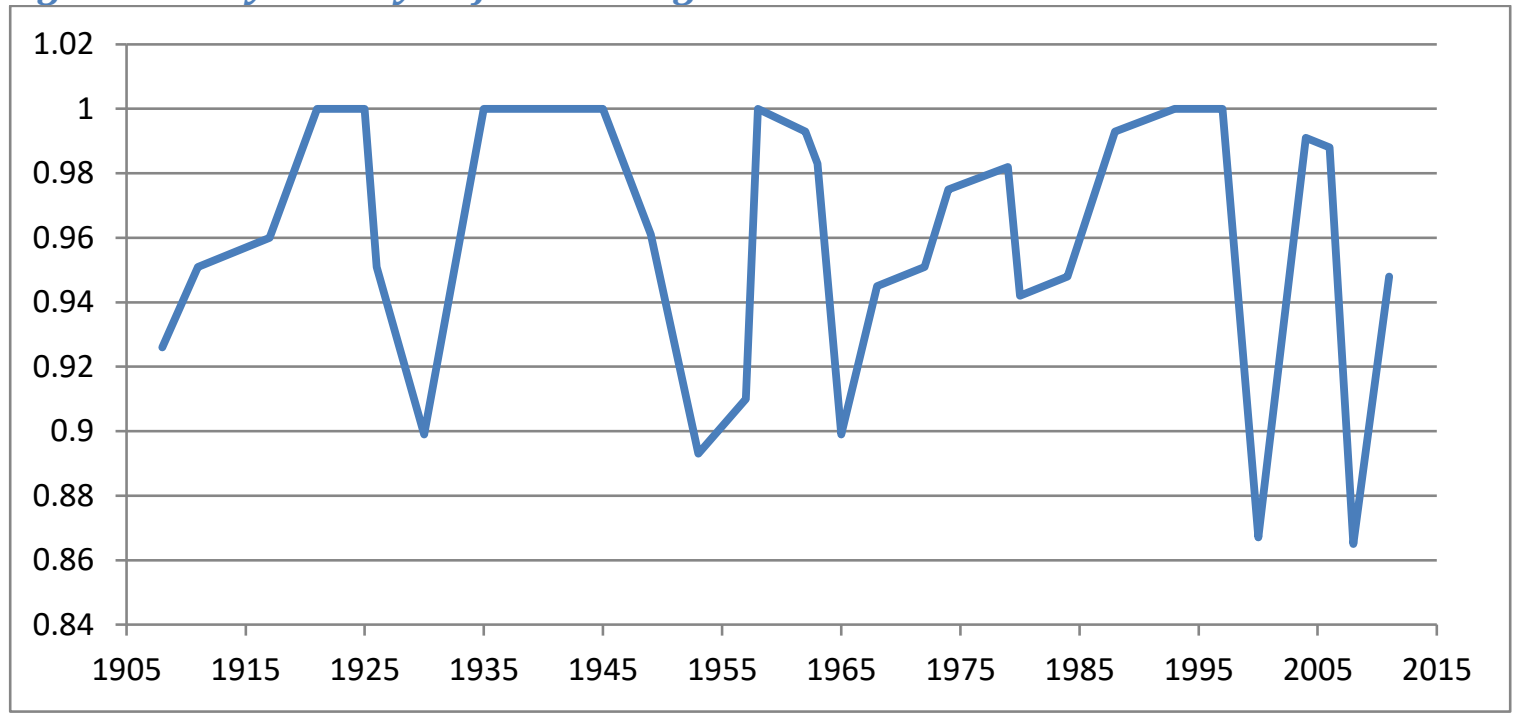

\section{The Splinter Index and the Probability of Loss}

As a final measure of competition, we look at my first chapter where I developed a measure of competition that uses the previous work of the work of Boyne (1998) and Kayser and Lindstadt (2015). The measures of competition developed in my first chapter and by Kayser \& Lindstadt are robust to the number of parties in the system - which is to say the measure can be applied for a system with any given number of parties running. The measures have a direct connection to the loss of power for the government, and they are congruent with the executive's perspective on their own political security.

The measure developed in my first chapter calculates the probability of the incumbent government losing the election, known as the "loss probability ratio ${ }^{31}$ ", by using a distribution of past election results and the current seat-gap between the incumbent and the second place party. The Kayser \& Linstadt method uses a function, $g(x)$, which is a kernel density estimator of all historical estimated seat swings. The probability of loss (LPR) is calculated such that

\footnotetext{
${ }^{31}$ This is simply the estimated probability that the incumbent will lose the next election. Hence, 1-'probability of loss' is the probability of winning.
} 


$$
L P R=\int_{-\infty}^{-d} g(x) d x
$$

Where $d$ is the seat share gap between the incumbent and the opposition.

The LPR developed in my first chapter builds on the Kayser \& Lindstadt method in two ways. Firstly, by modifying $g(x)$ such that it was not a function of all previous elections, but instead only a function of the most recent elections. The most recent elections range from 8 previous elections to 11 previous elections. Secondly, I substituted estimated seat swings for historical seat swings.

The LPR developed in my first chapter can be converted into an index that ranges from 0 to 1 . I proposed that an LPR of $0 \%$ - which describes a state where the government has no chance of loss - represents a political state which resembles a dictator, and hence there is no observable political competition. Likewise, an LPR of $100 \%$ represents a lame-duck government who has no chance of winning. A political state with an LPR of $100 \%$ is said to be uncompetitive since the incumbent has no incentive to compete. While lameduck politicians exist by law in some circumstances, such as an American president who has served two full terms ${ }^{32}$, in the Canadian context, a party and its leader - can be elected indefinitely, either consecutively or nonconsecutively. Hence, an LPR of $100 \%$ would imply that the political environment is such that there is no place for the incumbent party to compete ${ }^{33}$.

The competition index formula is,

$$
\text { Competion Index }=1-\left|\frac{0.5-L P R}{0.5}\right|
$$

\footnotetext{
${ }^{32}$ Since the $22^{\text {nd }}$ amendment to the American constitution was passed in 1951, no American president can be elected for more than 2 terms. It is possible for a president to take office via the line of succession, and then be elected for 2 terms.

${ }^{33}$ In Splinter's (2017) analysis of the Canadian context, an LPR of $100 \%$ never occurred -- which is congruent with the idea that the incumbent party always has at least some predicted chance of winning.
} 
As the reader can readily see, the competition index will provide a value of 0 when the LPR is either 1 or 0 - which are both low competition environments. A value of 1 for the index represents maximum competition, and a value of 0 represents no competition. Hence, competition increases as the index rises.

\section{Figure 6: LPR and Splinter Index over Time}

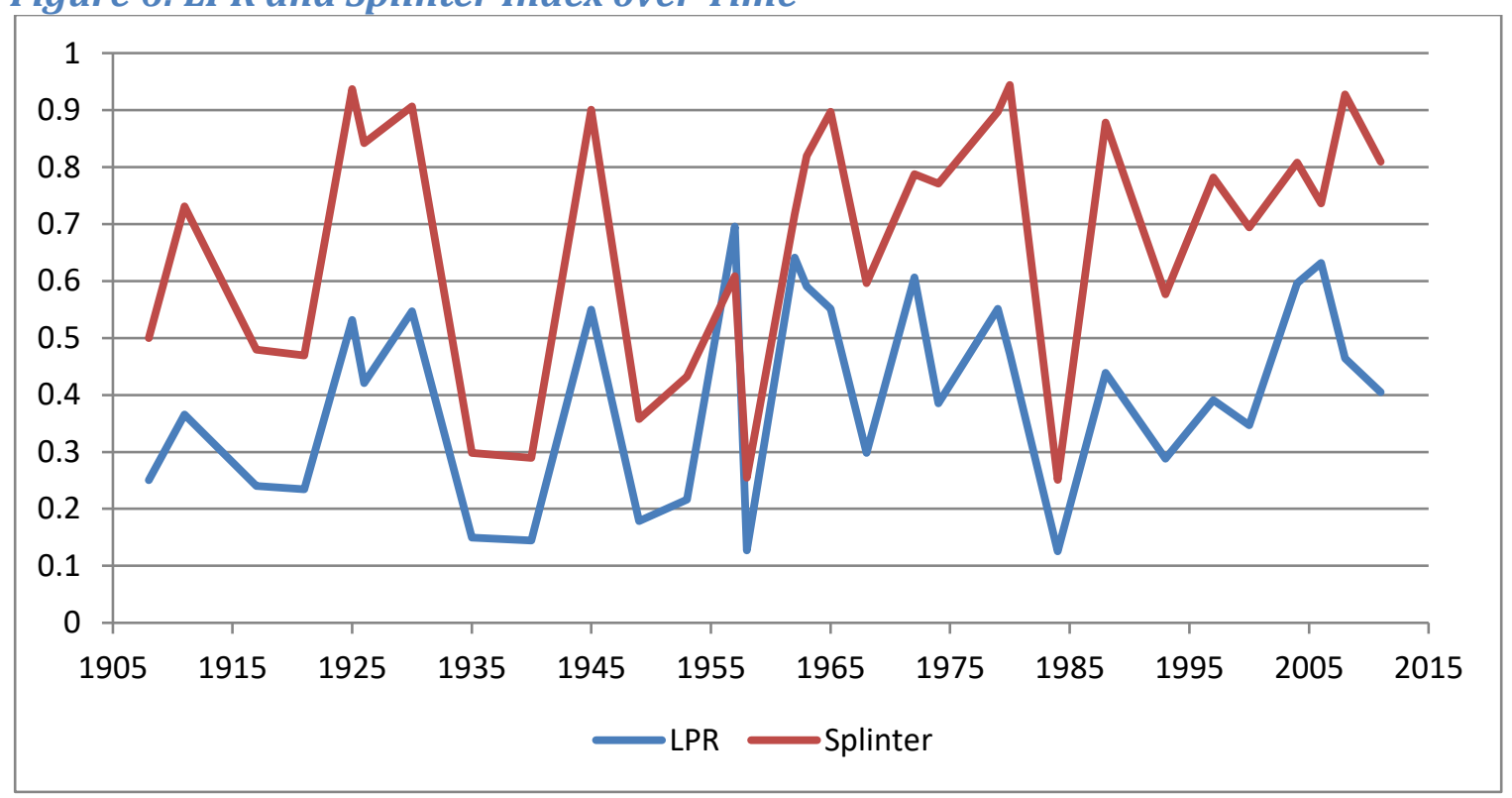

Figure 6 shows the loss probability ratio and the derived competition index over time. This graph readily shows the relationship between the Splinter competition index and the LPR. A wider variety of probabilities form the LPR would result in the measures being less closely correlated. The correlation between the LPR and the Splinter competition index, as measured by Pearson's R is 0.81 .

\subsection{Economic Variables}

When attempting to measure the relationship between the political sphere and the economic sphere, there is no shortage of economic variables available. My paper's motivation for selecting economic variables comes from the vast literature on the topic (Tufte 1978, Hibbs 1982, Norpoth 1996, Kneedbone 1999 
\& 2001, Lewis-Beck \& Stegmaier, 2000; Smith 2003, Ferris, Park \& Winer 2008, Ferris \& Voia 2009; Dewan \& Shepsle, 2011; Grofman, 2016; Przeworski, 2016).

Economic variables that are included in this paper as explanatory variables are the inflation rate, the unemployment rate, the growth rate of government spending, the growth rate of per capita GDP, and the change in tax size. These choices are elaborated upon below.

\section{Inflation and the Unemployment Rate}

The government calls an election using an 'optimal stopping rule' that was discussed in the previous section. In short, the government is trying to win an election and needs the voters to support them. Ultimately, it is the voters' opinion of the government that is paramount. Since the government cannot observe the voters' opinion directly, the government must make an educated guess.

The economic voter intimately observes inflation as measured by the $\mathrm{CPI}$ and it is the change in purchasing power that motivates a voter. The voter can also see the unemployment rate, both directly and superficially. Unemployment rates can be felt through first-hand experiences or witnessed through regularly published unemployment rate statistics. It is not hard to imagine that a first-hand experience with unemployment would sway the voter's opinions, and a voter who is aware of the unemployment rate only indirectly could still be swayed.

\section{Real Income}

Similar to the aforementioned variables, a voter directly observes their own income and can also witness general economic performance. Statistics on GDP are regularly published and reported on in Canada. Income is the most widely used predictor of how a voter feels about the government in the literature. I assume it is the growth rate of this variable that the voters are most interested in instead of the level. 


\section{Exponentially Weighted Growth}

In the spirit of Ferris \& Voia (2009), a variable that captures the dynamic attitude towards economic growth is included in the model. The idea is that different growth rates in different periods are not all equal. As each period passes, the impact of having unusually high income-growth increases. While voters may enjoy high growth in income in the first year of office for a government, it's very unlikely that the government would call an election in the first year using solely that as motivation. As each year passes, the government runs out of future opportunities to experience a high income-growth year that makes the government look favorable in the eyes of the voters. By including a variable for exponentially weighted growth, I can test if the hypothesis that the reservation growth rate in the model falls over time during a government's tenure.

\section{Change in Tax Size and Government Spending}

Voters are aware of how high taxes are, and tax levels can sway their opinion of the government. Lower tax levels may leave the electorate with a favorable opinion of the government and the inverse can also hold true. The expectation is that as taxes are lowered, the government becomes more likely to call an election. Government spending, in contrast to a variable like GDP per capita, would likely be witnessed more passively through an increase in transfers or new infrastructure projects. In both cases, I assume that voters are more interested in the change of these values, rather than in the level.

\section{Results}

An ideal model not only displays statistical significance and predictive power, but must also satisfy realistic criteria. Each variable must make some intuitive sense 
to be included and generated predictions must also be in-line with historical observations.

\section{Figure 7: The Empirical Hazard Function}

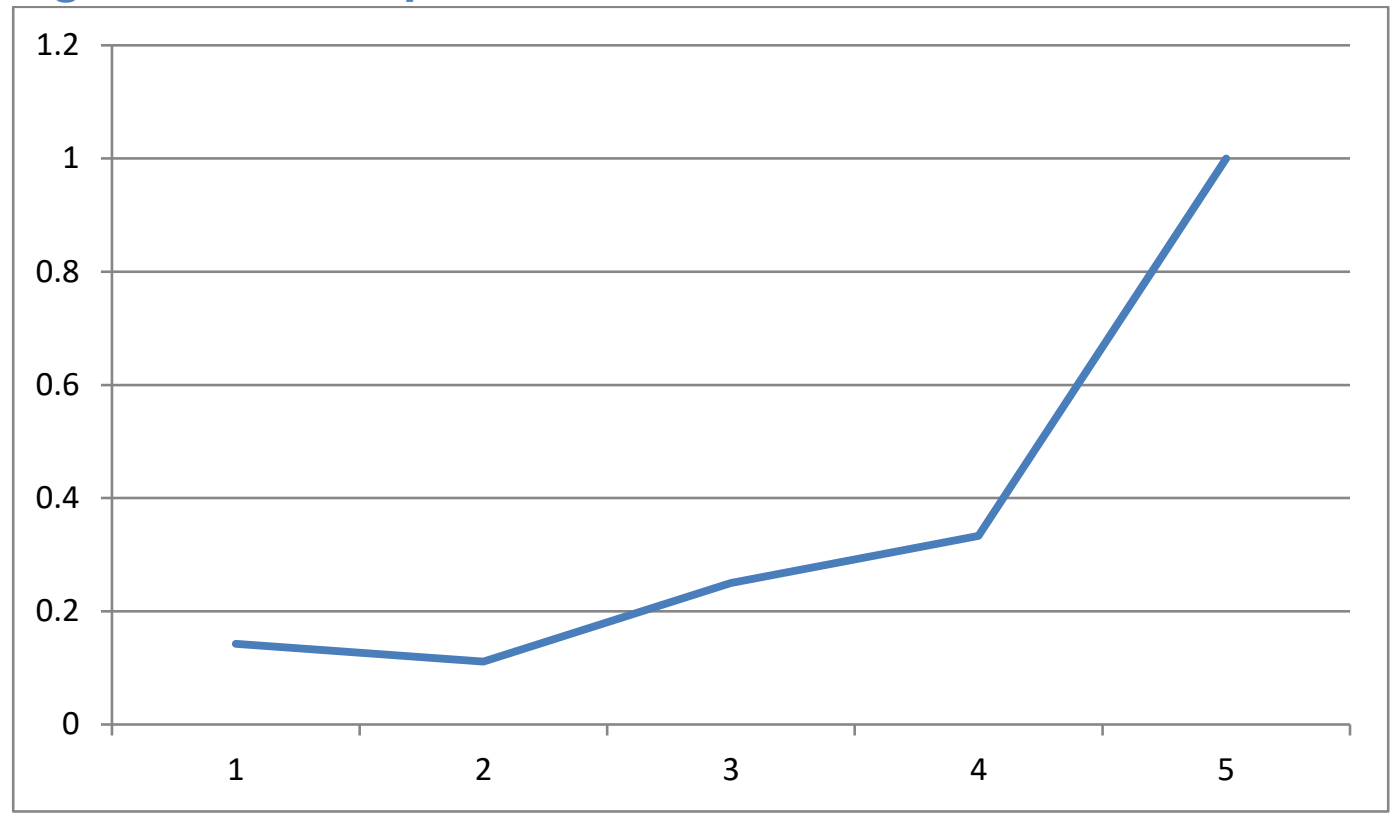

The Kaplan-Meier estimated hazard function provides a baseline to compare the estimated models. The Kaplan-Meier estimated hazard is a non-parametric estimator that shows the characteristics of the underlying data ${ }^{34}$. The KaplanMeier estimated survival is described by,

$$
\hat{S}(t)=\prod_{i: t_{i} \leq t}\left(1-\frac{d_{i}}{n_{i}}\right)
$$

with $t_{i}$ a time when at least one event happened, $d_{i}$, the number of events that happened at time $t_{i}$ and $n_{i}$ the individuals known to survive at time $t_{i}$.

\footnotetext{
${ }^{34}$ The Kaplan-Meier estimated survival function plot would be a series of declining horizontal steps, and with a large enough sample size, this would approach the true survival function for that population. In this paper, population data is available and fully used, and the hazard function derivation of the survival function can be plotted to show the actual frequency of earlyelection calls.
} 
In figure 7 we can see that a distinguishing feature of this estimated hazard function is that it first slightly decreases before increasing after year two. The hazard function shows a distinctive increase from the fourth to the fifth year, with a kink occurring in the fourth year.

The results from the Cox proportional hazard (Cox $\mathrm{PH})$ models, seen in table 1 below, have many revealing results. The first notable result is the large and consistent predictive power that the unemployment rate demonstrates. The unemployment rate offers more predictive power when combined with its lags, and often offers more explanatory power as more lags are included. What is noteworthy is that the pattern is not the same for each lag, implying some government timing of elections. The estimated coefficient for the previous year's unemployment rate is above a value of one, meaning that a one unit increase in the unemployment rate results in an increase in the likelihood an election will be called this year. The sign ${ }^{35}$ switches when looking at the second year lag, which has an estimated coefficient below 1 , which means this decreases the likelihood an election will be called this year. We can interpret this as an incumbent government, witnessing a high unemployment rate, will put off calling an election until the next year. The third year lag of the unemployment rate is not as statistically significant as the one year and two year lags, but does offer overall explanatory power and significance to the model. When dealing with elections, we must remember that a third year lag will frequently be an economic event that happened during the previous parliament instead of the current parliament.

The inflation rate behaves mostly as expected. The inflation rate is only significant some of the time for the Cox $\mathrm{PH}$ models. A higher inflation rate results in a lower likelihood that an election will be called.

\footnotetext{
${ }^{35}$ The 'sign' of a coefficient when it is the form $\exp (\beta)$ refers whether it is above or below 1 . Above 1 is positive and below 1 is negative. When $\exp (\beta)$ is equal to 1 , this means $\beta$ is equal to zero.
} 
Table 1: Cox PH Results, $\exp \beta$ estimates (Robust Huber/White $\mathrm{z}$ values in brackets below estimates)

\begin{tabular}{|c|c|c|c|c|c|c|c|c|c|}
\hline $\begin{array}{c}\text { Variable } \\
\text { Type } \\
\end{array}$ & Covariates & Model 1 & Model 2 & Model 3 & Model 4 & Model 5 & Model 6 & Model 7 & Model 8 \\
\hline \multirow[t]{13}{*}{ Economic } & UR & $\begin{array}{l}0.11^{* *} \\
(-2.47)\end{array}$ & $\begin{array}{l}0.14^{* *} \\
(-2.36)\end{array}$ & $\begin{array}{c}0.25 \\
(-1.07)\end{array}$ & & & & & \\
\hline & UR (1) & $\begin{array}{c}1.62^{* * *} \\
(2.72)\end{array}$ & $\begin{array}{c}1.19 * * \\
(2.29)\end{array}$ & $\begin{array}{l}1.54^{* *} \\
(2.49)\end{array}$ & $\begin{array}{l}1.32 * * \\
(2.57)\end{array}$ & $\begin{array}{c}1.32^{* * *} \\
(2.78)\end{array}$ & $\begin{array}{c}1.29 * * * \\
(2.78)\end{array}$ & $\begin{array}{c}1.27^{* *} \\
(2.36)\end{array}$ & $\begin{array}{l}1.39 * * \\
(2.55)\end{array}$ \\
\hline & UR (2) & $\begin{array}{l}0.06 * * \\
(-2.53)\end{array}$ & & $\begin{array}{l}0.06 * * \\
(-2.27)\end{array}$ & $\begin{array}{c}0.03 * * * \\
(-2.64)\end{array}$ & $\begin{array}{c}0.05 * * * \\
(-2.77)\end{array}$ & $\begin{array}{c}0.08^{* * *} \\
(-2.82)\end{array}$ & $\begin{array}{c}0.1 * * \\
(-2.45)\end{array}$ & $\begin{array}{l}0.02 * * \\
(-2.57)\end{array}$ \\
\hline & UR (3) & & & & $\begin{array}{l}1.9 * * \\
(1.99)\end{array}$ & $\begin{array}{c}1.42 \\
(1.21)\end{array}$ & & & $\begin{array}{c}1.69 \\
(1.64)\end{array}$ \\
\hline & Inflation(1) & & $\begin{array}{c}0.79 \\
(-1.31)\end{array}$ & $\begin{array}{c}0.45^{*} \\
(-1.87)\end{array}$ & $\begin{array}{c}0.73^{*} \\
(-1.88)\end{array}$ & $\begin{array}{c}0.84 \\
(-1.2)\end{array}$ & $\begin{array}{c}0.88 \\
(-0.75)\end{array}$ & $\begin{array}{l}0.73^{*} \\
(-1.9)\end{array}$ & $\begin{array}{l}0.61^{* *} \\
(-2.39)\end{array}$ \\
\hline & Inflation(2) & $\begin{array}{c}0.74^{* *} \\
(-2.2)\end{array}$ & $\begin{array}{c}0.93 \\
(-0.31)\end{array}$ & $\begin{array}{c}1.23 \\
(0.64)\end{array}$ & & & & & \\
\hline & G & & & $\begin{array}{l}1.12^{* *} \\
(2.00)\end{array}$ & $\begin{array}{c}1.07 \\
(1.45)\end{array}$ & $\begin{array}{c}0.97 \\
(-0.61)\end{array}$ & & & $\begin{array}{c}1.12 * * \\
(2.06)\end{array}$ \\
\hline & $\mathrm{G}(1)$ & & $\begin{array}{c}1.09 \\
(1.22)\end{array}$ & & & & & & \\
\hline & Real GDP pc & $\begin{array}{l}0.51^{* *} \\
(-2.25)\end{array}$ & $\begin{array}{c}0.56^{*} \\
(-1.84)\end{array}$ & $\begin{array}{c}0.58 \\
(-1.54)\end{array}$ & & & & & \\
\hline & Real GDP pc (1) & $\begin{array}{c}1.36 \\
(1.25)\end{array}$ & $\begin{array}{c}0.79 \\
(-1.11)\end{array}$ & $\begin{array}{l}1.93^{*} \\
(1.69)\end{array}$ & $\begin{array}{l}1.91^{* *} \\
(2.16)\end{array}$ & $\begin{array}{c}1.6 * \\
(1.81)\end{array}$ & $\begin{array}{c}1.74^{* *} \\
(2.12)\end{array}$ & $\begin{array}{l}1.86^{*} \\
(1.93)\end{array}$ & $\begin{array}{l}2.3^{* *} \\
(2.41)\end{array}$ \\
\hline & Real GDP pc (2) & $\begin{array}{l}1.31^{*} \\
(1.93)\end{array}$ & $\begin{array}{c}1.18 \\
(1.08)\end{array}$ & $\begin{array}{l}1.53^{* *} \\
(1.98)\end{array}$ & & & & & \\
\hline & Exp. Weight. Gr. & & & & & & & $\begin{array}{c}1.00 \\
(-0.48)\end{array}$ & \\
\hline & D Ln Tax Size & & & & & & $\begin{array}{c}0.00 \\
(-1.64)\end{array}$ & & \\
\hline \multirow[t]{2}{*}{ Incumbent } & Consecutive & & $\begin{array}{l}0.6601 \\
(-1.28)\end{array}$ & $\begin{array}{c}0.55^{*} \\
(-1.69)\end{array}$ & $\begin{array}{l}0.52^{* *} \\
(-2.13)\end{array}$ & $\begin{array}{c}0.93 \\
(-0.25)\end{array}$ & $\begin{array}{c}1.06 \\
(0.23)\end{array}$ & $\begin{array}{c}0.91 \\
(-0.38)\end{array}$ & $\begin{array}{l}0.47^{* *} \\
(-2.31)\end{array}$ \\
\hline & Liberal & & $\begin{array}{c}2.81 \\
(1.36)\end{array}$ & $\begin{array}{c}0.51 \\
(-0.67)\end{array}$ & $\begin{array}{c}0.43 \\
(-1.3)\end{array}$ & $\begin{array}{c}1.59 \\
(0.66)\end{array}$ & & & $\begin{array}{c}0.27^{*} \\
(-1.79)\end{array}$ \\
\hline \multirow[t]{6}{*}{ Competition } & LPR & & & & & $\begin{array}{c}1.19 * * \\
(2.57)\end{array}$ & $\begin{array}{c}1.15^{* * *} \\
(3.53)\end{array}$ & $\begin{array}{c}1.12^{* * *} \\
(3.14)\end{array}$ & \\
\hline & Comp. Index 1 & & $\begin{array}{c}1.01 \\
(0.58)\end{array}$ & $\begin{array}{c}0.94 \\
(-1.47)\end{array}$ & & & & & $\begin{array}{c}0.93 * * * \\
(-2.84)\end{array}$ \\
\hline & Comp. Index 2 & & & & $\begin{array}{c}0.95 * * * \\
(-3.16)\end{array}$ & & & & \\
\hline & $\mathrm{HHI}$ & & & & & $\begin{array}{c}1.13 \\
(1.21) \\
\end{array}$ & & & \\
\hline & $\mathrm{R}^{2}$ & 0.441 & 0.406 & 0.611 & 0.556 & 0.643 & 0.692 & 0.673 & 0.499 \\
\hline & Log-Likelihood & -42.89 & -47.1 & -39.24 & -40.58 & -38.4 & -33.72 & -31.68 & -41.79 \\
\hline
\end{tabular}

${ }^{* * *}\left({ }^{* *}\right)\left[{ }^{*}\right]$ significant at $1(5)$ and [10] percent

\begin{tabular}{|c|c|c|c|}
\hline Covariate & Explanation & Covariate & Explanation \\
\hline UR & Unemployment Rate & LPR & Loss Probability Ratio \\
\hline G & Growth rate of Government Spending & Comp. Index 1 & Index Derived from Loss Probability, Historical \\
\hline Real GDP pc & Growth Rate of Real GDP Per Capita & Comp. Index 2 & Index Derived from Loss Probability, Kayser-Lindstadt \\
\hline
\end{tabular}


Changes in government spending are not usually statistically significant, and when they are, the changes in government spending show that as the growth rate of government spending increases, there is a higher likelihood of an election being called. This is in-line with our reasoning that the government is timing the election to maximize their chances of winning the election.

The one year lag of the change in real income was shown to have more explanatory power than the current year value and, curiously, the variable and its lag show opposite signs. While it's intuitive that higher incomes would induce a government to call an election, the below 1 values seen in models 1,2 , and 3 do not have reasonable explanations. In general, the observed pattern is that higher real incomes result in the government being more likely to call an election.

The 'consecutive' variable, while only occasionally significant, was always estimated with the expected sign. A value below one is in-line with the hypothesized relationship that political capital expires over time. Governments, aware that their capital has been diminished, are less likely to call an election if they have already won a previous election or two. In other words, a government is more likely to call an election early if they have not immediately previously held government.

The 'Liberal' variable - equal to 1 if the Liberal Party of Canada is the government and 0 if not - was rarely significant and was not consistent in sign or magnitude. The variable was included in the regressions since it offered explanatory power to the overall model and meaningfully increased the loglikelihood value.

The measures of competition taken from my first chapter were shown to be consistently significant and in-line with their hypothesized values. It is noteworthy that the 'loss probability ratios (LPR)' behave in the opposite direction of the competition indexes that were calculated from the LPRs.

The results show that as competition decreases, the government is less likely to call an election. The intuition here is difficult - hence the superior explanatory 
power of the $L P R$ - because two very different scenarios characterize low competition. The 'dictator' and the 'lame-duck' are the aforementioned situations that occur at the extrema of the index. A government that is very confident that they will win the election because they have no opposition will readily call an election to extend their term another 5 years. However, a lame-duck government, seeing no chance of victory will hold off an election to collect the rent from their current governing tenure.

The results from the Cox PH show that the LPR behaves in a more straightforward manner. As the probability of a loss increases, the government is more likely to call an election early. The LPR is not calculated annually, but is calculated for each parliament; hence the LPR remains static during a government. An intuitive approach would suggest that as the probability of a loss increases, the government is more likely to hold off on an election. This idea would be cogent if the LPR was dynamically calculated during the government's tenure. Since the LPR is static, the government has no better odds of winning the election - as measured by the LPR - if they call an election later. Hence, the conclusion that I draw is that governments that are more likely to lose the next election are the same governments that are more likely to engage in strategic election timing to best maximize their chances of winning. Explained simply in an example, a true dictator, with an LPR of 0 , has no incentive to do any election timing and will simply serve out their term until the next election - which the dictator is guaranteed to win.

The modified version of the Herfindahl-Hirschman index $(\mathrm{HHI})$ that I proposed, using $\mathrm{N}-1$ parties, instead of $\mathrm{N}$ parties to calculate the $\mathrm{HHI}$ was never shown to be significant or add value to a model. The modified $\mathrm{HHI}$ used in the literature (Ferris \& Voia, 2009) had some explanatory power, but was less valuable than the other aforementioned measures of competition.

The Przeworski and Sprague index, the ENP, the AMS, and the percentage of seats the government has showed little explanatory power when used individually. To test for interactions between the measures, they were all 
combined in one model while removing the LPR to see if this would have any effect. In table 2, on the left hand side, it is a variant of model 5 but with all the measures of competition added. The right hand side shows a variant of model 5 with the LPR removed but all the other measures of competition added. The LPR dominates the statistical significance of the other measures of competition in model $5 \mathrm{~A}$, and we see no statistical significance of the measures of competition. In model 5B with the LPR removed, the ENP and the PS index are statistically significant, but the interpretation of the coefficients is difficult. The estimated coefficient values are so small that the effect has little interpretable meaning. 
Table 2: Results from Combining Measures of Competition

\begin{tabular}{|lrrr|}
\hline \multicolumn{4}{|c|}{ Model 5A } \\
& LPR Included & \\
\hline & Coefficient & P-Value & Indicator \\
Liberal & 0.445600 & 0.55 & \\
Consecutive & 1.204000 & 0.58 & \\
Seats & $\mathbf{0 . 9 2 9 7 0 0}$ & $\mathbf{0 . 1 0}$ & \\
ENP & $\mathbf{0 . 0 0 0 0 0 1}$ & $\mathbf{0 . 1 4}$ & \\
AMS & $\mathbf{0 . 0 0 0 0 0 2}$ & $\mathbf{0 . 1 9}$ & \\
PS & $\mathbf{0 . 0 0 0 0 0 0}$ & $\mathbf{0 . 2 7}$ & \\
G & 1.021000 & 0.81 & \\
Inflation (1) & 0.560600 & 0.03 & $* *$ \\
Real GDP pc (1) & 1.352000 & 0.29 & \\
UR (1) & 1.477000 & 0.01 & $* * *$ \\
UR (2) & 0.016960 & 0.01 & $* *$ \\
UR (3) & 2.617000 & 0.06 & $*$ \\
HHI & 0.960800 & 0.88 & \\
LPR & 1.233000 & 0.04 & $* *$ \\
& & & \\
\hline Log-Likelihood & -34.234 & & \\
Pseudo R-Squared & 0.765 & & \\
\hline
\end{tabular}

\begin{tabular}{|lrrc|}
\hline \multicolumn{5}{|c|}{ Model 5B } \\
& Alternative Measures of Competition & \\
\hline & Coefficient & P-Value & Indicator \\
Liberal & 0.098720 & 0.03 & $* *$ \\
Consecutive & 0.848600 & 0.57 & \\
Seats & $\mathbf{0 . 9 6 5 0 0 0}$ & $\mathbf{0 . 3 5}$ & \\
ENP & $\mathbf{0 . 0 0 0 0 0 0}$ & $\mathbf{0 . 0 5}$ & $* *$ \\
AMS & $\mathbf{0 . 2 4 8 6 0 0}$ & $\mathbf{0 . 8 5}$ & \\
PS & $\mathbf{0 . 0 0 0 0 0 0}$ & $\mathbf{0 . 0 2}$ & $* *$ \\
G & 1.124000 & 0.10 & $*$ \\
Inflation (1) & 0.545100 & 0.01 & $* *$ \\
Real GDP pc (1) & 1.364000 & 0.26 & \\
UR (1) & 1.225000 & 0.04 & $* *$ \\
UR (2) & 0.174700 & 0.08 & $*$ \\
UR (3) & 1.349000 & 0.41 & \\
HHI & 0.652600 & 0.01 & $* *$ \\
& & & \\
& & & \\
\hline Log-Likelihood & -36.358 & & \\
Pseudo R-Squared & 0.709 \\
\hline
\end{tabular}

$* * *(* *)[*]$ significant at $1(5)$ and $[10]$ percent 
Figure 8: Estimated Hazard Functions of Model 5A and 5B

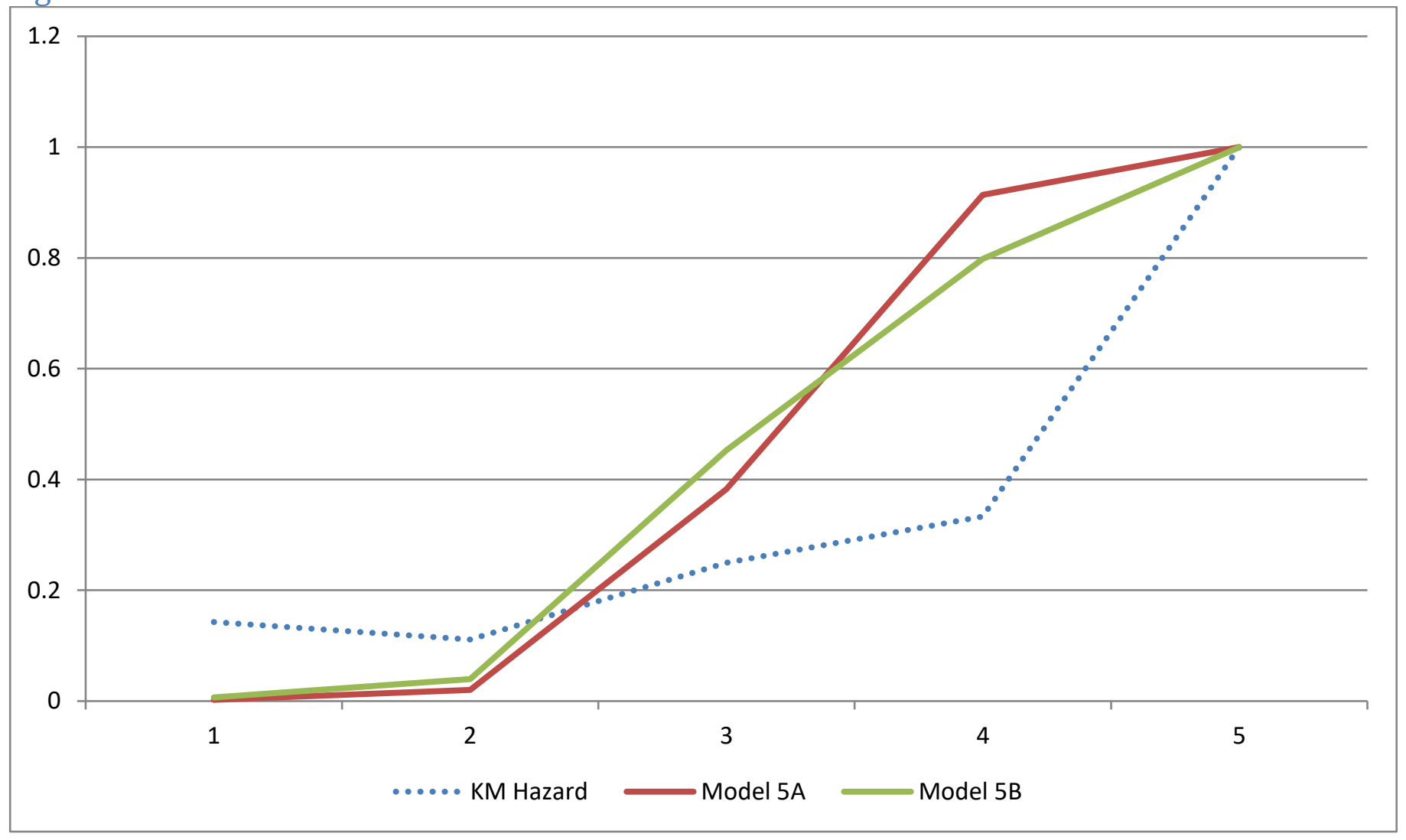


Figure 9: Estimated Hazard Functions

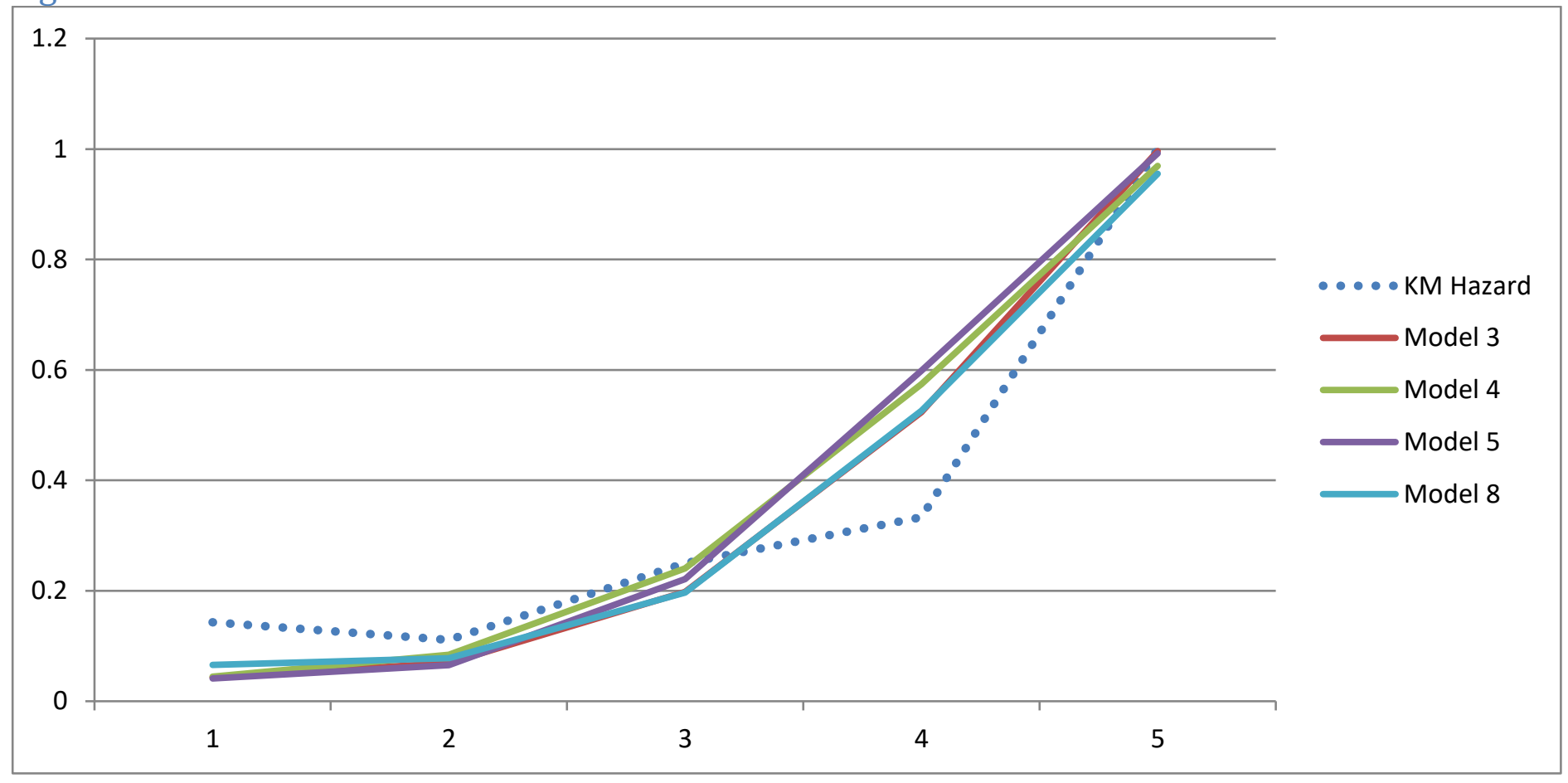


Figure 8 shows the estimated hazard functions for models $5 \mathrm{~A}$ and $5 \mathrm{~B}$. These models are represented by a predicted hazard function that was calculated using the mean value of the variables. The models do not correspond well to the Kaplan-Meier hazard function. Models $5 \mathrm{~A}$ and $5 \mathrm{~B}$ both overestimate and underestimate the hazard rate, while they are also lacking the distinctive features seen in the Kaplan-Meier hazard function. This is likely due to the coefficient values of the competition measures being extreme.

Figure 9 presents the estimated hazard functions for models 3, 4, 5, and model 8. The estimates are all very similar to each other and follow the Kaplan-Meier hazard function fairly closely. The hazard functions in figure 9 miss two distinctive features seen in the non-parametric estimator; they lack a noticeable kink when moving from year three to year four, and they do not decrease from year one to year two. The strength of the models - as measured by their pseudo R-Squared values and log likelihoods - varies, but is generally high compared to some of the other models.

All of the models featured in figure 9 were constructed using a similar pattern for the unemployment rate and included similar variables. Each of the models had statistically significant measures of competition included. 


\section{Figure 10: Estimated Hazard Functions}

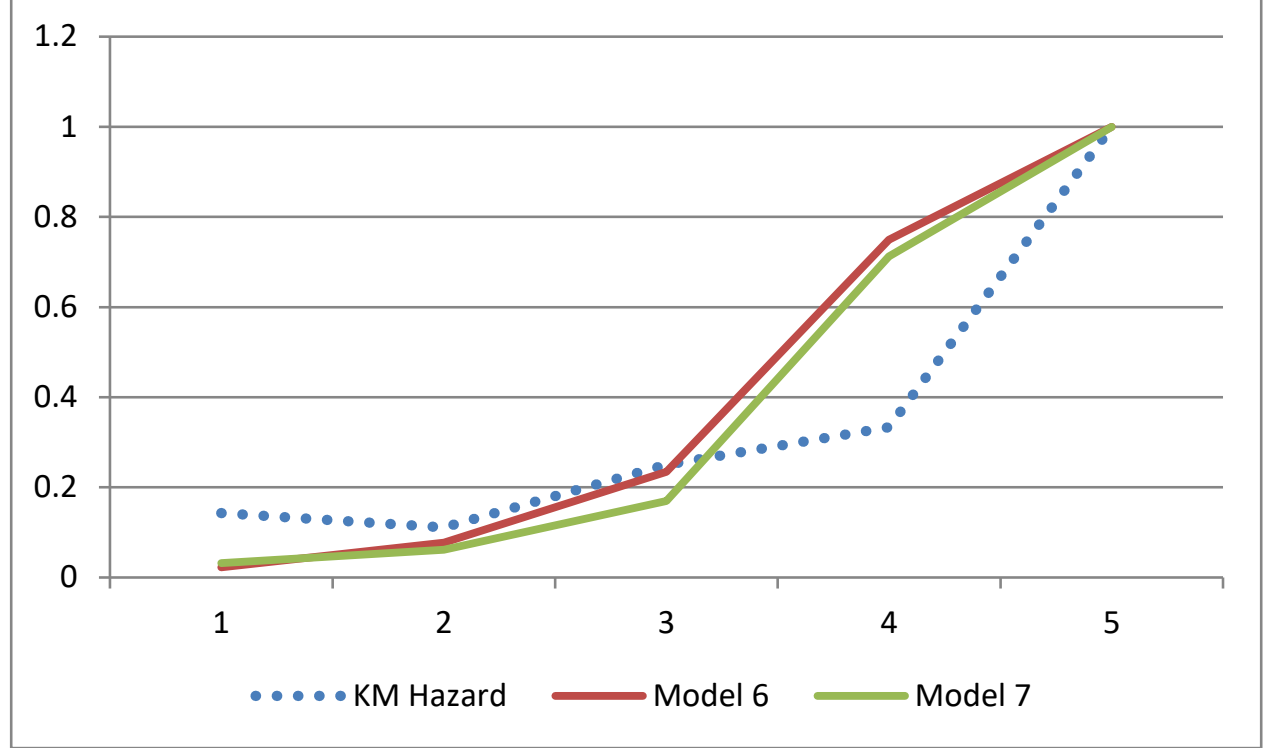

Figure 10 presents the predicted hazard functions from models 6 and 7 . Models 6 and 7 had the highest pseudo R-Squared values and two of the three highest log-likelihood values. These models distinguished themselves by not having the third year lag of the unemployment rate and including the Ferris \& Voia (2009) proposed variables: exponentially weighted growth rate of real income and the change in the tax size.

While the models have higher explanatory power, they seem to fit the data more poorly compared to the other models. The distinctive kink in year four that exists in the Kaplan-Meier hazard function around year 4 is inverted in these models. The kink for models 6 and 7 exists between years 2 and 3 , instead of between years 3 and 4 . As a result of this, these models would over-predict the hazard rate in year 4 by an average of nearly $40 \%$. 


\section{Figure 11: Estimated Hazard Functions}

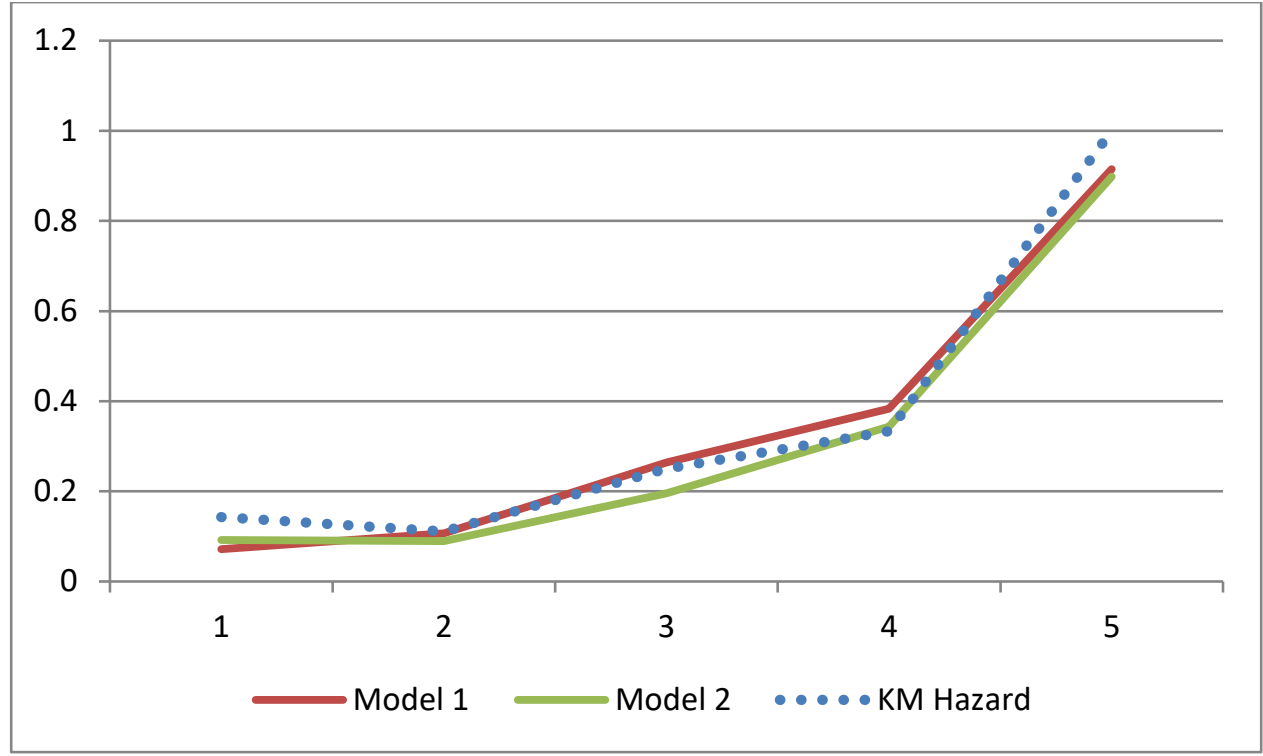

Figure 11 presents the estimated predicted hazard functions for models 1 and 2 . Models 1 and 2 follow the Kaplan Meier hazard function closely. Model 2 is the only model to show a decrease from year 1 to year 2 . These models match the kink seen in year 4 to a high degree.

Models 1 and 2 are distinguished from the other models in a couple of ways. Neither model has a statistically significant measure for competition. Both models have noticeably lower predictive power, as measured by the pseudo R-Squared, and both of these models have a log-likelihood that is below the others. Models 1 and 2 also include real per capita income in the current year. It's possible that the lower predictive power of the models means they simply approach their baseline model, resembling more closely the Kaplan-Meier hazard function for this reason.

\section{Explanatory Power of Variables: Log-likelihood decomposition}

Looking at table 3 below, we can see that the unemployment rate adds the most to model 7 in terms of the explanatory power as measured by its contribution to the log-likelihood value. The LPR also contributes significantly. The combined explanatory power of the other variables - consecutive, real GDP per capita, and exponentially weighted growth - is noticeable. The contribution value of inflation is less in magnitude. 
Table 3: Log-likelihood decomposition of Model 7

Log Likelihood

\begin{tabular}{lc}
\hline No Explanatory Variables & -52.58 \\
\hline Consecutive, Real GDP pc, Exp. Weighted Growth & -45.07 \\
\hline Added Inflation & -43.45 \\
\hline Added LPR & -39.38 \\
\hline Full Model (Added UR variables) & -31.68 \\
\hline
\end{tabular}




\section{Principal Component Analysis Duration Analysis}

Figure 12: Scree Plot of Eigenvalues

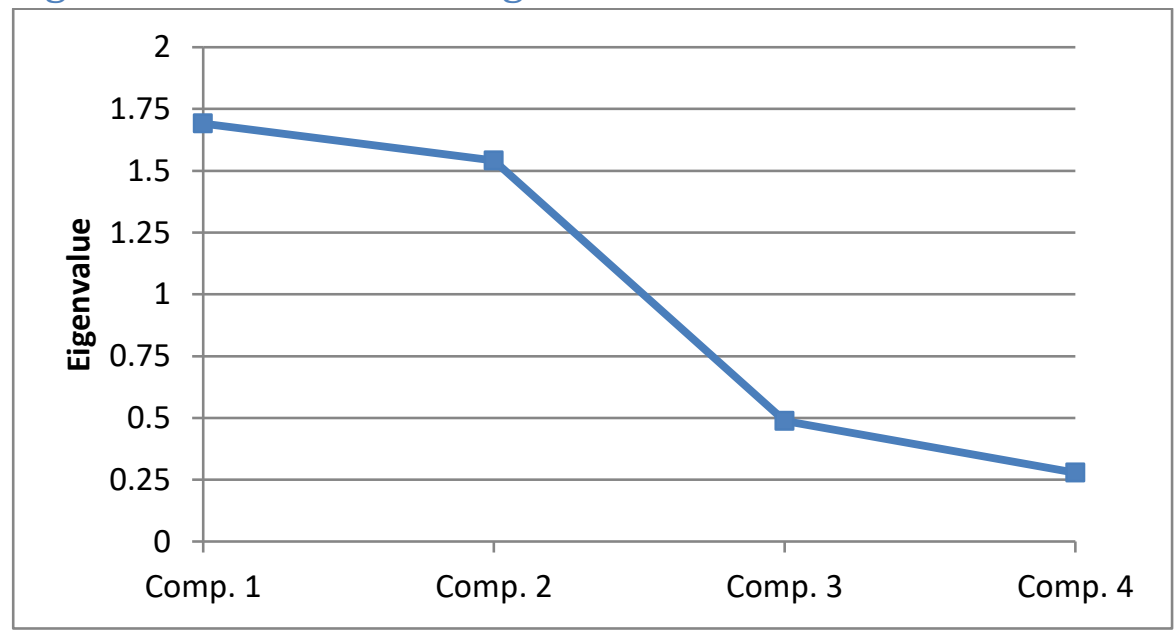

Figure 13: Percentage of Variance Explained

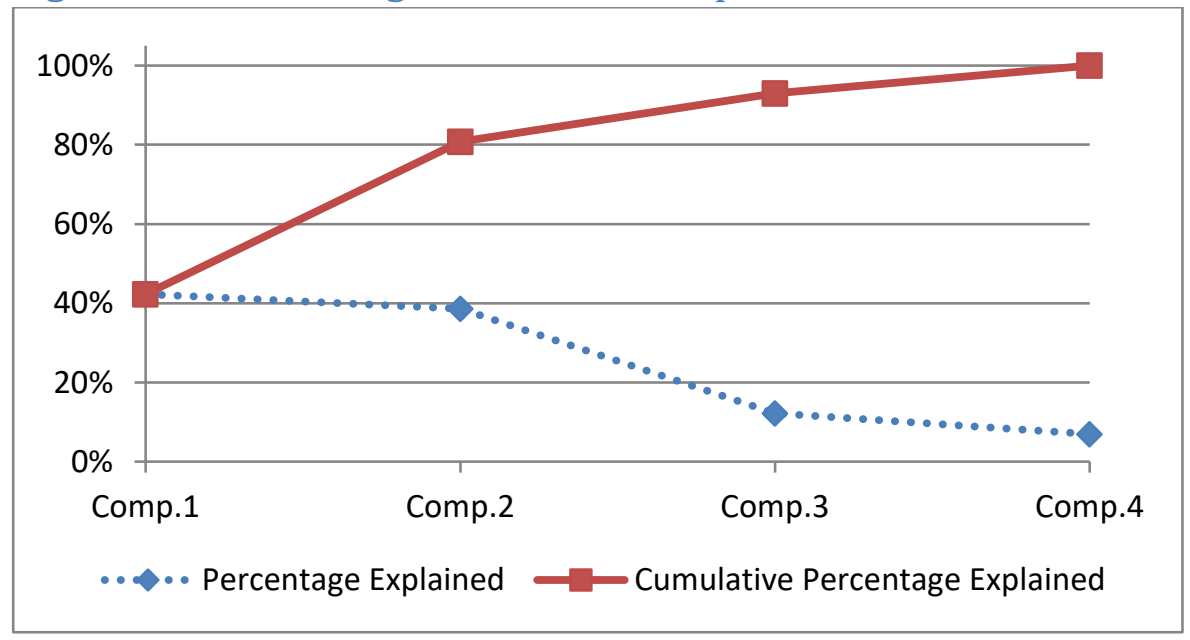

The constructed variables, known as the 'economic outlook' variables, are developed from the economic variables in the model: the growth rate of income, inflation, change in government spending, and the unemployment rate. As the reader can see, over $80 \%$ of the variation found in the economic variables can be explained by only 2 'economic outlook' variables. The intuition behind these constructed variables is that they are from the point-of-view of the voting citizen. The voting citizen will take into account each variable when making their decision 
of who to vote for, and the amalgamation of these variables creates an 'economic outlook' proxy variable. It is this sentiment, not the actual observed variables that can drive a voters' decision and, in turn, decide which party is elected. 
Table 4: Cox PH Results of PCA Models, $\exp \beta$ estimates (Robust Huber/White z values in brackets below estimates)

\begin{tabular}{cccc}
\hline \hline Variable Type & Variable & PCA Model 1 & PCA Model 2 \\
\hline Incumbent & Liberal & 1.09 & 1.09 \\
& & $(0.173)$ & $(0.181)$ \\
Competition & Consecutive & 0.98 & 0.99 \\
Economic PC & Splinter & $(-0.113)$ & $(-0.032)$ \\
& & 0.28 & 0.31 \\
& PCA1 & $(-0.775)$ & $(-1.053)$ \\
& & 1.00 & 1.00 \\
& PCA2 & $(0.301)$ & $(0.086)$ \\
& & 1.00 & 1.00 \\
& PCA1(1) & $(-0.959)$ & $(-1.033)$ \\
& & 1.00 & \\
& PCA2(1) & $(-0.323)$ & \\
\hline & 1.00 & \\
\hline & Pseudo R & $(0.224)$ & \\
\hline & & 0.105 & 0.121 \\
\hline$\left.* * * * *{ }^{*}\right]$ significant at 1 (5) and [10] percent & -47.59 & -51.23 \\
\hline
\end{tabular}

In table 4 we see selected results from the principal component analysis Cox $\mathrm{PH}$ regressions. The principal components were introduced in an attempt to turn the four economic variables into 1 or 2 components, known as 'economic outlook' variables. While we saw that the economic outlook variables captured over $80 \%$ of the variation observed, they lack the fundamentals that existed within each of the individual variables. The components were not statistically significant, and the models performed poorly. The first model included the two components and no lags of those components. In PCA model 1 there were no observed statistically significant variables and the pseudo R-Squared was lower than the previously seen models. The previous models without PCA made extensive use of lags, but adding the lags in the PCA model did not help increase any explanatory power of the model. Other combinations with the principal components were used but none offered much explanatory power. Furthermore, one of the motivations for using the principal components was to reduce the number of variables used and 
increase the degrees of freedom. Using two or three lags of each would hinder the degrees of freedom and defeat the purpose of introducing PCA.

\section{Robustness}

As seen in figures 9,10 , and 11 from the previous section, most of the models fit fairly well graphically. Models 1 and 2 fit particularly well, whereas models 6 and 7 fit more poorly.

A robustness check is performed on the models using the Cox-Snell residuals. The Cox-Snell residuals are plotted against the Nelson-Aalen cumulative hazard. If a model is well-fitted then the resulting plot will be close to the 45 degree line. The models perform fairly well by this metric, but higher deviation from the 45 degree line is observed as the Cox-Snell residuals increase in magnitude. A Cox-Snell residual plot from model 1 is included in figure 14 .

The Cox-Snell residual plot for model 7 is included in figure 15 . Where figure 14 shows that the fit is not as good as model 1 , model 7 performs better on other metrics. Model 7 has noticeably higher pseudo R-Square, higher log-likelihood, and more significant variables. 
Figure 14: Goodness of Fit Using Cox-Snell Residuals for Model 1

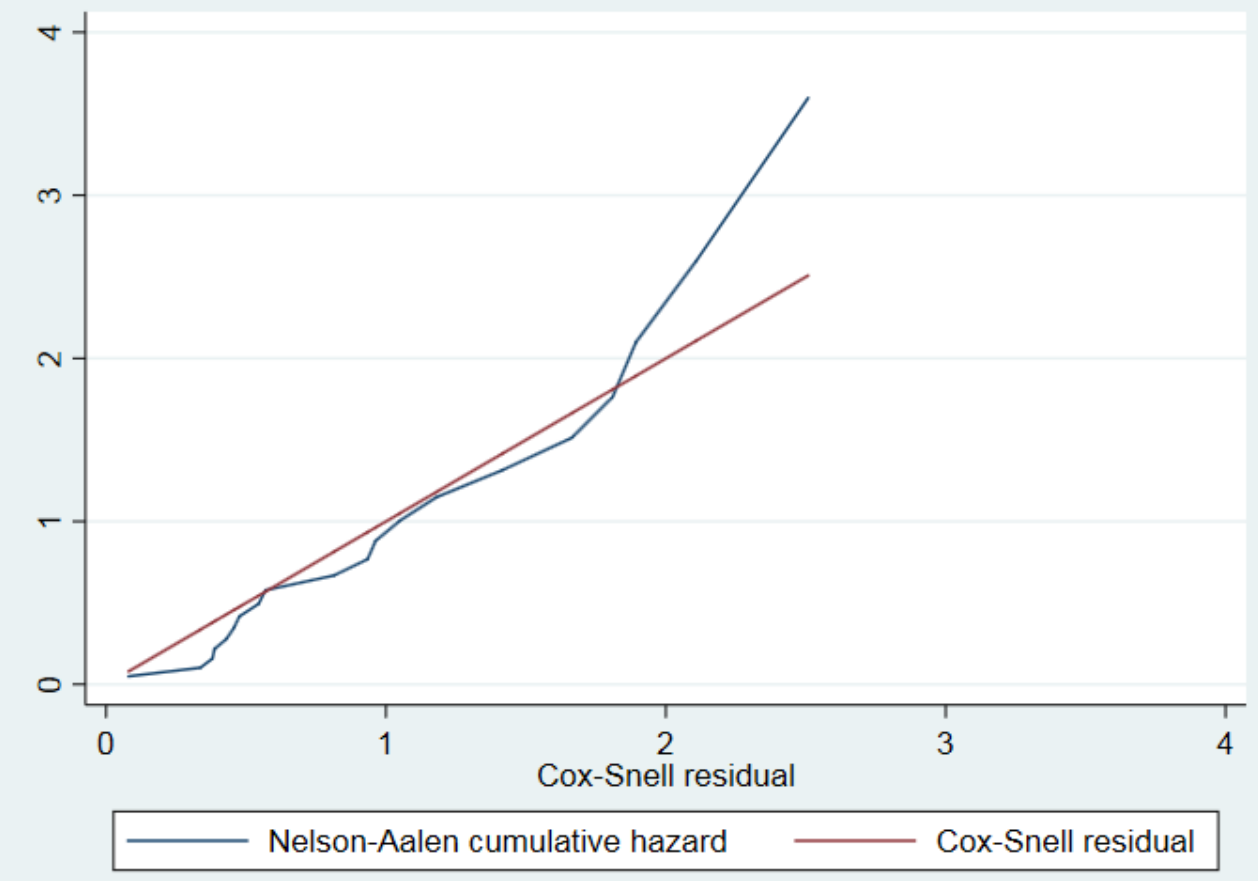

Figure 15: Goodness of Fit Using Cox-Snell Residuals for Model 7

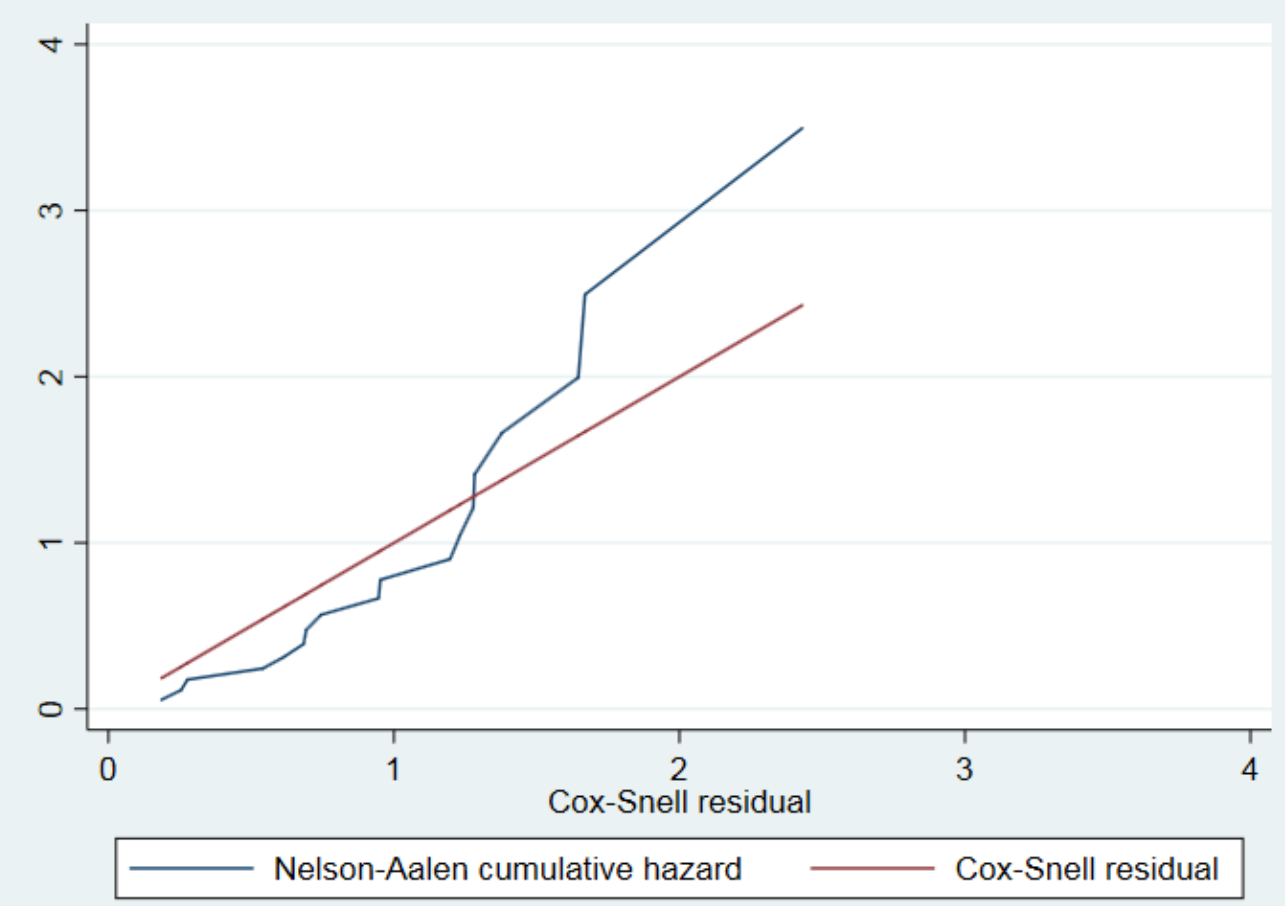


Table 5 below presents the results of the Gompertz parametric hazard regression for each model. The results of the Gompertz regression are very similar - both in sign and magnitude - to the results of the Cox proportional hazard model. What is different between the two models is the statistical significance of some of the variables. In the Cox PH model, inflation and the change in government spending contributed to the explanatory power of the model, however the variables themselves were often not statistically significant. Inflation and the change in government spending in the Gompertz model are not only statistically significant, but consistently significant at the alpha $1 \%$ level or better. Another difference between the two set of results is the statistical significance for the 'consecutive' variable. The variable is more frequently significant in the Gompertz regressions and seems to have a larger impact in terms of its smaller magnitude. In this case, a magnitude that noticeably closer to 0 , and further from 1 , will have a larger impact that a variable closer to 1 . 
Table 5: Gompertz Results, $\exp \beta$ estimates (Robust Huber/White z values in brackets below estimates)

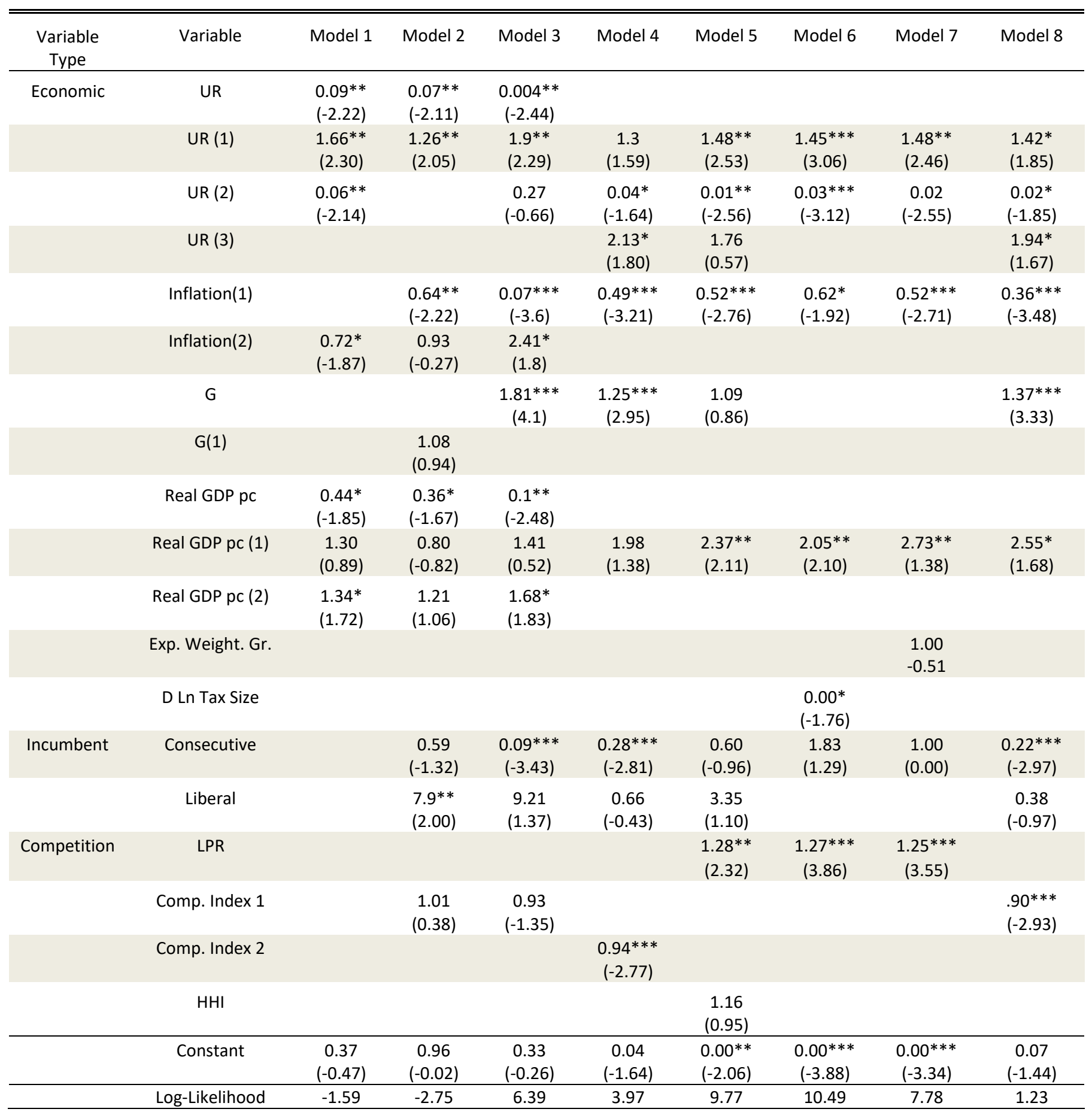

$* * *(* *)[*]$ significant at 1 (5) and [10] percent

\begin{tabular}{|c|c|c|c|}
\hline Covariate & Explanation & Covariate & Explanation \\
\hline UR & Unemployment Rate & LPR & Loss Probability Ratio, Historical 11 \\
\hline G & Growth rate of Government Spending & Comp. Index 1 & Index Derived from Loss Probability, Historical \\
\hline Real GDP pc & Growth Rate of Real GDP Per Capita & Comp. Index 2 & Index Derived from Loss Probability, Kayser-Lindstadt \\
\hline Exp. Weight. Gr. & Exponentially Weight Growth & & \\
\hline
\end{tabular}




\section{Conclusion}

In this paper I have used duration analysis to examine several theories about election timing. In the Canadian case, there is a strong observed relationship between the economic indicators and the political sphere. We observe that the government reacts to signals from the economy and then subsequently calls an election. The government's decision to call an election is partially motivated by the inflation rate, real income, and the unemployment rate. Government spending appears to coincide with the calling of an election, suggesting that the incumbent may be trying to influence the population in their favour. Political capital, as measured by the number of consecutive governments a party has governed for, plays a role in the government's decision to call an election. The academic field of political competition is expanding and offers explanatory power for when an election is called. This result suggests the government is aware of the political climate and how competitive the political sphere is prior to an election. Lastly, as seen in the section on principal components, economic variables offer more explanatory power separately than when they are combined into components using principal component analysis. 'Economic outlook' components offer little explanatory power and do not capture any interaction terms that may exist between the economic and non-economic variables. 


\section{Chapter 3}

\section{Introduction}

While many measures of electoral competition already exist in the literature, my contention is that these measures are merely indicators that attempt to reveal a real - but unmeasured - concept of electoral competition. Some indicators of political competition are too narrow in scope and only applicable to certain political structures, while other indicators only capture a single element of a more broadly understood idea of competition. By combining the indicators of electoral competition with selected underlying causal variables, I estimate a latent variable that measures the true level of competition in a mature democracy.

In this paper I develop a general index of political competition using a structural equation model known as a MIMIC model (multiple-indicator, multiple-cause model). I use a variety of measures of competition as indicator variables and a large range of economic and socio-political variables as causal variables.

Competiveness is integral to the proper functioning of both democracies and markets. Electoral competition is desirable because elected representatives from competitive districts are more responsive to their constituents (Ansolabehere, Snyder, \& Stewart, 2001; Powel, 2000), and they deliver superior quality and more prompt services (Belsey and Burgess, 2002; Asdera, Boix, \& Payne, 2003). The electoral competition also spurs the provision of increased social welfare (Lewis-Beck, 1977) and overall better government at the local level (Tvinnereim, 2004). Competitive electoral systems have higher voter turnout (Powell, 1986; Selb, 2009), and result in elected representatives being held more accountable (Canes-Wrone, Brady, \& Cogan, 2002; Przeworski, 2010). Electoral competition has been linked to better overall economic performance (Pinto and Timmons, 
2005; Besley, Persson and Sturm, 2010), and also improves the interests of consumers (Rogowski and Kayser, 2002; Besley and Coate, 2003).

This paper is structured as follows: in section 2, I compare the understanding of economic-competition with the understanding political-competition. In section 3, I discuss the model and literature. In section 4, I expand on the different dimensions of political competition, and why these dimensions are included in my general index of competition. I then explore the different MIMIC (Multiple Indicator Multiple Cause) models in section 5 and their meaning and results in section 6 . Section 7 concludes. There is an application of the error correction method proposed by Buehn and Schneider (2008) in the appendix.

\section{Contrasting Economic Competition with Political Competition} In economics, while we observe firms competing with each other, firms also act cooperatively with their customers and suppliers. Customers and other firms must always voluntarily enter agreements with each other and it is at the discretion of each actor to induce the other participant to cooperate. Labourers must agree to work for wages and benefits, and customers will only agree to buy a product if they think it is of good value. Rubin (2019) argues that the entire economy hinges on cooperation rather than competition.

Economic history provides us with examples where producers that could best cooperate saw the most success. In late $19^{\text {th }}$ century in America, the large monopolies and cartels were the first cooperative trusts for the industries of oil, railroads, shipping, mineral mining, finance, and steel. The most successful firms were able to absorb or cooperate with their competitors, and strike deals with firms in other industries for mutual benefits. The trusts engaged in internal cooperation and they also heavily cooperated with each other to maintain the status quo which protected economic profits. While there is no shortage of literature and dogma in favor of competition, it was cooperation that allowed for large financial consortiums to finance infrastructure projects that no smaller financial institutions would have been able to complete. Examples like the 
hegemony of Standard Oil in its home market of the United States allowed it to dominate foreign markets for some time before eventually facing competition from overseas rivals, with whom it also came to terms with and cooperated with as time passed.

Expansive firms were able to exploit economies of scale to keep prices low which was encouraged to avoid negative public backlash. This perverse form of cooperation can be thought of as an implicit deal between the monopolies and the public. So long as prices were kept at reasonable rates, the public tolerated the existence of powerful firms. In recent times, firms like Google and Facebook currently cooperate with their users by providing free services in exchange for user derived data. The cooperative stance between these tech companies and their users, at the time of this writing, is an implicit deal that the companies provide sufficiently useful services without making personal information extraction excessively invasive. The creation of network monopolies, like that of the Microsoft Windows operating system monopoly, was forged by the cooperation of hardware providers, the Microsoft Corporation, and other software developers. This initial cooperation must be constantly maintained - whereby each party remains constantly compatible with the others.

Political competition exists in contrast to economic competition. While economic competition is well studied, Rubin (2019) suggests the economic sphere is actually better represented as a realm dominated by cooperation. While benefits of economic cooperation can occasionally be clandestine, these benefits contrast starkly with political competition, which is a zero-sum game that appeals to our more visceral nature. In political competition, there are winners and losers and one actor's gain is another's loss. While it is generally assumed to be irrelevant to one consumer if another consumer also purchases a product (assuming nonrivalry in consumption), whenever a political party gains power it comes at the expense of some other party. The cooperation that is observed in politics has the sole goal of gaining power from those who are not in the cooperative coalition. 
While the political competition situation may seem dire, economics, on the other hand, can theoretically offer growth to all and everyone can benefit from ideas like Ricardian-trade. Such win-win situations are not always obvious and these truths can be lost on the uninformed public (Caplan, 2007). The ideas of political competition permeate economic thought to such a degree that these ideas can bias lay-people and economists alike into believing zero-sum (or net-negative) ideas; such as the proposal that 'tariffs to mitigate unbalanced trade' benefit everyone.

\section{The Model}

Derived from the work of Joreskog \& Goldberger $(1975)^{36}$, I use a MIMIC model to create a latent variable for political competition. Three sets of variables are employed: the causal variables, the latent variable, and the indicator variables. The indicator variables are a variety of competition indexes that attempt to measure one or more aspect of political competition. The causal variables are the variables that are hypothesized to influence the underlying latent variable.

\subsection{Literature}

The MIMIC model has been employed historically in many different research fields: political analysis with structural equation modelling (Stapleton 1978), social risk factors detection extended to latent class analysis (Yang 2005), psychological tests in item response theory context (Woods 2009), educational science in multilevel framework (Finch and French 2013; Kim et al. 2015), and in macro-economic analysis, the MIMIC Model has been used by Maltritz et al. (2012) to evaluate the country default risk.

Perhaps the MIMIC model's most renowned use in the recent history of economics is the application of MIMIC models to estimate the underground-

\footnotetext{
${ }^{36}$ Before the MIMIC model received its name from Jöreskog \& Goldberger, it had previously been discussed by Zellner (1970), Hauser and Goldberger (1971) and Jöreskog (1973). It was later expanded by Weck (1983), Frey and Weck (1983), Frey and Weck-Hannemann (1984), and Aigner et al. (1988) in the shadow economy context.
} 
economy. The first economists to consider the size of the hidden economy as an 'unobservable (latent) variable' were Frey \& Weck-Hannemann (1984), followed by others with similar analyses who have covered a variety of countries, including, but not limited to: Loayza (1996) for Latin America countries, Giles (1995, 1999) for New Zealand, Giles \& Tedds (2002) for Canada, Del'Anno (2003) for Italy, Bajada \& Schneider (2005) for Asia-Pacific countries, and Buehn and Schneider (2013) for 38 different countries from 1999 to 2010.

\section{Figure 1: Hypothesized MIMIC path for estimating the shadow economy}

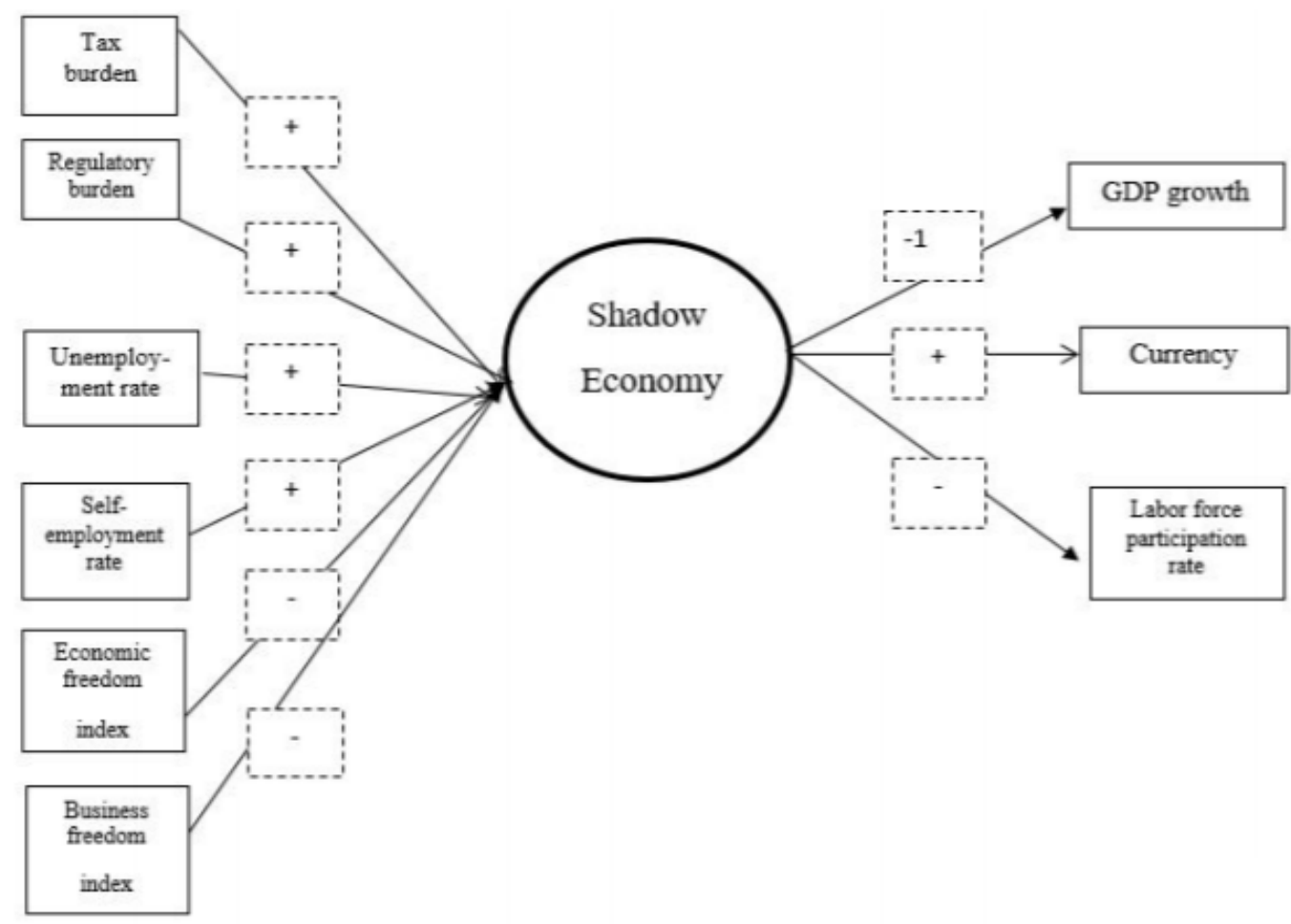

Source: Hassan \& Schneider (2016)

To estimate the underground-economy the MIMIC model treats the undergroundeconomy as the latent variable. The causal variables, as seen in figure 1 (taken from Hassan \& Schneider, 2016), are on the left-hand side of the figure. The causal variables are economic variables like the tax burden, the unemployment rate, and economic indexes like the economic freedom index and the business freedom index. The right-hand side of the model has the indicator variables. The indicator variables are variables that are supposed to be influenced by the 
shadow economy. The indicator variables of interest in this example are GDP growth, currency, and the labour force participation rate. All the variables used as causal variables and indicator variables are observable. The purpose of the MIMIC model is to find the underlying latent variable that can explain the variation between these two distinct sets of variables. In this example, the shadow economy influences the observable economy because most of the money generated in the underground-economy ends up in the legal economy (Schneider \& Enste, 2002; Schneider, 2010; Williams \& Schneider, 2016), hence GDP growth can be a good theoretical indicator of the shadow economy. To further this example, a potential cause of the underground economy could be the tax burden. The higher the amount of tax, the more incentive individuals have to avoid the tax. There is some risk associated with tax evasion, and a rational person would weigh the cost of being detected versus the benefit of avoiding taxation. As the tax-rate increases, ceteris paribus, the cost-benefit analysis increases in the favour of tax evasion. Each of the variables used as causal variables should have a valid theoretical causal relationship to the latent variable, and each of the indicator variables should have a theoretical relationship explaining how they are influenced by the latent variable. In section 4 , I will explain each variable used in my model and how they are causal or indicative of the latent variable.

It is of note that a requirement for the field of underground-economy research is to calibrate the MIMIC model such that a real dollar value estimate of the underground-economy can be obtained. As illustrated in the literature, calibration of the latent variable of the MIMIC model can be difficult and can lead to different results depending on the methodology applied (Breusch, 2005). An advantage of the methodology of this paper is that the political competition indexes that are employed as indicators are not measured in units that have meaning outside of the index, and thus the MIMIC model that is estimated does not require any calibration. 


\section{$3.2 \quad$ Structure}

Figure 2: General Structure of a MIMIC Model

Causes

Indicators

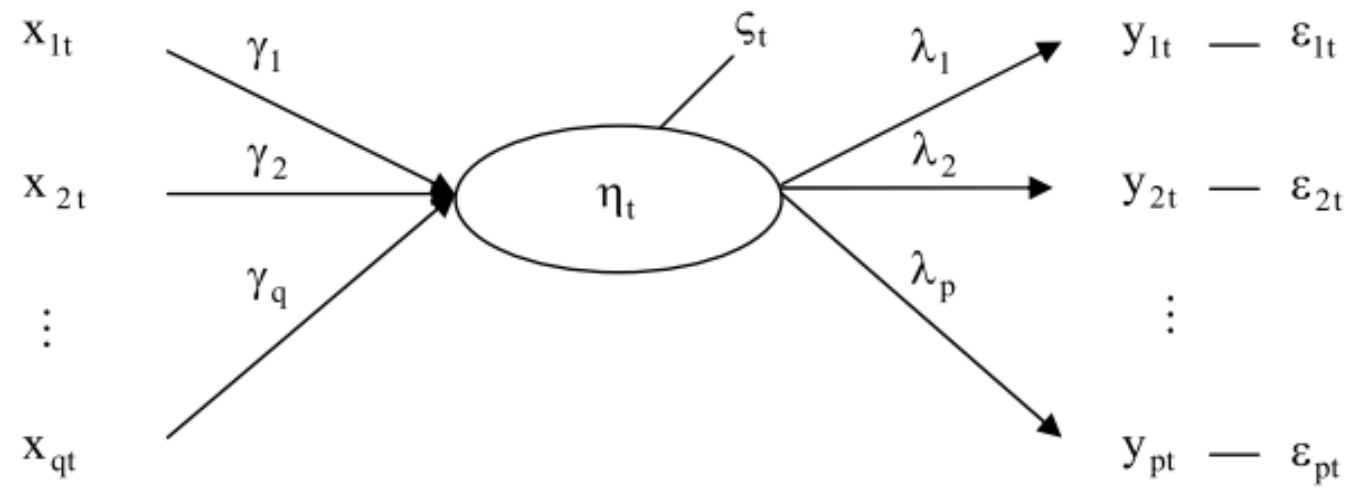

General Structure of a MIMIC Model

Source: Buhn \& Schneider 2008

At its heart, the MIMIC model allows a latent variable to explain the relationship between, on the one hand, a number of observable indicators, and on the other hand, a set of observed causal variables. The latent variable in the MIMIC model is the unobserved variable that minimizes the distance between the sample covariance matrix and the covariance matrix that would be predicted by the model. MIMIC models are constructed from two distinct parts: the structural model and the measurement model. The structural model is the relationship between the unobserved latent variable and the causal variables (equation 1), whereas the measurement model is the relationship the indicator variables and the unobserved latent variable (equation 2).

Jöreskog \& Goldberger defined the MIMIC as a system of equations using a latent variable, $\mathrm{y}^{*}$, which is measured by indicators, $\mathrm{y}_{\mathrm{i}}$, and is caused by $\mathrm{x}_{\mathrm{i}}$.

$$
y^{*}=\alpha_{1} x_{1}+\cdots+\alpha_{k} x_{k}+\varepsilon
$$




$$
y_{1}=\beta_{1} y^{*}+u_{1}, \ldots, y_{m}=\beta_{m} y^{*}+u_{m}
$$

In vector format, the system of equations appear thus:

$$
\begin{gathered}
\boldsymbol{x}=\left(x_{1}, \ldots, x_{k}\right)^{\prime}, \mathbf{y}=\left(y_{1}, \ldots, y_{m}\right)^{\prime}, \boldsymbol{u}=\left(u_{1}, \ldots, u_{m}\right)^{\prime}, \\
\boldsymbol{\alpha}=\left(\alpha_{1}, \ldots, \alpha_{k}\right)^{\prime}, \boldsymbol{\beta}=\left(\beta_{1}, \ldots, \beta_{m}\right)^{\prime}, \boldsymbol{\theta}=\left(\theta_{1}, \ldots, \theta_{m}\right)^{\prime}, \\
y^{*}=\boldsymbol{\alpha} \boldsymbol{x}^{\prime}+\varepsilon \\
\mathbf{y}=\boldsymbol{\beta} y^{*}+\boldsymbol{u} \\
E\left(\varepsilon \boldsymbol{u}^{\prime}\right)=\mathbf{0}^{\prime}, E\left(\varepsilon^{2}\right)=\sigma^{2}, E\left(\boldsymbol{u} \boldsymbol{u}^{\prime}\right)=\boldsymbol{\vartheta}^{2},
\end{gathered}
$$

To estimate this model, the latent variable, $\mathrm{y}^{*}$, is then substituted in each of the indicator equations to obtain the structural form.

$$
\begin{gathered}
\mathbf{y}=\boldsymbol{\beta}\left(\boldsymbol{\alpha} \boldsymbol{x}^{\prime}+\varepsilon\right)+\boldsymbol{u}=\Pi^{\prime} \mathbf{x}+\mathbf{v} \\
\Pi=\boldsymbol{\alpha} \boldsymbol{\beta}^{\prime} \\
\mathbf{v}=\beta \varepsilon+\boldsymbol{u}
\end{gathered}
$$




\section{$4 \quad$ Applying the MIMIC Model: Political Competition}

\section{Choice of Variables}

In this paper the set of $\mathbf{y}$ from equation (2) are: the effective number of parties ${ }^{37}$, the Przeworski and Sprague Index, the percentage of seats won by the government, the adjusted marginal seats, the Dickson seat-swings, the loss probability ratio, and the associated Splinter Index. All of these indexes are defined below.

The MIMIC model is constructed to capture different elements of political competition. The Przeworski and Sprague Index is used to estimate competition at the constituency-level. The adjusted marginal seats, percentage of seats won by the government, the Dickson seat-swings, the loss probability ratio and the Splinter Index all measure competition at the system-level. The final aspect of competition is the concept of contestability which is captured by the effective number of parties (Dash, Ferris, \& Winer, 2019). Contestability is distinguished from other types of competition because it relies on the existence of credible alternative parties to form government. It is not necessary that any credible alternative party has a high likelihood of gaining power, or that the electoral outcome is uncertain; contestability only requires that if a credible alternative party gained power they would govern to a sufficiently high degree of competency (Baumol, 1982).

A detailed explanation for the choice of the causal variables is provided in the Causal Variables section (section 4.2) following the Indicators of Political Competition section.

\footnotetext{
${ }^{37}$ Some modifications of this general idea are included as separate variables.
} 


\subsection{Indicators of Political Competition}

The indicator variables used in this paper come from a variety of original sources. The authors who developed the indicator variables often claim their indicators to be overall measures of political competition. I argue that these indicator variables each portray just one aspect of the general measure of political competition.

\section{(i) Effective Number of Parties}

Comparing an election to the number of firms in an industry, the literature often states that if more parties are competing this can imply more options for the public to choose from and thus more competition. To explore this idea, the number of parties running in an election can be evaluated at both the macro level and the district or constituency level.

As noted by Laakso \& Taagepera (1979) not all parties are equal. With few barriers to entry, any single district may have many parties competing. Some parties are well supported locally and have a reasonable chance of victory in a district, whereas other parties have much lower levels of support and very little chance of achieving electoral success. In any given election, the number of parties that decide to run candidates may fluctuate while competition levels can remain insensitive to these changes. Laakso \& Taagepera (1979) handle the problem of distinguishing between "serious contenders" and "frivolous contenders", by looking at their 'market share'. Similar to economics, where any firm may potentially enter a market, we would be hard-pressed to say the industry is competitive unless many of the firms had a sizeable market share for the products they were selling. The Herfindahl-Hirschman index ${ }^{38}$ measures the level of market competition by squaring the market share values, hence creating an exponential weighting-system that singles out firms with large market shares

\footnotetext{
${ }^{38}$ Herfindahl-Hirschman index is an index that ranges from 0 to 10000 , which is calculated as a sum of the market shares of each firm in the industry. As the industry goes towards a monopoly, the index approaches 10000 .
} 
and reveals unbalanced or uncompetitive markets. Markets may be unbalanced or uncompetitive in the sense that only one or a few firms have a disproportionate amount of market share. This same idea can be applied to parties vote shares, creating the 'effective number of parties' (ENP), or in other words, the number of parties that actually have sufficient vote share.

Laakso \& Taagepera define the ENP at the constituency level as,

$$
E N P_{j t}=\frac{1}{\sum_{i}^{I} v_{i j t}^{2}}
$$

And the aggregate over all the constituencies gives the system-wide ENP:

$$
E N P_{t}=\frac{\sum_{j=1}^{J} E N P_{j t}}{J}
$$

Where $v_{i j t}$, is the vote-share of candidate $i$ in constituency $j$ in election $t$. The ENP will be equal to the number of parties running in the constituency if the voteshare for each party is the same. When many parties run in the election, but only a few parties obtain the majority of the votes, the ENP will be smaller than the total number of parties running.

Ferris, Winer, \& Grofman (2016) address the idea borrowed from economics that says that as the ENP increases, competition in an election increases. This line of reasoning comes under scrutiny from Ferris, Winer, \& Grofman (2016) as it seemingly contradicts the theory of Duverger's Law ${ }^{39}$ (1954), which states that over time the number of parties competing in any district should tend towards two. A violation of Duverger's Law implies something - possibly a lack of

\footnotetext{
${ }^{39}$ Duverger claimed that any party will try to increase market share by moving towards the center of the political spectrum and offering a wider range of policies. Fringe parties will get fewer votes and over time only two parties will remain: a party slightly left of center, and a party slightly right of center.
} 
competition - is occurring that is pushing the parties away from Duverger's predicted equilibrium. Hence, while the ENP can measure competition, the predictive-value comes from when the ENP deviates from two, not simply the total number of parties. Dash, Ferris, \& Winer (2019) argue that the deviation away from two parties is a reduction in contestability.

\section{(ii) Przeworski and Sprague Index}

The Przeworski \& Sprague (1971) index is a type of volatility adjusted vote margin. The vote margin is the difference between the vote total of the winner and the vote total of the second place party. The smaller the margin is, the closer the district is, and hence the more competitive the election.

Vote margins can be examined both at the national level and at the district level. For a single member district majoritarian country (such as Canada), the national vote margin is less indicative of competition compared to examining how close each district was in the election.

As noted (Przerworksi, 1971; Elkins, 1974; Bartolini, 1990; Ferris, Winer, \& Grofman, 2016), a weakness in using the national or district winning vote margins is that the margin itself cannot be used independently as a measure of election-closeness without taking into account the volatility of the vote in each of the districts. With very stable vote outcomes, a small margin will not be indicative of a close election. However, with high variance in the vote patterns, a close margin suggests the outcome was very competitive. This motivated Przeworski \& Sprague (1971), and those after them (Ferris, Winer, \& Grofman, 2016; Dash, Ferris, \& Winer, 2019), to adjust the vote margins to take into account variability.

To define the party-based Przeworski \& Sprague (PS) competition index, the leading vote deficit, $h_{p j}^{t+1}$, is computed for each party, $p$, in each constituency, $j$, and at election $t+1$ : 


$$
h_{p j}^{t+1}=\frac{\left(v_{1 j t}-v_{p j t}\right)}{\text { Volatility }_{s t i}}
$$

Where $v_{p j t}$ is the votes obtained by party $p$, in each constituency, $j$, and at election $t$.

Recognizing that not all parties or districts remain the same over time, Ferris, Winer, \& Grofman (2016) make some adjustments to then aggregate up to a national measure of competition.

$$
c_{p j}^{t+1}=\left\{\begin{array}{c}
1 \text { if } 0 \leq h_{p j}^{t} \leq 1 \\
\frac{1}{h_{p j}^{t}} \text { if } h_{p j}^{t}>1
\end{array}\right.
$$

For a highly competitive party, $c=1$ because the vote deficit for that party is less than the portion of the electorate that switched parties in the previous election.

The measurement can then be aggregated across all the parties in each constituency $j$ :

$$
C_{j}^{t+1}=\sum_{p=1}^{P} c_{p j}^{t+1} v_{p j t}
$$

When $C_{j}=0$, this indicates there is no competition in the constituency. National average competitiveness is then defined as

$$
C_{N J}^{t+1}=\sum_{j=1}^{J} C_{j}^{t+1} a d j_{-} v w_{j t+1}
$$

Where adj_vw $w_{j t+1}$ is the adjusted vote weight for each constituency, where I define adj_vw $_{j t}=($ votes in constituency $j$ at $t) /($ aggregate state votes at $t)$. 


\section{(iii) Adjusted Marginal Seats (AMS)}

Hartle (1985) defines a marginal constituency as a district that cannot be ignored by the incumbent, in the sense that economic rents cannot be taken from the district without a risk that the incumbent will lose the constituency. There is difficulty in implementing this definition. An alternative has been proposed by Bodet (2014) to define a safe seat as a seat that lies in the safe side of a tail in a distribution of vote margins. To see which seats are calculated to be safe, Ferris, Winer, \& Grofman (2016) obtain the volatility adjusted vote margins from the previous three elections and uses two standard deviations to create the tails of the distribution of vote margins. Once the number of marginal seats is known, this number can be converted into a proportion relative to all the seats. The proportion of marginal seats is used as a measure of competition.

\section{(iv) Splinter Index and the Probability of Loss}

In the first chapter of this dissertation, I developed a measure of competition that builds off the work of Kayser \& Lindstadt (2015). The 'probability of loss' for the incumbent party is used as a measure of competition in these papers ${ }^{40}$. Kayser \& Lindstadt employ the idea of electoral risk as one of the underlying components of electoral competition. The purpose of competition is to ensure that alternatives are available and electoral risk directly measures the probability an alternative government will be elected.

\footnotetext{
${ }^{40}$ The probability of loss is simply the estimated probability that the incumbent will lose the next election. Hence, 1-'probability of loss' is the probability of winning.
} 


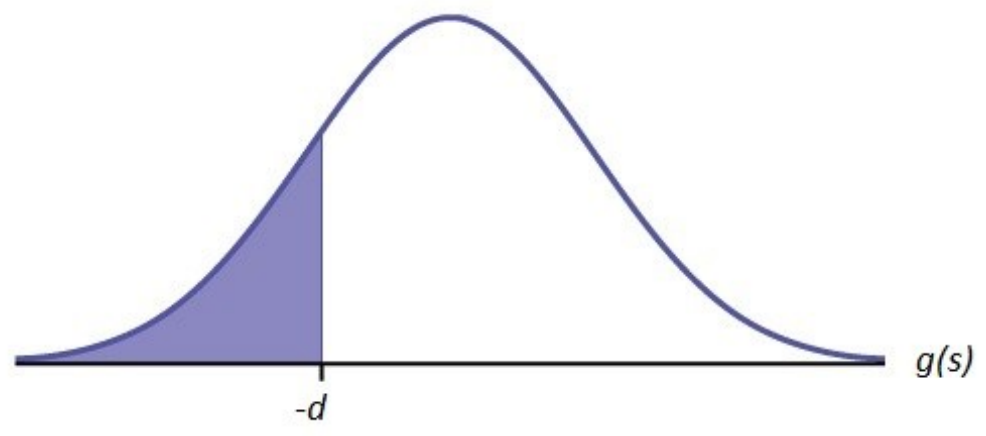

In figure 3 , the shaded area represents the loss probability ratio (LPR).

$$
L P R=\int_{-\infty}^{-d} g(s) d s
$$

Where $d$ is the seat-share gap.

The LPR is the likelihood of a seat-swing being large enough to unseat the incumbent. The seat-share gap, $d$, is the current difference in seat-shares between the incumbent and the opposition party. Any seat-swing against (which is why $d$ is negative in the integral) the incumbent of size $d$ or larger results in the incumbent having the new largest seat-share.

The measures of competition developed by Splinter and Kayser \& Lindstadt have a direct connection to the loss of power for the government and they are congruent with the government-executive's perspective on their own political security. The Splinter index and the Kayser \& Lindstadt 'loss probability ratio' are calculated using the two largest parties in terms of seat share, but they can be generalized to take into account any number of parties. In chapter 1 of this dissertation, I calculate the probability of the incumbent government losing the election by using a distribution of past election results and the current seat-gap between the incumbent and the second place party. This probability of loss, or loss probability ratio (LPR), can be calculated several ways and be converted into an index that ranges from 0 to 1 . I propose that an LPR of $0 \%$, which is a 
state where the government has no chance of loss, represents a political state which resembles a dictator, and hence there is no observable political competition. Likewise, an LPR of $100 \%$ represents a lame-duck government who has no chance of winning. I will describe a political state that has an LPR of $100 \%$ to be uncompetitive since the incumbent has no incentive to compete. While lame-duck politicians exist by law in some circumstances, such as an American president who has served two full terms ${ }^{41}$, in the Canadian context, a party - and its leader - can be elected indefinitely, either consecutively or nonconsecutively. Hence, an LPR of $100 \%$ implies that the political environment is such that no incumbent party can compete ${ }^{42}$.

Given the LPR, the competition index formula is

$$
\text { Competion Index }=1-\left|\frac{0.5-L P R}{0.5}\right|
$$

This index will yield a value of 0 when the LPR is either 1 or 0 - which, as discussed above, describes low-competition environments. A value of 0 for the index represents no competition, and a value of 1 represents maximum competition. Hence, competition increases as the index rises. When the LPR is equal to 0.5 , representing a $50 \%$ chance that the incumbent government will win re-election, the competition index is at 1 , its highest level. To justify this claim, given that there are only two possible outcomes (the government wins re-

\footnotetext{
${ }^{41}$ Since the $22^{\text {nd }}$ amendment to the American constitution was passed in 1951, no American president can be elected for more than 2 terms. It is possible for a president to take office via the line of succession, and then after be elected for 2 more terms. Furthermore, after two winning two terms, nothing prevents one of the political parties from nominating a new presidential candidate, who can then contest and win the presidential election.

${ }^{42}$ In the first chapter's analysis of the Canadian context, an LPR of $100 \%$ never occurred which is congruent with the idea that the incumbent party always has at least some predicted chance of winning.
} 
election, or it does not) I propose that a $50 \%$ chance of winning is when electoral uncertainty regarding the outcome is at its highest ${ }^{43}$.

\section{(v) Dickson Swing Ratios}

Dickson (2009) uses provincial level swing-ratios to estimate the responsiveness of each provinces' elasticity and sensitivity towards government policies and initiatives. A swing-ratio is defined as elasticity between seats and votes. The swing ratio is a percentage change in seats resulting from a $1 \%$ change in votes.

Responsiveness is one of the elements of political competition. A rational government in a democracy would attempt to influence the population to favour the incumbent government using the tools the government has access to, namely: laws, regulations, and fiscal policies. As the level of responsiveness increases, the influence the government can obtain through fiscal policies increases as well. When responsiveness is very high, the government will tailor policies that are appreciated by the citizens. When responsiveness is very low, the government has no incentive to create any policies that the citizens are interested in - which is a state similar to that of a one-party political system. Thus, high responsiveness is an indicator of high competition, and low responsiveness is an indicator of low competition.

Dickson proposed that higher elasticities of seats to votes would result in more government spending in that province. These province's elasticities can be aggregated up to the federal level to get nation-wide swing-ratios. The swingratio formula that Dickson uses is in equation (17) and the derivations to obtain equation (17) are below. Equation (14) shows that there is some assumed relationship between the seat-share won and the vote-share garnered. The alpha exponent is an unknown that can be estimated through a regression after the

\footnotetext{
${ }^{43}$ The LPR makes no distinction between majority and minority governments; any party who win the plurality of seats is considered the winner of the election.
} 
equation has been modified to equation (15). Equation (16) is the formula for the effective number of parties, which then gets substituted into equation (17), which shows that the swing-ratio (the seats-votes elasticity) is a function solely of the number of effective parties, the number of votes received by party $i$, and alpha.

$$
\begin{gathered}
S_{i}=\frac{V_{i}^{\alpha}}{\sum_{1}^{n} V_{i}^{\alpha}} \\
\ln \frac{S_{i}}{1-S_{i}}=\propto \ln \frac{V_{i}}{1-V_{i}} \\
\frac{n e=\frac{1}{\sum_{1}^{n} V_{i}^{2}}}{\partial S_{i}}=\frac{\propto(n e-1)^{1-\propto}\left[\left(\frac{1}{V_{i}}\right)-1\right]^{\alpha-1}}{V_{i}^{2}\left(1+(n e-1)^{1-\alpha}\left[\left(\frac{1}{V_{i}}\right)-1\right]^{\alpha}\right)^{2}}
\end{gathered}
$$

In the above equations, seat-shares are represented by $S_{i}$ and the vote-shares are represented by $V_{i}$. 'ne' is the number of effective parties and $\frac{\partial S_{i}}{\partial V_{i}}$ is the seats-votes elasticity.

\section{(vi) Seats}

The percentage of seats won by the governing party is an indicator of how competitive the last election was. This measure captures competition between elections. The higher the percentage seats won, the more dominant the victory was, and the less influence the opposition was able to muster. Very large wins in terms of percentage seats won would be indicative of a low competition environment. This interpretation takes a clear stand on how we interpret 
competition. For example, competition could be viewed as the voters having many available alternatives, such as in the 1993 Canadian election, when two new major parties came to the electoral forefront (the Reform Party of Canada and the Bloc Quebecois). However, with many parties available for vote-splitting, the Liberal Party of Canada won a large majority. In this case, the interpretation is that the election was not competitive from the point of view of the Liberal party. 


\subsection{Causal Variables}

The set of $\boldsymbol{x}$ from equation (1) consist of economic and socio-political variables. The causal variables are the explanatory variables that are assumed to influence electoral competition. The economic variables are: the unemployment rate, the growth rate of government spending, the inflation rate, and the growth rate of real income. The socio-political variables are: the proportion of the population that is urban, the openness of the country, the turnout in the election, the average number of electors, the number of registered voters, the salary change for members of parliament, the pension parameters change for the members of parliament, the ratio of immigrants to non-immigrants, and the percentage of the population engaged in agriculture. I shall come back to the socio-political variables later.

Competition is important in so far as it is a process for obtaining good outcomes. To illustrate, should a monopolist provide consumers with good quality products, at low prices, and in a sufficient quantity, there would be no concern for intervention against the monopolist. A monopolist causes concern when they use their market power to move away from a competitive equilibrium, in order to provide substandard goods and/or higher than-otherwise prices. However, a monopolist can be induced to provide good services by the introduction of other competitors or from merely the threat of other competitors entering the market. If the threat is credible, the monopolist will behave more competitively than one might expect, ceteris paribus. Likewise, if a monopolist is attempting to avoid (not just) direct competition from other firms, but also avoid intervention from a governing authority, they will be induced to provide better services or goods at competitive prices. This idea lends itself analogously to the world of politics. Governments in power are trying to limit competition to their governance. Governing parties can then be induced to provide good governance by facing credible threats of competition from other parties. I propose that the population attributes the state of the economy to the power of the governing party. In other 
words, the government is blamed for bad economic outcomes and is rewarded for good economic outcomes. So long as the economy is doing well, the population will not have an incentive to replace the governing party.

The state of the economy, $\mathbf{X}$, is constructed from several variables, $\mathrm{x}_{1}, \mathrm{x}_{2}, \ldots, \mathrm{x}_{\mathrm{n}}$, where $n$ is the number of variables that are used as measures of the state of the economy. In the following section I will provide further motivation for the economic variables that I have selected.

\subsubsection{Economic Factors}

\section{(i) Change in the Unemployment Rate}

The unemployment rate influences competition by influencing the economic environment. Unemployment rates can be felt through first-hand experiences or witnessed through regularly-published unemployment rate statistics. It is not hard to imagine that a first-hand experience with unemployment would sway the voter's opinions, and a voter who is aware of the unemployment rate (if only indirectly) could still be swayed. In this paper I use the year-over-year change in the unemployment rate to measure the effect of the unemployment rate on competition.

\section{(ii) Inflation}

The economic voter intimately observes inflation as measured by the $\mathrm{CPI}$ and it is the change in purchasing power that motivates a voter. High inflation rates could be seen as a sign that the government has lost control of the economy and/or there is uncontrolled printing by the central bank. Businesses and consumers generally prefer stable prices. Large changes in prices could result in the population souring on the current government, thus increasing competition and opening the door for an opposition party to replace the incumbent. 


\section{(iii) Real Income}

Similar to the aforementioned variables, a voter directly observes their own income and can also take heed of general economic performance. Statistics on GDP are regularly published and reported on in Canada. In the literature, income is the most widely used predictor for how a voter feels about the government. I propose that it is the growth rate of this variable that the voters are most interested in instead of the level. Increasing real incomes for individuals would cause voters to feel more confident in their government and declining incomes would incentivise the electorate to vote for change.

\section{(iv) Change in Tax Size and Government Spending} Voters are aware of how high taxes are, and tax levels can sway their opinion of the government. Lower tax levels may leave the electorate with a favorable opinion of the government and the inverse can also hold true. The expectation is that as taxes are lowered, the government becomes more likely to call an election. Government spending, in contrast to a variable like GDP per capita, would likely be witnessed more passively through an increase in transfers or new infrastructure projects. In both cases, I propose that voters are more interested in the change of these values, rather than in the level.

\section{(v) Openness of the economy}

The degree of the openness of the economy is measured by the total amount of trade (Imports + Exports) divided by total national income. 


\subsubsection{Demographic impacts on Competition}

\section{(i) The Immigration Ratio, Religious Fragmentation, Percentage in Agriculture, Percentage Urban}

The following variables all affect competition through the way they influence voting and demographic patterns in Canada. These demographic variables affect the status quo and may be reflected in the public's outlook on the incumbent government.

The immigration ratio is the ratio between the total population of immigrants to the total population of native-born Canadians. The religion variable employed is an index similar to a modified Herfindahl-Hirschman index. The elements in the religious fragmentation index equation are the percentage of Protestants, Catholics, Jews, Mormons, other, and unknown. This religious fragmentation index is approximately equal to the probability that two people selected at random will be from the same religious group.

$$
\text { Religious Fragmentation Index }=1-\sum_{1}^{\mathrm{I}} \text { Religious Group Percentange } \mathrm{i}_{\mathrm{i}}^{2}
$$

$$
\text { Where } i=1,2, \ldots, I
$$

The urban proportion variable describes the percentage of the population that is living in cities and, likewise, the agriculture variable describes the percentage of Canadians engaged in agriculture as their main income.

\section{(ii) Percentage Registered Voters and Voter Turnout} The percentage of registered voters measures engagement of the populace in the electoral process. Since Canada does not have compulsory voting, the percentage of registered voters indicates how many citizens choose to participate in the democracy. A low percentage indicates disinterest and likely causes a lower level of competition whereas a high percentage reveals that citizens believe their vote matters and they are ready to vote, spurring an 
increase in overall competition. A low percentage of registered voters, and the disinterest that this signals, means that the incumbent government does not have to cater as closely to the interests of the citizens as they otherwise would have to. When citizens are highly interested in the election, this means that the parties must cater their policies to the actively engaged citizens or face electoral failure.

Similarly, voter turnout acts as a good signal of interest in the election, however, it only occurs at election time, unlike the percentage of registered voters that is also measured between elections.

(iii) Member of Parliament Salary and Pension Parameters The compensation that MPs receive influences their decision to seek office or reelection. The more candidates who are actively seeking office can cause competition. Increases in salary can incentivise current MPs to seek re-election and cause new members to seek office.

Changing pension parameters for MPs can influence new MPs to seek election, but the changing pension parameters likely has a larger impact on current MPs. Pension parameters related to time served can influence an MP to try and serve only the time required to obtain their full pension and affect the candidates running in the subsequent elections.

\section{The Empirical Model}

In this section I estimate five different models which each illustrate different concepts and variations of a well-constructed model. Model 1 examines the combination of all the previously-examined variables to see if any pattern emerges and to see which variables offer some insight or explanatory power. Model 2 is a variation of Model 1 where some of the less-significant indicator variables are replaced with some of the 'loss probability ratio' variables that offer explanatory power. Model 2 also drops some of the less predictive causal 
variables. Model 3 is constructed in order to create a model with more predictive power using only a small number of selected casual variables. Model 4 is a variation of the other models and it is constructed to illustrate the impact of changing the anchor variable from the Splinter index to the Kyaser \& Lindstadt probability of loss. The anchor variable is an indicator variable for which the path coefficient in the structural equation model is set to one. The anchor variable influences the rest of the model and it also influences the characteristics of the latent variable. Model 5 is the most parsimonious model. Model 5 illustrates that only a few causal variables are required for a model to have explanatory power, but other models (Model 3) can be more statistically significant.

\section{Model 1:}

$$
\begin{aligned}
& \text { Political Competition } * \\
& \qquad \begin{aligned}
& * \\
& \\
&+\alpha_{3} \text { Inflation }+\alpha_{4} \text { Growth Rate of Real Income } \\
&+\alpha_{5} \Delta \text { Openness of the Economy }+\alpha_{6} \text { Immigration Ratio } \\
&+\alpha_{7} \Delta \text { Pension Parameters }+\alpha_{8} \Delta \text { Registered Voters }+\varepsilon
\end{aligned}
\end{aligned}
$$

$$
\begin{gathered}
\text { Splinter Index }=\beta_{1} \text { Political Competition }^{*}+u_{1} \\
\Delta E N P \text { Ratio }=\beta_{2} \text { Political Competition }{ }^{*}+u_{2} \\
\text { Dickson Swing Ratios }=\beta_{3} \text { Political Competition }{ }^{*}+u_{3} \\
\Delta \text { Przeworski - Sprgaue Index }=\beta_{4} \text { Political Competition }{ }^{*}+u_{4} \\
\text { Adjusted AMS }=\beta_{5} \text { Political Competition }^{*}+u_{5}
\end{gathered}
$$

This model incorporates all the indicators examined in this paper and all the causal variables included in the paper. 


\section{Model 2:}

$$
\begin{aligned}
& \text { Political Competition }{ }^{*} \\
& \qquad \begin{array}{l}
=\alpha_{1} \Delta U R+\alpha_{2} \text { Growth Rate of Government Spending } \\
+ \\
+\alpha_{3} \text { Inflation }+\alpha_{4} \text { Growth Rate of Real Income } \\
+\alpha_{5} \Delta \text { Pension Parameters }+\alpha_{6} \Delta \text { Registered Voters }+\varepsilon
\end{array}
\end{aligned}
$$

$$
\begin{gathered}
\text { Splinter Index }=\beta_{1} \text { Political Competition }{ }^{*}+u_{1} \\
\Delta E N P \text { Ratio }=\beta_{2} \text { Political Competition }{ }^{*}+u_{2} \\
\text { Dickson Swing Ratios }=\beta_{3} \text { Political Competition }{ }^{*}+u_{3} \\
\text { Kayser }- \text { Lindstadt Probability of Loss }{ }^{*} \\
=\beta_{4} \text { Political Competition }{ }^{*}+u_{4}
\end{gathered}
$$

Model 2 is a variation of model 1 where I have removed the following variables: openness of the economy, immigration ratio, the Pzeworski Sprague index, and the Adjusted Marginal Seats index. I have added the Kayser-Lindstadt version of Loss Probability Ratio.

\section{Model 3:}

$$
\begin{aligned}
& \text { Political Competition* } \\
& \qquad \begin{array}{l}
=\alpha_{1} \text { Growth Rate of Government Spending } \\
+\alpha_{2} \text { Growth Rate of Real Income } \\
+\alpha_{3} \Delta \text { Pension Parameters }+\varepsilon
\end{array}
\end{aligned}
$$

$$
\begin{gathered}
\text { Splinter Index }=\beta_{1} \text { Political Competition }^{*}+u_{1} \\
\Delta E N P \text { Ratio }=\beta_{2} \text { Political Competition }^{*}+u_{2}
\end{gathered}
$$




$$
\begin{gathered}
\text { Dickson Swing Ratios }=\beta_{3} \text { Political Competition }{ }^{*}+u_{3} \\
\text { Kayser }- \text { Lindstadt Probability of Loss } \\
=\beta_{5} \text { Political Competition }^{*}+u_{5}
\end{gathered}
$$

Model 3 is a further modified version of model 2 with the following variables removed: the change in the unemployment rate, the inflation rate, and the percentage of registered voters.

\section{Model 4:}

$$
\begin{aligned}
& \text { Political Competition } * \\
& \qquad \begin{array}{l}
=\alpha_{1} \Delta U R+\alpha_{2} \text { Growth Rate of Government Spending } \\
+\alpha_{3} \text { Inflation }+\alpha_{4} \text { Growth Rate of Real Income } \\
+\alpha_{5} \text { Pension Parameters }+\alpha_{6} \text { Registered Voters } \\
+\alpha_{7} \text { Average Electors }+\alpha_{8} \text { Turnout } \\
+\alpha_{9} \text { Growth rate of Government Spending }+\varepsilon
\end{array}
\end{aligned}
$$

$$
\begin{gathered}
\begin{array}{c}
\text { Kyaser Lindstadt Probability of Loss } \\
=\beta_{1} \text { Political Competition } \\
*
\end{array} \\
\text { Historical Probability of Loss }=\beta_{2} \text { Political Competition }{ }^{*}+u_{2} \\
\text { Kyaser Lindstadt Probability of Loss, Pre }- \text { Election } \\
=\beta_{3} \text { Political Competition } * u_{3} \\
\text { Pzeworski Sprague }=\beta_{4} \text { Political Competition }{ }^{*}+u_{4} \\
\text { ENP Ratio }=\beta_{5} \text { Political Competition } * u_{5}
\end{gathered}
$$

Model 4 shows a model with many of the causal variables and many of the indicators of political competition including some variations of the loss probability ratio. This model is distinguished from the other models because it is the only one that does not include the Splinter Index. 


\section{Model 5:}

Political Competition $^{*}=\alpha_{1} \Delta U R+\alpha_{2}$ Pension Parameters $+\varepsilon$

$$
\begin{gathered}
\text { Splinter Index }=\beta_{1} \text { Political Competition }{ }^{*}+u_{1} \\
\text { Kyaser Lindstadt Probability of Loss, Pre }- \text { Election } \\
=\beta_{2} \text { Political Competition }{ }^{*}+u_{2}
\end{gathered}
$$

Model 5 , similar to model 3 , is the most parsimonious model in terms of causal variables. It includes a variety of indicators of political competition. 


\section{Discussion of Results}

The results of model 1, seen in Table (1), show a poor overall fit and no significant variables. More parsimonious models are shown to have a better explanation of the data. In model 2, the Pzeworski Sprague index and the Adjusted Marginal Seats index were removed and the Kayser-Lindstadt Probability of Loss was included. Model 2 shows a slight improvement in the overall fit of the model and the significance of the indicators. The only causal variable shown to be significant is the change in the number of registered voters.

Model 3 has overall statistical significance and shows that the change in the pension parameters for the members of parliament is statistically significant.

Model 4 shows a model with many statistically significant causal variables but the overall model is not statistically significant. The purpose of this model is to illustrate that significant casual variables or indicator variables is not sufficient for the overall model to be statistically significant. Model 5 , similar to model 3 , shows us that the more parsimonious models perform better for overall significance. Every variable except for the Adjusted AMS is statistically significant.

The estimate for the unemployment rate is consistently negative suggesting that increasing unemployment rate decreases competition. This could be interpreted as two ways; lower competition implies a foregone conclusion, insinuating that the incumbent government is safely going to stay in power, or we can confidently guess they will be removed from office. I think the latter explanation is more likely.

The growth rate of per capita income does not have a consistent sign or statistical significance; however it did tend to contribute to the overall significance of the model. It is possible that in alternative models the variable would have a more clear interpretation. 
The positive sign from the pension parameters implies that as pension parameters increase, competition increases, however the negative sign in the first-difference of this variable suggests that as the percent change of the variable increases, competition decreases.

The inflation rate was only statistically significant once and the magnitude of the coefficient was quite small implying there is a very small effect on competition compared to other variables.

Changes in the amount of government spending was never statistically significant in the models examined, but the variable did contribute to the overall significance of the models.

Changes in the percentage turnout for the election, the average number of electors in each district, and the percentage voters registered were shown to be significant.

The change in the level of openness in the economy, the ratio of immigrants to Canadian-born citizens, and the percentage of voters registered had little overall impact on political competition.

Amongst the indicator variables, they were generally consistent in sign, magnitude, and statistical significance. The Splinter Index was selected as the variable to be fixed to the value of one (in all the models except model 4) because these models tended to have higher statistical significance compared to other variables ${ }^{44}$. The influence this has is observed in the graphs of the political competition over time (see figures $4 \& 5$ ).

The indicator variables generally had very high statistical significance. The loss probability ratio (LPR) was generally very significant, similar to the Dickson swing ratios and the Effective Number of Parties. The adjusted marginal seats and the Pzeworski-Sprague index were not shown to be statistically significant and their coefficient estimates were not consistent.

\footnotetext{
${ }^{44}$ The indicator variable fixed to one is the anchor variable.
} 
The overall fit of the models is evaluated using a Chi-square test against a baseline model. In this case, a p-value above 0.05 is considered a better-fitting statistically significant model ${ }^{45}$. The baseline model is a model that has the best fit possible since it perfectly reproduces all of the variances, covariances, and means. Since it is, by construction, impossible to do better than the saturated model, it becomes the standard for comparison with estimated models ${ }^{46}$.

Figures (4) and (5) show the predicted political competition indexes from each model. Predicted values are calculated from factor scores which are computed with a linear regression by using the mean vector and the variance matrix from the fitted model ${ }^{47}$. Figure (5) has model 4 removed for scaling issues to better illustrate the volatility of the other indexes. Models 2,3 , and 5 all follow the same general pattern whereas model 1 is a measure with lower volatility. However, Model 1 contained no statistically significant variables and had poor overall fit. Models 2 and 3 follow each other very closely compared to the other models. With the exception of one outlier year, the models show that competition was higher in the years from the mid-1950s until the early 1980s compared to the years afterwards. Competition then increased from the early 1980 s until the early 2000 s when the level of competition returned to about the rate of the pre-1980s period of increased competition. The period of the early 80 s to the early 2000 s was dominated by large majority governments. First the Progressive Conservatives under Brian Mulroney won the largest majority government in Canadian history in 1984, followed by another convincing, albeit smaller, victory in 1988. The elections of 1993, 1997, and 2000 were all clear Liberal victories

\footnotetext{
${ }^{45}$ The model is tested against a perfectly fit model; which is to say a model that captures all the variance possible. Thus, for example, a p-value of 0.00 shows there is statistical significant difference between the estimated model and a perfectly fit model. The higher the $p$-value the more explanatory power the model has.

${ }^{46}$ https://stats.idre.ucla.edu/stata/faq/what-are-the-saturated-and-baseline-models-in-sem/

${ }^{47}$ The predicted values of latent variables, also known as predicted factor scores, are the expected values of the variables given the values of the observed variables. Stata Structural Equation Modelling Reference Manual, Release 13, A Stata Press Publication StataCorp LP College Station, Texas
} 
where the Liberals held large majorities. The models here show that this period was less competitive than the earlier 1950 s to 1980 s period. The 1980 s were a period of conservative revivalism; whereas the 1990s exhibit fractured right-wing support in Canada and increased reputation of the Liberals. These two parties, traditional rivals and always the others opposition party, did not pose a serious threat to each other for a period of about 20 years. The elections from 2004 until 2011 were much more competitive, with three minority governments in a row an indicator that support between opposition and incumbent parties was split. 
Figure 4: Electoral Competition over Time - Predicted Values

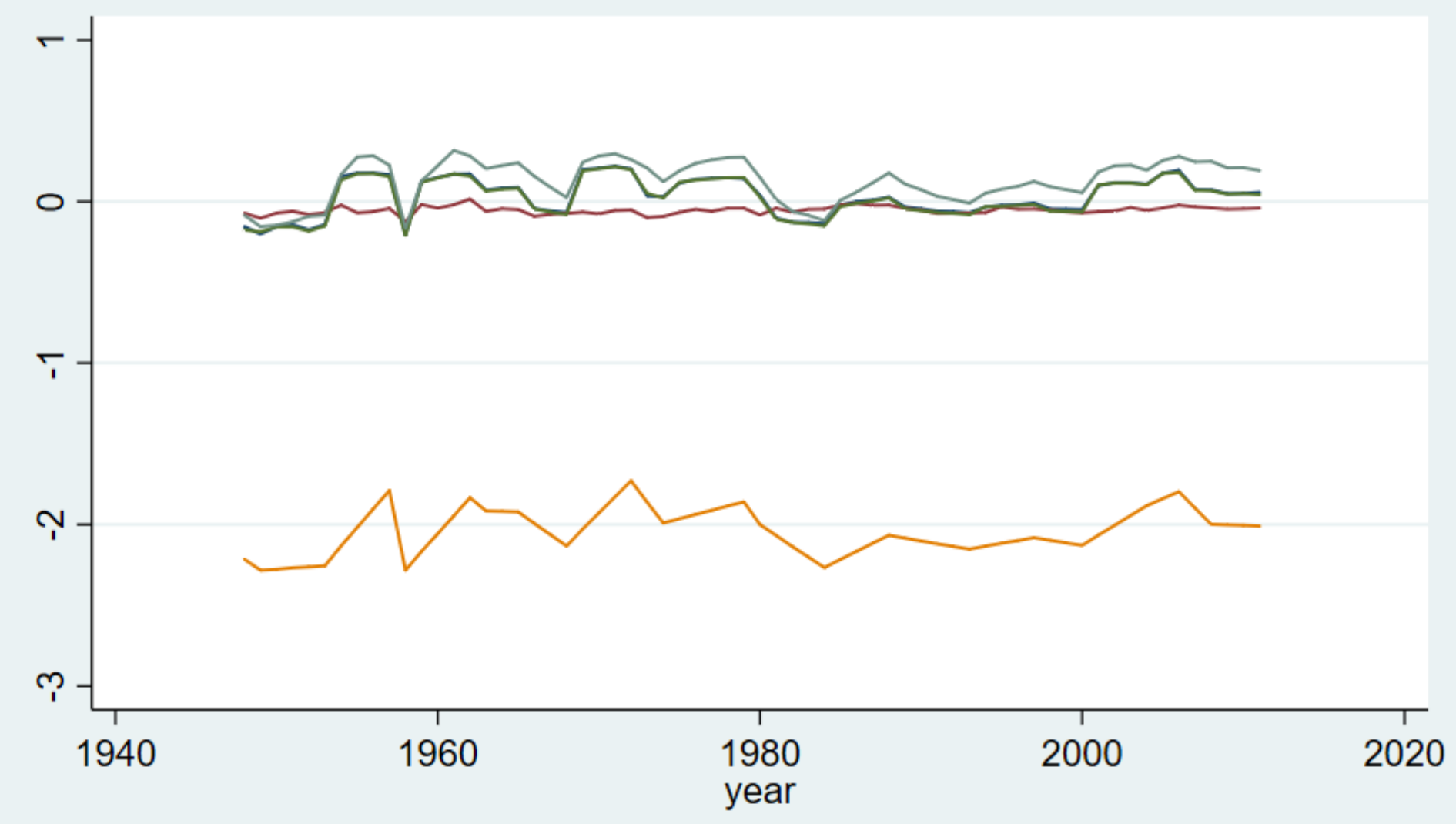

\begin{tabular}{|rr|}
\hline Model 1 & Model 2 \\
Model 3 & Model 4 \\
\hline Model 5 & \\
\hline
\end{tabular}


Figure 5: Electoral Competition over Time-Predicted Values

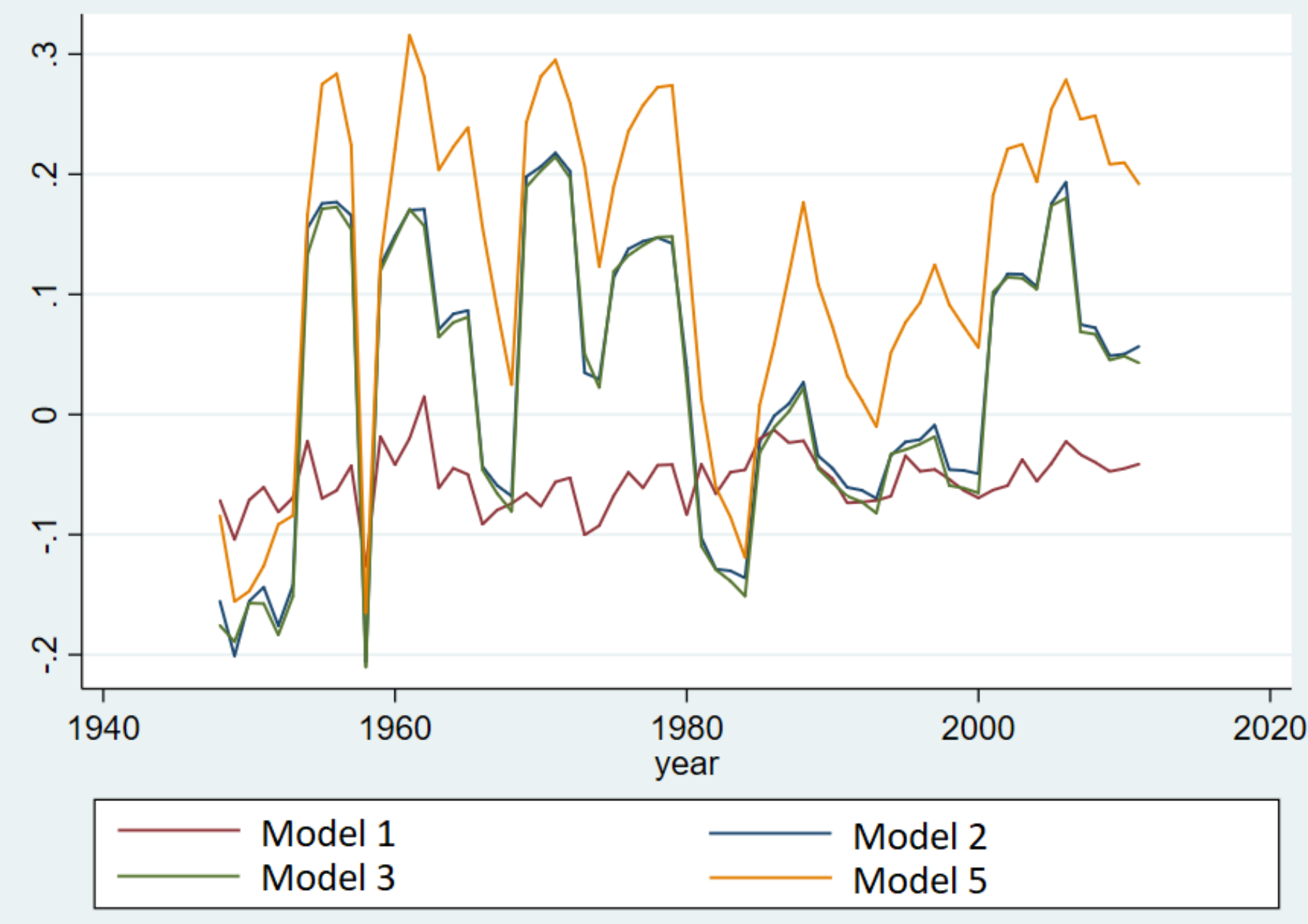


Table 1: Results from MIMIC Model Estimation

\begin{tabular}{|c|c|c|c|c|c|}
\hline \multirow{2}{*}{\multicolumn{6}{|c|}{ Causal Variables }} \\
\hline & & & & & \\
\hline \multirow[t]{2}{*}{ Change in Unemployment Rate } & -2.38 & -1.77 & & -5.05 & -3.61 \\
\hline & $(-0.76)$ & $(-0.64)$ & & $(-2.72)^{* * *}$ & $(-1.72)^{*}$ \\
\hline \multirow[t]{2}{*}{ Real GDP Per Capita Growth Rate } & -0.63 & 0.58 & 0.76 & -1.05 & \\
\hline & $(-0.78)$ & $(0.53)$ & $(1.05)$ & $(-1.34)$ & \\
\hline \multirow[t]{2}{*}{ Pension Parameters } & & & & 0.09 & 0.22 \\
\hline & & & & (0.99) & $(2.31)^{* *}$ \\
\hline \multirow[t]{2}{*}{ Change in Pension Parameters } & -0.01 & -0.21 & -0.34 & & \\
\hline & $(-0.16)$ & $(-1.28)$ & $(-1.94)^{*}$ & & \\
\hline \multirow[t]{2}{*}{ Canadian Inflation Rate } & 0.00 & 0.00 & & 0.01 & \\
\hline & $(0.00)$ & $(0.22)$ & & $(2.64)^{* * *}$ & \\
\hline \multirow[t]{2}{*}{ Government Spending Growth Rate, T-1 } & 0.08 & -0.20 & 0.15 & & \\
\hline & $(0.73)$ & $(-0.65)$ & $(0.79)$ & & \\
\hline \multirow[t]{2}{*}{ Government Spending Growth Rate, T-2 } & -0.02 & 0.21 & & -0.24 & \\
\hline & $(-0.41)$ & (0.99) & & $(-1.54)$ & \\
\hline \multirow[t]{2}{*}{ Percentage Turnout } & & & & -0.01 & \\
\hline & & & & $(-4.21)^{* * *}$ & \\
\hline \multirow[t]{2}{*}{ Average Electors } & & & & 0.00 & \\
\hline & & & & $(4.86)^{* * *}$ & \\
\hline \multirow[t]{2}{*}{ Change in Average Electors } & 0.00 & 0.00 & & & \\
\hline & $(-0.72)$ & (1.13) & & & \\
\hline \multirow[t]{2}{*}{ Percent Voters Registered } & & & & -0.02 & \\
\hline & & & & $(-6.57)^{* * *}$ & \\
\hline \multirow[t]{2}{*}{ Change in Percent Voters Registered } & -0.01 & -0.02 & & & \\
\hline & $(-0.78)$ & $(-1.8)^{*}$ & & & \\
\hline \multirow[t]{2}{*}{ Change in Openness } & 0.00 & & & & \\
\hline & $(-0.49)$ & & & & \\
\hline \multirow[t]{2}{*}{ Immigration Ratio } & -0.05 & & & & \\
\hline & $(-0.78)$ & & & & \\
\hline \multicolumn{6}{|l|}{ Indicator Variables } \\
\hline Splinter Index, Historical & 1.00 & 1.00 & 1.00 & & 1.00 \\
\hline \multirow[t]{2}{*}{ Loss Probability Ratio, Kayser Lindstadt, T-1 } & & 1.29 & 1.28 & 0.99 & 0.94 \\
\hline & & $(4.39)^{* * *}$ & $(4.41)^{* * *}$ & $(10.23)^{* * *}$ & $(4.09)^{* * *}$ \\
\hline \multicolumn{2}{|l|}{ Loss Probability Ratio, Kayser Lindstadt } & & & 1.00 & \\
\hline \multirow[t]{2}{*}{ Effective Number of Parties } & & & & 0.35 & 0.33 \\
\hline & & & & $(3.87)^{* * *}$ & $(3.23)^{* * *}$ \\
\hline \multirow[t]{2}{*}{ Swing Ratios, Dickson } & 7.34 & 1.48 & 1.48 & & 1.32 \\
\hline & $(0.78)$ & $(3.51)^{* * *}$ & $(3.75)^{* * *}$ & & $(3.64)^{* * *}$ \\
\hline \multirow[t]{2}{*}{ Loss Probability Ratio, Historical } & & & & 1.04 & \\
\hline & & & & $(40.83)^{* * *}$ & \\
\hline \multirow[t]{2}{*}{ Pzeworski Sprague, Local Volatility } & -0.02 & & & 0.04 & \\
\hline & $(-0.15)$ & & & (1.29) & \\
\hline Change in the ENP Ratio & -0.44 & -0.06 & -0.06 & & \\
\hline & $(-0.76)$ & $(-2.99)^{* * *}$ & $(-3.13)^{* * *}$ & & \\
\hline Adjusted Marginal Seats & 0.43 & & & & -0.03 \\
\hline & $(0.4)$ & & & & $(-0.54)$ \\
\hline Model Fit & & & & & \\
\hline Chi, P-Value & 0.00 & 0.01 & 0.64 & 0.00 & 0.06 \\
\hline
\end{tabular}

$* * *(* *)[*]$ significant at $1(5)$ and [10] percent 


\section{Conclusion}

A novel general index of political competition has been created showing the impact of socio-economic causal variables. Indicator variables have shown to be meaningful and highly statistically significant. The hypothesized significance of the Pzeworski-Sprague and adjusted marginal seats indexes were not as expected but the impact of other measures of competition were significant and impactful.

The general political competition index is sensitive to the fixed indicator variable and, ceteris paribus, more parsimonious models are shown to be more significant overall.

Political competition in Canada can be summarized in three periods. The first period is a period of high competition, from the 1950s to the early 1980s. The second period is a period of low competition that last from the mid 1980s to the early 2000 s. The third period, from the early 2000 s to the 2015 election, is a period of high competition.

The causal variables of competition in the significant models are the unemployment rate, the pension parameters, the growth rate of income, and the growth rate of government spending. Many indicators of political competition were important for describing different elements of political competition. The Loss Probability Ratios (and derivatives of this variable) are consistently significant and are important in statistically significant models. The effective number of parties and the Dickson swing ratio are also important in terms of their significance and contribution to the statistically significant models. 


\section{Bibliography}

Abramowitz, A. (1988). An improved model for predicting presidential election outcomes. Political Science , 843-847.

Abramowitz, A. (1996). Bill and Al's excellent adventure: forecasting the 1996 presidential election. Am. Polit. Q. , 434-442.

Adsera, A., Boix, C., \& Payne, M. (2003). Are you being served? Political accountability and quality of government. Journal of Law, Economics \& Organization .

Aigner, D., Schneider, F., \& Ghosh, D. (1988). Me and my shadow: estimating the size of the US hidden economy from time series data. Cambridge (Mass.): Cambridge University Press, pp. 224243.

Aitchison, J. R. (2003). The statistical analysis of compositional data. Caldwell, NJ: The Blackburn Press.

Akerman, J. (1947). Political economic cycle. Kyklos , 107-117.

Alesina, A., Londregan, J., \& Rosenthal, H. (1993). A model of the political economy of the United States. American Political Science Review , 12-33.

Anderson, C. J. (2007). The End of Economic Voting? Dilemmas and the Limits of Democratic Accountability. Annual Review of Politcal Science .

Anderson, C., \& O'Connor, K. (2000). System change, learning, and public opinion about the economy. British Journal of Political Science , 147-172.

Anderson, G. M., \& Tollison, R. D. (1991). Congressional Influence and Patterns of New Deal Spending. Journal of Law and Economics , 161-75.

Ansolabehere, S., Snyder, J., \& Stewart, C. (2001). Candidate Positioning in U.S. House Elections. American Journal of Political Science. June, 77 , 1673-704.

Arcelus, F., \& Meltzer, A. (1975). The effect of economic variables on congressional elections. Amer. Pol. Sci. Rev , 1232-1239.

Balke, N. S. (1990). The Rational Timing of Parliamentary Elections. Public Choice , 65:201-16.

Bartolini, S., \& Mair, P. (1990). Identity, Competition, and Electoral Availability: The Stability of European Electorates. Cambridge: Cambridge University Press.

Basinger, S., \& Lavine, H. (2005). Ambivilance, information, and electoral choice. American Political Science Review , 749-767.

Baumol, W. J. (1982). Contestable markets: An uprising in the theory of industry structure. American Economic Review , 1-15.

Belsey, T., \& Case, A. (1995). Does political accountability affect economic policy choices? Quarterly Journal of Economics , 37:245-26. 
Berlinksi, S., Dewan, T., \& Dowding, K. (2007). The Length of Ministerial Tenure in the United Kingdom 1945-97. British Journal of Political Science , 37:245-26.

Besley, T., \& Burgess, R. (2002). The Political Economy of Government Responsiveness: Theory and Evidence from India. The Quarterly Journal of Economics , 389-430.

Besley, T., \& Coate, S. (2003). Centralized versus decentralized provision of local public goods: a political economy approach. Journal of Public Economics , 2611- 2637.

Besley, T., Persson, T., \& Sturm, D. M. (2010). Political Competition, Policy and Growth: Theory and Evidence from the US. Review of Economic Studies , 77, 1329-1352.

Bodet, M. A. (2014). Strongholds and Battlegrounds: Measuring Party Support Stability in Canada. Canadian Journal of Political Science , 46(3): 575-596.

Box-Steffensmeier, J., \& Jones, B. (1997). Time is of the essence: event history models in political science. American Journal of Political Scince , 156-161.

Boyne, G. (1998). Party Competition and Local Spending Decisions. British Journal of Political Science, $185-222$.

Breusch, T. (2005). Estimating the Underground Economy, Using MIMIC Models. Working Paper. National University of Australia, Canberra, Australia.

Brian F. French, W. H. (2013). Extensions of Mantel-Haenszel for Multilevel DIF Detection. Educational and Psychological Measurement .

Buehn, A., \& Schneider, F. G. (2008). MIMIC models, cointegration and error correction: an application to the French shadow economy. Cesifo Working Paper No. 2200.

Buehn, A., \& Schneider, F. (2013). Size and Development of Tax Evasion in 38 OECD Countries: What Do We (not) Know. Johannes Kepler University Working Paper.

C Bajada, F. S. (2005). The shadow economies of the Asia-Pacific. Pacific Economic Review.

Calvo, E. (2009). The competive road to proportional representation. World Politics , 254-95.

Campbell, J. (1996). Polls and votes: the trial-heat presidential election forecasting model, certainty, and political campaigns. Am. Polit. Q. , 408-433.

Campbell, J., \& Wink, K. (1990). Trial-heat forecasts of the presidential vote. Am. Polit. Q. , 251269.

Canes-Wrone, B., Brady, D. W., \& Cogan, J. F. (2002). Out of Step, Out o fOffice: Electoral Accountability and House Members' Voting. American Political Science Review , 96(1):127-40.

Caplan, B. (2008). The Myth of the Rational Voter: Why Democracies Choose Bad Policies. Princeton: Princeton University Press.

Chowdury, A. R. (1997). Political Surfing over Economic Waves: Pariliamentary Election Timing in India. American Journal of Political Science , 110:769-98. 
Chrystal, K., \& Alt, J. (1981). Some problems in formulating and testing a politco-economic model of the United Kingdom. Eonomics Journal , 730-736.

Couch, J. F., \& Shugart, W. F. (1998). The Political Economy of New Deal Spending. Cheltenham, U.K.: Edward Elgar.

Dash, B. B., Ferris, J. S., \& Winer, S. (2019). The measurement of electoral competition, with application to Indian states. Electoral Studies .

Del'Anno, R. (2003). Estimating the shadow economy in Italy: A structural equation approach. Discussion Paper .

Demsetz, H. (1968). Why Regulate Utilities? Journal of Law and Economics , 55-65.

Dewan, T., \& Shepsle, K. A. (2011). Political Economy Models of Elections. Annual Review of Political Science .

Dickson, V. (2009). Seat-vote curves, loyalty effects and the provincial distribution of Canadian government spending. Public Choice, 317-333.

Downs, A. (1957). An economic theory of democracyy. New York: Harper \& Row.

Downs, A. (1957). An economic theory of political action in democracy. Journal of Political Economy , 135-150.

Duverger, M. (1954). Politcal Parties: Their Organization and Activity in the Modern State. Methuen.

Elkins, D. J. (1974). The Measurement of Party Competition'. American Political Science Review, 682-700.

Endersby, J. W., Galatas, S. E., \& Rackaway, C. B. (2002). Closeness COunts in Canada: Voter Participation in the 1993 and 1997 Federal Elections. Journal of Politics , 610-631.

Erikson, R. (1989). Economic conditions and the presidential vote. Am. Polit. Sci. Rev. , 568-573.

Eulau, H., \& Lewis-Beck, M. (1985). Economic Conditions and Electoral Outcomes in the United States and Western Europe. New York: Agathon.

Eun Sook Kim, M. Y.-m. (2015). Within-Level Group Factorial Invariance With Multilevel Data: Multilevel Factor Mixture and Multilevel MIMIC Models. Structural Equation Modeling: A Multidisciplinary Journal .

Fair, R. (1978). The effect of economic events on votes for president. Rev. Econ Stat. , 159-173.

Ferris, J. S., \& Voia, M.-C. (2013). Do business cycle peaks predict election calls in Canada? European Journal of Political Economy .

Ferris, J. S., \& Voia, M.-C. (2009). What Determines the Length of a Typical Canadian Parliamentary Government. Canadian Journal of Political Science , 881-910. 
Ferris, J., Winer, S., \& Grofman, B. (2016). The Duverger-Demsetz Perspective on Electoral Competitiveness and Fragmentation: With Application to the Canadian Parliamentary System, 1867 - 2011. In The Political Economy of Social Choices (pp. 93-122). Springer.

Frey, B. a.-H. (1984). The Hidden Economy as an 'Unobserved Variable'. European Economic Review.

Frey, B. S., \& Weck, H. (1983). Estimating the Shadow Economy: A 'Naive' Approach. Oxford Economic Papers , 23-44.

Frey, B., \& Garbers, H. (1971). Einfluss wirtschaftlicher Variabler auf die Popularitatder Regierung: Eine empirische Analyse. Jahrb. Natl. ok" on. Stat. , 281-295.

Frey, B., \& Schneider, F. (1978). A Politico-Economic Model of the United Kingdom. Economics Journal , 243-253.

Gaines, B. J., \& Taagepera, R. (2013). How to operationalize "two partyness". Journal of Election, Public Opinion and Parties .

Gelman, A., \& King, G. (1994). A unified method of evaluating electoral systems and redistricting plans. American Journal of Political Science , 38:514-54.

Gelman, A., \& King, G. (1990). Estimating incumbency advantage without bias. American Journal of Political Science , 34:1142-64.

Gelman, A., \& King, G. (1990). Estimating the electoral consequences of legislative redistricting. Jounral of the American Statistical Association , 274-82.

Giles, D. E. (1999). Modelling the Hidden Economy and the Tax-Gap in New Zealand. Empirical Economics , 621-40.

Golden, M., \& Min, B. (2013). Distributive Politics Aroun the World. Annual Reviews of Political Science, 73-99.

Goodhart, C., \& Bhansali, R. (1970). Political Economy.

Goodman, S., \& Kramer, G. (1975). Comment on Arcelus and Meltzer, the effect of aggregate economic conditions on congressional elections. Amer. J. of Pol. Sci. , 1255-1265.

Grofman, B. (2016). Perspectives on the Comparative Study of Electoral Systems. Annual Review of Political Science.

Grofman, B., \& Selb, P. (2009). A fully general index of political competition. Electoral Studies, 28: 291-296.

Gudgin, G., \& Taylor, P. (2012). Seats, votes, and the spatial organisation of elections. ECPR Press.

Hartle, D. (1985). Achieving Electoral Success in a Multi-Constituency System Through Discriminatory Parties. Unpublished, Economic Council of Canada . 
Hartley, K. (1987). Reducing Defence Expenditure: A Public Choice Analysis and a Case Study of the UK. Peace, Defence and Economic Analysis , 399-423.

Hassan, M., \& Schneider, F. (2016). Size and Development of the Shadow Economies of 157 Countries Worldwide: Updated and New Measures from 1999 to 2013. IZA Discussion Paper No. 10281 .

Hibbs, D. (1982). President Reagan's mandate from the 1980 elections: a shift to the right? Am. Polit. Q. , 387-420.

Holbrook, T., \& Garand, J. (1996). Homo economus? Economic information and economic voting. Polit. Res. Q. , 49:351-75.

Huber, J., \& Martinez-Gallardo, C. (2008). Replacing Cabinet Ministers: Patterns of Ministerial Stability in Parliamentary Democracies. American Political Science Review , 102:169-80.

Inogushi, T. (1981). Explaining and Predicting Japanese General Elections, 1960-1980. Journal of Japanese Studies , 7:255-318.

Ito, T. (1990). The Timing of Elections and Political Business Cycles in Japan. Journal of Asian Economics , 1:135-56.

Jackman, S. (1994). Measuring Electoral Bias: Australia. British Journal of Political Science , 24:319-57.

Joreskog, K. G. (1973). Analysis of Covariance Structures. New York: Academic Press.

Joreskog, K. G., \& Goldberger, A. S. (1975). Estimation of a Model with Multiple Indicators and Multiple Causes of a Single Latent Variable. Journal of the American Statistical Association , 631639.

Kam, C., \& Indridason, I. (2005). The Timing of Cabinet Reshuffles in Five Westminster Parliamentary Systems. Legislative Studies Quarterly , 30:327-63.

Kaplan, E. L., \& Meier, P. (1958). Nonparametric Estimation from Incomplete Observationsa. Journal of the American Statistical Association , 457-481.

Kayser, M. A., \& Lindstadt, R. (2015). A Cross-National Measure of Electoral Competitiveness. Political Analysis , 242-253.

Kayser, M. (2005). Who Surfs, Who Manipulates? The Determinants of Opportunistic Election Timing and Electorally Motivated Economic Intervention. American Political Science Review, 99:17-27.

Kendall, M., \& Stuart, A. (1950). The Law of the Cubic Proportion in Election Results. The British Journal of Sociology , 183-196.

Key, V. (1966). The Responsible Electorate. New York: Vintage Books. 
Kiewiet, D., \& Udell, M. (1998). Twenty-five Years after Kramer: An Assessment of Economic Retrospective Voting based upon Improved Estimates of Income and Unemployment. Economics \& Politics , 219-248.

King, G. (1990). Electoral responsiveness and partisan bias in multiparty democracies. Legis/ative Studies Quarterly , 15:159-81.

King, G., Alt, J., Burns, N., \& Laver, M. (1990). A Unified Model of Cabinet Dissolution in Parliamentary Democracies. American Journal of Political Science , 34:846-71.

Kneebone, R., \& McKenzie, K. (n.d.). Electroal and partisan cycles in fiscal policy: An examination of Canadian provinces.

Kneebone, R., \& McKenzie, K. (1999). Past (in)discretions: Canadian federal and provincial fiscal policy. Toronto: University of Toronto Press.

Kramer, G. (1971). Short-term fluctuations in U.S. voting behaviour, 1896-1964. American Political Science Review , 131-143.

Laakso, M., \& Taagepera, R. (1979). Effective number of parties: a measure with application to West Europe. Comparative Political Studies , 12, 3-28.

Larcinese, V., Rizzo, L., \& Testa, C. (2006). Allocating the U.S. Federal Budget to the States: The Impact of the President. Journal of Politics , 447-456.

Lewis-Beck, M. S. (1977). The Relative Importance of Socioeconomic and Political Variables for Public Policy. The American Political Science Review , 71, 559-566.

Lewis-Beck, M. S., \& Stegmaier, M. (2000). Economic Determinants of Electoral Outcomes. Annual Review of Political Science, 183-219.

Lewis-Beck, M., \& Rice, T. (1992). Forecasting Elections. Washington, DC: Congressional Quarterly Press.

Lewis-Beck, M., \& Rice, T. (1984). Forecasting U.S. House Elections. Legis. Stud. Q. , 475-486.

Lewis-Beck, M., \& Tien, C. (1996). The future in forecasting: prospective presidential models. Am. Polit. Q. , 468-91.

Lin, D., Banjevic, D., \& Jardine, A. K. (2006). Using principal components in a proportional hazards model with applications in condition-based maintenance. Journal of the Operational Research Society, 57:8, 910-919.

Linzer, D. (2012). The Relationship between Seats and Votes in Multiparty Systems. Politcal Analysis , 400-416.

Loayza, N. (1996). The Economics of the Informal Sector: A Simple Model and Some Empirical Evidence from Latin America. Carnegie-Rochester Conf: Series Public Policy. 45, pp. 129-62. Carnegie-Rochester: World Bank. 
Lupia, A., \& Strom, K. (1995). Coaltion Termination and the Strategic Timing of Parliamentary Elections. American Political Science Review , 89:648-65.

Madhani, P. (2010). Rebalancing Fixed and Variable Pay in a Sales Organization: A Business Cycle Perspective. Compensation \& Benefits Review , 179-189.

Maltritz, D. B. (2012). Modelling country default risk as a latent variable: a multiple indicators multiple causes approach. Applied Economics , 44(36):4679-4688.

Mayhew, D. R. (1974). Congressional elections: the case of the vanishing marginals. Polity , 295317.

Miller, W., \& Mackie, M. (1973). The electoral cycle and the asymmetry of government and the opposition popularity: an alternative model of the relationship between economic conditions and political popularity. Politcal Studies , 263-279.

Mosley, P. (1978). Images of the "floating voter" or the "politcal business cycle" revisted. Political Studies , 375-394.

Mueller, J. (1970). Presidential popularity from Truman to Johnson. American Political Science Review, 18-34.

Niemi, R. G., \& Fett, P. (1986). The Swing Ratio: An Explanation and an Assessment. Legislative Studies Quarterly, 11:75-90.

Nordhaus, W. (1975). The Political Business Cycle. Review of Economic Studies , 169-90.

Norpoth, H. (1996c). Of time and candidates: a forecast for 1996. Am. Polit. Q. , 443-67.

Peffley, M., \& Williams, J. (1985). Attributing presidential responsibility for national economic problems. American Politics Quarterly, 393-425.

Peffley, M., Feldman, S., \& Sigelman, L. (1987). Economic conditions and party competence: process or belief reivision. Journal of Politics , 100-121.

Persson, T., \& Tabellini, G. (2003). Do Electoral Cycles Differ across Political Systems. IGIER Working Paper \#232, Boccini University .

Pinto, P. M., \& Timmons, J. F. (2005). The Political Determinants of Economic Performance: Political Competition and the Sources of Growth. Comparative Political Studies, 38(1), 26-50.

Pissarides, C. (1980). British government popularity and economic performance. Economics Journal , 569-581.

Powell, B. G. (1986). American Voter Turnout in Comparative Perspective. American Political Science Review , 80(1):17-43.

Powell, G. B. (200). Elections as Instruments of Democracy: Majoritarian and Proportional Visions. Yale, Connecticut: Yale University Press.

Przeworski, A. (2010). Democracy and the Limits of Self-Government. Cambridge: Cambridge University Press. 
Przeworski, A. (2016). Democracy: A Never-Ending Quest. Annual Review of Political Science . Przeworski, A., \& Sprague, J. (1971). Concepts in Search of an Explicit Formulation: A Study in Measurement. Midwest Journal of Political Science , 183-218.

Puddington, A., Piano, A., Eiss, C., \& Roylance, T. (2007). Freedom in the World: The Annual Survey of Political Rights and Civil Liberties. Freedom House.

R. M. Hauser, A. S. (1971). The Treatnebt of Unobservable Variable in Path Analysis. Sociological Methodology .

Rae, D. (1971). The Political Consequences of Electoral Laws. New Haven: Yale University Press.

Rogoff, K., \& Sibert, A. (1988). Elections and macroeconomic policy cycles. Review of Economic Studies , 91:1-16.

Rogowski, R., \& Kayser, M. A. (2002). Majoritarian Electoral Systems and Consumer Power: Price-Level Evidence from the OECD Countries. American Journal of Political Science , 46(3):52639.

Rubin, P. (2019). The Capitalism Paradox: How Cooperation Enables Free Market Competition. Bombardier Books.

Rudolph, T. J. (2003). Institutional Context and the Assignment of Political Responsibility. Journal of Politics , 190-215.

Schneider, F., \& Enste, D. (2002). The Shadow Economy. An International Survey. Cambridge University Press.

Schneider, F., \& Williams, C. (2013). The Shadow Economy. The Institute of Economic Affairs, IEA. London, UK.

Schneider, F., Buehn, A., \& Montenegro, C. E. (2010). New Estimates for the Shadow Economies all over the World. International Economic Journal .

Selb, P. (2009). A Deeper Look at the Proportionality-Turnout Nexus.". Comparative Political Studies , 42(4):527-48.

Smith, A. (2003). Election Tming in Majoritarian Parliaments. British Journal of Poltical Science, 33:397-18.

Smith, A. (1996). Endogenous Election Timing in Majoritarian Parliamentary Systems. Economics and Politics , 8:85-110.

Splinter, J. (2017). Economic Indicators and the Probability of Electoral Defeat.

Stapleton, D. C. (1978). Analyzing Political Participation Data with a MIMIC Mmodel. In Sociological Methodology. San Francisco, CA: K. F. Schuessler.

Stigler, G. (1973). General economic conditions and national elections. American Economic Review , 1960-1967. 
Strom, K. (1989). Inter-party Competition in Advanced Democracies. Journal of Theoretical Politics .

Strom, K., \& Swindle, S. (2002). Strategic Parliamentary Dissolution. American Political Science Review , 96:575-91.

Taagepera, R. (1986). Reformulating the cuve law for proportional representation elections. The American Political Science Review , 489-504.

Taagepera, R., \& Shugart, M. (1989). Seats and votes: The effects and determinants of electoral systems. New Haven: Yale University Press.

Tedds, D. E. (2002). Taxes and the Canadian Underground Economy. Toronto: Canadian Tax Foundation.

Thiel, H. (1969). The desired politcal entropy. The American Political Science Review , 521-525.

Tufte, E. (1975). Determinants of the outcomes of midterm elections. . Amer. Pol. Sci. Rev. , 812826.

Tufte, E. (1978). Political Control of the Economy. Princeton, NJ: Princeton University Press.

Tvinnereim, E. (2004). Democratic Contestation and Citizen Satisfaction in German States. Unpublished Manuscript (http://socsci2.ucsd.edu/ aronatas/scrretreat/Tvinnereim. Endre.pdf) .

Voia, M.-C., \& Ferris, J. S. (2013). Do business cycle peaks predicit election calls in Canada? European Journal of Political Economy , 102-118.

Watt, D. (1968, March). Labour's hard road to recovery. Fin. Times , p. 8:15.

Weck, H. (1983). Eine Möglichkeit zur Einschränkung der öffentlichen Verwaltung? Eine ökonomische Analyse. Frankfurt.

Whiteley, P. (1986). Macroeconomic performance and government popularity in Britain: the short-run dynamics. Eur. J. Polit. Res. , 45-61.

Winer, S. L., Ferris, J. S., \& Grofman, B. (2014). On the Measurement of Electoral Competitiveness: With Application to Canada, 1867-2011. Unpublished working paper .

Wlezien, C., \& Erikson, R. (1996). Temporal horizons and presidential election forecasts. Am. Polit. Q. , 24:492-505.

Woods, C. M. (2008). Empirical Selection of Anchors for Tests of Differential Item Functioning. Applied Psychological Measurement .

Wright, G. (1974). The Political Economy of New Deal Spending:An Econometric Analysis. Review of Economics and Statistics , 30-38.

Yang, X. S. (2005). Qualitative or Quantitative Differences? Latent Class Analysis of Mathematical Ability for Special Education Students. The Journal of Special Education , 38(4), 194-207. 
Zellner, A. (1970). Estimation of Regression Relationships Containing Unobservable Variables. International Economic Review , 441-454. 


\section{Data Sources:}

Ferris/ Winer: Canadian Electoral Data set, Elections 1-42,1867-2015, forthcoming at www.carleton.ca/winer

Ferris/Winer: Canadian Economic and Fiscal Data Set, 1867-2015, forthcoming at www.carleton.ca/winer 


\section{Appendix A: The Linzer (2012) method for calculating swing- ratios.}

1. Starting with the first pattern of contestation, select one of the $R_{m}$ components distributions by sampling once from a multinomial distribution with probabilities $\hat{\pi}^{m}$.

2. Draw $\tilde{Y}_{j}$ from the selected component distributions to create a hypothetical district characterized by the number of votes cast, $\tilde{z}_{j}$, and $P_{m}-1$ log of vote-ratios, $\tilde{\lambda}_{j 2}$ $, \tilde{\lambda}_{j 3}, \ldots$

3. Repeat this process until each pattern of contestation has $N_{m}$ simulated districts.

4. Stack the $D^{c}$ simulated districts across all patterns of contestation.

5. Transform the party log of vote-ratios back into units of party vote-shares, such that $\tilde{v}_{j p}=\frac{e^{\tilde{\lambda}_{j p}}}{\sum_{q=1}^{P_{m}} e^{\tilde{\lambda}_{j q}}}$ within each district. Since party one was chosen as the reference party, $\tilde{\lambda}_{j 1}=0$ by definition. If a party did not compete in the $m^{\text {th }}$ pattern of contestation, its vote share is set to zero.

6. Multiply together the simulated district sizes and party vote-shares, $\tilde{z}_{j} \tilde{v}_{j p}$, to find the hypothetical number of votes cast for each party in each contested district. This accounts for malapportionment.

7. Calculate parties' simulated national-level vote shares, $\tilde{V}_{p}$, by dividing their simulated vote total, $\sum_{j=1}^{D^{c}} \tilde{z}_{j} \tilde{v}_{j p}$, by the simulated number of votes cast for all parties, $\sum_{j=1}^{D^{c}} \tilde{z}_{j}$

8. Calculate parties' simulated national-level seat shares, $\tilde{S}_{p}$, as the number of hypothetical districts in which the party received a plurality of votes, plus the number of districts (set aside from above) in which the party ran unopposed, divided by $D$. 


\section{Appendix B: Swing-ratios}

\begin{tabular}{|c|c|c|c|c|c|c|c|c|c|c|}
\hline Election & $\mathrm{BQ}$ & Conservative & Labour & Liberal & NDP & Other & Progressive & Reform/Alliance & Real Cred. & Social Credit \\
\hline 1 & & 0.42 & & 0.21 & & 0.81 & & & & \\
\hline 2 & & 0.51 & & 0.28 & & 0.37 & & & & \\
\hline 3 & & 0.37 & & 0.28 & & 0.38 & & & & \\
\hline 4 & & 0.84 & & 0.5 & & 0.3 & & & & \\
\hline 5 & & 1.03 & & 0.38 & & 0.16 & & & & \\
\hline 6 & & 1.69 & & 1.17 & & 0.02 & & & & \\
\hline 7 & & 1.71 & & 1.74 & & 0.47 & & & & \\
\hline 8 & & 3.06 & & 2.89 & & 0.57 & & & & \\
\hline 9 & & 2.92 & & 2.92 & & & & & & \\
\hline 10 & & 2.3 & & 2.05 & & 0.32 & & & & \\
\hline 11 & & 1.63 & & 1.64 & & & & & & \\
\hline 12 & & 2.7 & & 2.35 & & & & & & \\
\hline 13 & & 1.22 & 0.01 & 1.31 & & & & & & \\
\hline 14 & & 1.53 & 0.47 & 1.44 & & 0.43 & 1.24 & & & \\
\hline 15 & & 2.69 & & 2.67 & & 0 & 0.81 & & & \\
\hline 16 & & 2.69 & & 2.67 & & 0 & 0.81 & & & \\
\hline 17 & & 3.35 & & 3.37 & & 0.33 & & & & \\
\hline 18 & & 2.23 & & 2.38 & 1.26 & 0.51 & & & & 2.27 \\
\hline 19 & & 1.55 & & 1.72 & 1.1 & 0.99 & & & & \\
\hline 20 & & 2.07 & & 2.21 & 1.51 & 0.64 & & & & 1.77 \\
\hline 21 & & 1.49 & & 1.93 & 0.92 & 0.7 & & & & 1.69 \\
\hline 22 & & 1.81 & & 2.18 & 1.3 & & & & & 1.45 \\
\hline 23 & & 2.26 & & 2.09 & 1.29 & 0 & & & & 1.42 \\
\hline 24 & & 2.22 & & 1.54 & 0.91 & & & & & 0.56 \\
\hline 25 & & 2.6 & & 2.46 & 1.19 & & & & & 1.38 \\
\hline 26 & & 2.01 & & 2.06 & 0.88 & & & & & 1.26 \\
\hline 27 & & 1.7 & & 2.11 & 1.07 & & & & 1.21 & 0.94 \\
\hline 28 & & 2.08 & & 2.46 & 1.3 & & & & 1.79 & \\
\hline 29 & & 2.3 & & 2.78 & 1.58 & & & & & 1.08 \\
\hline 30 & & 2.17 & & 2.64 & 1.16 & & & & & 1.19 \\
\hline 31 & & 2.06 & & 2.15 & 1.47 & & & & & 0.69 \\
\hline 32 & & 2.2 & & 2.19 & 1.67 & & & & & 0.33 \\
\hline 33 & & 2.18 & & 1.64 & 1.52 & & & & & \\
\hline 34 & & 2.93 & & 2.62 & 1.88 & & & 0.35 & & \\
\hline 35 & 1.26 & 0.54 & & 2.12 & 1.29 & & & 2.08 & & \\
\hline 36 & 1.99 & 1.33 & & 2.51 & 1.39 & & & 2.14 & & \\
\hline 37 & 1.91 & 1.29 & & 2.51 & 1.09 & & & 1.99 & & \\
\hline 38 & 1.7 & 2.4 & & 2.7 & 1.49 & & & & & \\
\hline 39 & 1.95 & 2.38 & & 2.41 & 1.83 & & & & & \\
\hline 40 & 1.94 & 2.22 & & 2.09 & 1.85 & 0.17 & & & & \\
\hline 41 & 0.83 & 1.92 & & 1.6 & 2.03 & & & & & \\
\hline
\end{tabular}


Appendix C: Correlation Matrix of the Measures of Political Competition

\begin{tabular}{|c|c|c|c|c|c|c|}
\cline { 2 - 7 } \multicolumn{1}{c|}{} & AMS & ENP & PS & LPR & Seats & Splinter \\
\hline AMS & 1 & & & & & \\
\hline ENP & 0.07 & 1 & & & & \\
\hline PS & -0.16 & 0.05 & 1 & & & \\
\hline LPR & -0.08 & 0.33 & 0.06 & 1 & & \\
\hline Seats & 0.16 & -0.37 & -0.10 & -0.69 & 1 & \\
\hline Splinter & 0.15 & -0.25 & -0.24 & -0.81 & 0.59 & 1 \\
\hline
\end{tabular}




\section{Appendix D: American Variables}

The Cox $\mathrm{PH}$ regressions in the main section were all done again using American variables to try to see if the statistical correlations still existed without any chance of endogeneity. While previous work of Ferris \& Voia (2013) suggests endogeneity may not be a problem, it is a prudent to examine the effect that the American variables have in lieu of the Canadian variables.

In table A1 we see that the variables were generally not significant. While the Canadian and American variables are correlated with each other, they do not have the same explanatory power. The only variable to show some significance that was uniquely American, was the American unemployment rate, as seen in models 4 though 8 . Every model that included a measure of competition showed competition to be statistically significant. Model 6 stood out as having the highest log-likelihood value. It is of note that the LPR variable was close to a value of one in each regression and had opposite sign values depending on the model. This is both internally inconsistent and inconsistent with the results from the Canadian variable regression. 
Table A1: American Variable Results, $\exp \beta$ estimates (Robust Huber/White z values in brackets below estimates)

\begin{tabular}{|c|c|c|c|c|c|c|c|c|c|}
\hline $\begin{array}{c}\text { Variable } \\
\text { Type }\end{array}$ & Covariates & Model 1 & Model 2 & Model 3 & Model 4 & Model 5 & Model 6 & Model 7 & Model 8 \\
\hline \multirow[t]{13}{*}{ Economic } & UR & $\begin{array}{c}0.99 \\
(-0.83)\end{array}$ & $\begin{array}{c}0.99 \\
(-1.09)\end{array}$ & $\begin{array}{c}0.99 \\
(-0.62)\end{array}$ & & & & & \\
\hline & UR (1) & $\begin{array}{c}1.01 \\
(0.80)\end{array}$ & $\begin{array}{c}1.00 \\
(-0.38)\end{array}$ & $\begin{array}{c}1.01 \\
(0.85)\end{array}$ & $\begin{array}{c}1.02 \\
(1.44)\end{array}$ & $\begin{array}{c}1.01 \\
(1.39)\end{array}$ & $\begin{array}{l}1.01^{*} \\
(1.65)\end{array}$ & $\begin{array}{c}1.01 \\
(1.47)\end{array}$ & $\begin{array}{l}1.02 * \\
(1.86)\end{array}$ \\
\hline & UR (2) & $\begin{array}{c}0.56 \\
(-0.70)\end{array}$ & & $\begin{array}{c}0.98 \\
(1.49)\end{array}$ & $\begin{array}{l}0.98^{*} \\
(-1.79)\end{array}$ & $\begin{array}{l}0.98^{*} \\
(1.65)\end{array}$ & $\begin{array}{c}0.99 \\
(-1.45)\end{array}$ & $\begin{array}{l}0.99 * \\
(-1.68)\end{array}$ & $\begin{array}{l}0.97 * * \\
(-2.08)\end{array}$ \\
\hline & UR (3) & & & & $\begin{array}{c}1.00 \\
(0.15)\end{array}$ & $\begin{array}{c}1.00 \\
(0.17)\end{array}$ & & & $\begin{array}{c}1.00 \\
(0.31)\end{array}$ \\
\hline & Inflation(1) & & $\begin{array}{c}1.15 \\
(0.29)\end{array}$ & $\begin{array}{c}0.84 \\
(-0.40)\end{array}$ & $\begin{array}{c}1.00 \\
(0.00)\end{array}$ & $\begin{array}{c}0.92 \\
(-0.25)\end{array}$ & $\begin{array}{c}0.84 \\
(-0.97)\end{array}$ & $\begin{array}{c}0.80 \\
(-1.57)\end{array}$ & $\begin{array}{c}0.86 \\
(-0.45)\end{array}$ \\
\hline & Inflation(2) & $\begin{array}{c}0.99 \\
(-0.05)\end{array}$ & $\begin{array}{c}1.00 \\
(-0.01)\end{array}$ & $\begin{array}{c}1.53 \\
(1.45)\end{array}$ & & & & & \\
\hline & G & & & $\begin{array}{c}0.92 \\
(-0.42)\end{array}$ & $\begin{array}{c}0.91 \\
(-0.53)\end{array}$ & $\begin{array}{c}0.93 \\
(0.41)\end{array}$ & & & $\begin{array}{c}0.97 \\
(-0.17)\end{array}$ \\
\hline & $\mathrm{G}(1)$ & & $\begin{array}{c}1.14 \\
(1.36)\end{array}$ & & & & & & \\
\hline & Real GDP pc & $\begin{array}{c}0.88 \\
(-0.48)\end{array}$ & $\begin{array}{c}0.95 \\
(-0.19)\end{array}$ & $\begin{array}{c}1.02 \\
(0.05)\end{array}$ & $\begin{array}{c}1.85 \\
(1.12)\end{array}$ & & & & \\
\hline & Real GDP pc (1) & $\begin{array}{l}1.15 \\
(0.47)\end{array}$ & $\begin{array}{c}0.98 \\
(-0.08)\end{array}$ & $\begin{array}{c}1.66 \\
(0.84)\end{array}$ & & $\begin{array}{c}1.65 \\
(0.85)\end{array}$ & $\begin{array}{c}1.25 \\
(0.58)\end{array}$ & $\begin{array}{c}1.32 \\
(0.90)\end{array}$ & $\begin{array}{c}2.22 \\
(1.50)\end{array}$ \\
\hline & Real GDP pc (2) & $\begin{array}{c}0.86 \\
(-0.63)\end{array}$ & $\begin{array}{c}0.50 \\
(-1.60)\end{array}$ & $\begin{array}{c}0.69 \\
(-1.02)\end{array}$ & & & & & \\
\hline & Exp. Weight. Gr. & & & & & & & $\begin{array}{c}0.69 \\
(-0.40)\end{array}$ & \\
\hline & D Ln Tax Size & & & & & & $\begin{array}{c}0.00 \\
(-0.83)\end{array}$ & & \\
\hline \multirow[t]{2}{*}{ Incumbent } & Consecutive & & $\begin{array}{c}0.73 \\
(-1.30)\end{array}$ & $\begin{array}{c}0.77 \\
(-0.88)\end{array}$ & $\begin{array}{c}0.66 \\
(-1.35)\end{array}$ & $\begin{array}{c}0.81 \\
(-0.71)\end{array}$ & $\begin{array}{c}1.02 \\
(0.08)\end{array}$ & $\begin{array}{c}0.79 \\
(-0.94)\end{array}$ & $\begin{array}{c}0.70 \\
(-1.26)\end{array}$ \\
\hline & Liberal & & $\begin{array}{c}0.55 \\
(0.92)\end{array}$ & $\begin{array}{c}0.24 \\
(-1.62)\end{array}$ & $\begin{array}{c}0.32 \\
(-1.23)\end{array}$ & $\begin{array}{c}0.51 \\
(-0.64)\end{array}$ & & & $\begin{array}{c}0.25 \\
(1.50)\end{array}$ \\
\hline \multirow[t]{7}{*}{ Competition } & LPR 1 & & $\begin{array}{l}0.95 * * \\
(-2.28)\end{array}$ & $\begin{array}{l}0.95 * * \\
(-2.24)\end{array}$ & & $\begin{array}{l}1.08 * * \\
(2.02)\end{array}$ & $\begin{array}{c}1.08 * * * \\
(3.04)\end{array}$ & $\begin{array}{c}1.07 * * * \\
(2.68)\end{array}$ & \\
\hline & LPR 2 & & & & & & & & \\
\hline & Comp. Index 1 & & & & & & & & $\begin{array}{c}0.98^{*} \\
(-1.74)\end{array}$ \\
\hline & Comp. Index 2 & & & & $\begin{array}{l}0.97 * * \\
(-2.35)\end{array}$ & & & & \\
\hline & $\mathrm{HHI}$ & & & & & $\begin{array}{c}1.03 \\
(0.45)\end{array}$ & & & \\
\hline & $\mathrm{R}^{2}$ & 0.139 & 0.38 & 0.473 & 0.461 & 0.543 & 0.547 & 0.497 & 0.362 \\
\hline & Likelihood Ratio & -47.2 & -47.6 & -42.3 & -42.52 & -40.87 & -37.38 & -41.83 & -44.2 \\
\hline
\end{tabular}

***(**) [*] significant at 1 (5) and [10] percent

\begin{tabular}{llll} 
Covariate & Explanation & Covariate & Explanation \\
\hline \hline UR & Unemployment Rate & LPR & Loss Probability Ratio \\
G & Growth rate of Government Spending & Comp. Index 1 & Index Derived from Loss Probability, Historical \\
Real GDP pc & Growth Rate of Real GDP Per Capita & Comp. Index 2 & Index Derived from Loss Probability, Kayser-Lindstadt \\
Exp. Weight. Gr. & Exponentially Weight Growth & &
\end{tabular}




\section{Excluding the Unemployment Rate}

Quality data with a constant definition of the unemployment rate only goes back until the post-WW2 period. The duration analysis models can be constructed before this period but the unemployment rate must be excluded. My analysis has shown that the unemployment rate is consistently significant and provides a substantial amount of the explanatory power of the model. The results from models 7 and 8 are below using a larger time period, but excluding the unemployment rate.

The models showed less predictive power and the remaining variables show less statistical significance. The pseudo R-Squared is smaller. The LPR in both cases is still statistically significant. 
Table A2: Model 7 With no Unemployment Rate

\begin{tabular}{cccccc}
\hline & Coefficient & Std. Err. & Z Value & P Value & Indicator \\
\hline Consecutive & 1.10 & 0.16 & 0.59 & 0.55 & \\
LPR & 1.03 & 0.01 & 2.29 & 0.02 & $* *$ \\
\hline Inflation (1) & 1.02 & 0.06 & 0.28 & 0.78 & \\
Real GDP pc (1) & 1.03 & 0.08 & 0.34 & 0.73 & \\
D In Tax Size & 0.09 & 3.20 & -0.76 & 0.45 & \\
\hline
\end{tabular}

Log-Likelihood $=-75.76$

Pseudo $R^{2}=0.193$

Table A3:Model 8 With no Unemployment Rate

\begin{tabular}{cccccc}
\hline & Coefficient & Std. Err. & Z Value & P Value & Indicator \\
\hline Consecutive & 1.04 & 0.16 & 0.26 & 0.80 & \\
LPR & 1.04 & 0.02 & 2.74 & 0.01 & $* * *$ \\
Inflation (1) & 1.04 & 0.06 & 0.71 & 0.48 & \\
Real GDP pc (1) & 0.91 & 0.09 & -1.05 & 0.29 & \\
Exp. Weight. Gr. & 1.01 & 0.00 & 1.87 & 0.06 & $*$ \\
\hline
\end{tabular}

Log-Likelihood $=-71.00$

Pseudo $R^{2}=0.263$

***(**) [*] significant at 1 (5) and [10] percent

Covariate Explanation Covariate Explanation

\begin{tabular}{llll}
\hline \hline UR & Unemployment Rate & LPR & Loss Probability Ratio \\
G & Growth rate of Government Spending & Exp. Weight. Gr. & Exponentially Weight Growth \\
Real GDP pc & Growth Rate of Real GDP Per Capita &
\end{tabular}




\section{Appendix E: Error correction method (ECM) for the models to deal with potential cointegration}

The purpose for the error correction method (ECM) developed by Buehn \& Schneider (2008) is correct for errors caused by non-stationary data. Buehn \& Schneider (2008) show that equation (4) will be inconsistent if any of the errors are not stationary.

All the variables used in the 5 models in this paper are stationary. However, each of the models were tested for cointegration regardless using the Augmented Dickey Fuller (ADF) statistic. All models were shown to be cointegrated. As a result of the models being constructed with stationary data, there is no reason for them to be error-corrected. However, the original method for the error correction method for MIMIC models developed by Buehn \& Schneider (2008) was for data that was not transformed by first-differences. In this section I look at altered versions of the models where the first-differenced variables are replaced with their corresponding level-values.

Testing for cointegration in the models is different from standard one-equation tests because the MIMIC model is a type of structural equation modelling that employs multiple equations and hence and involves testing the potential cointegration between all the causal variables and each of the indicator variables.

As seen in Table (A4) below, every model was shown to have statistically significant cointegration. The indicator variables are listed in the columns to signify which equation of the MIMC model was being tested; the causal variables associated with that model number are used as the independent variables in each equation respectively.

Table (A4) is the results from the cointegration tests using the original 5 models. The results from the altered models (first differenced data removed) also showed they were each cointegrated. 
Table (A5) shows the MIMIC model results when no first-differenced variables are included. We see that no models show an overall statistical significance as seen by the model's p-values from the Chi Square test. This shows the importance of first differenced variables explanatory power for the models in the main section. 
Table A4: Z Statistics and P-Values from Augmented Dickey Fuller Test for Cointegration

Indicator Variables

\begin{tabular}{|c|c|c|c|c|c|c|c|c|c|c|c|}
\hline Model & & Splinter & $\begin{array}{l}\text { Change of } \\
\text { ENP }^{+}\end{array}$ & Dickson & $\begin{array}{l}\text { Change of } \\
\text { Przeworski } \\
\& \text { Sprague }^{\dagger+}\end{array}$ & $\begin{array}{l}\text { Adjusted } \\
\text { Marginal } \\
\text { Seats }\end{array}$ & $\begin{array}{c}\text { Loss Probability } \\
\text { Ratio, Kayser } \\
\text { Lindstadt, T-1 }\end{array}$ & $\begin{array}{c}\text { Loss Probability } \\
\text { Ratio, Kayser- } \\
\text { Lindstadt }\end{array}$ & $\begin{array}{c}\text { Loss } \\
\text { Probability } \\
\text { Ratio, His. }^{++}\end{array}$ & $\begin{array}{l}\text { Przeworski } \\
\& \text { Sprague }\end{array}$ & $\begin{array}{c}\text { Effective } \\
\text { Number of } \\
\text { Parties }\end{array}$ \\
\hline \multirow[t]{2}{*}{1} & $Z(t)$ & -4.357 & -5.636 & -3.876 & -5.242 & -3.482 & & & & & \\
\hline & P Value & 0.0026 & 0 & 0.0131 & 0.0001 & 0.0413 & & & & & \\
\hline \multirow[t]{2}{*}{2} & $Z(t)$ & -4.677 & -5.271 & -3.479 & & & -3.419 & & & & \\
\hline & P Value & 0.0008 & 0.0001 & 0.0417 & & & 0.0489 & & & & \\
\hline \multirow[t]{2}{*}{3} & $Z(t)$ & -4.574 & -5.982 & -3.898 & & & -3.86 & & & & \\
\hline & P Value & 0.0011 & 0 & 0.0122 & & & 0.0367 & & & & \\
\hline \multirow[t]{2}{*}{4} & $Z(t)$ & & & & & & -4.175 & -4.001 & -3.881 & -3.971 & -4.221 \\
\hline & P Value & & & & & & 0.0049 & 0.0088 & 0.0129 & 0.0097 & 0.0042 \\
\hline \multirow[t]{2}{*}{5} & $Z(t)$ & -4.875 & & -3.53 & & -4.227 & -4.175 & & & & -4.221 \\
\hline & P Value & 0.0003 & & 0.0362 & & 0.0041 & 0.0049 & & & & 0.0042 \\
\hline
\end{tabular}

† The first difference of the Effective Number of Parties

†† The first difference of the Przeworski \& Sprague Index

††† The loss probability ratio, measured using historical data (See Splinter 2017 for further explanation) 
Table A5: MIMC Model Results, Without First-Differenced Variables

\begin{tabular}{|c|c|c|c|c|c|}
\hline & Model 1b & Model 2b & Model 3b & Model 4b & Model 5b \\
\hline \multicolumn{6}{|l|}{ Causal Variables } \\
\hline \multirow[t]{2}{*}{ Change in Unemployment Rate } & -0.19 & -3.45 & & -1.93 & -0.43 \\
\hline & $(-0.43)$ & $(-3.53) * * *$ & & $(-2.33)^{* *}$ & $(-0.53)$ \\
\hline \multirow[t]{2}{*}{ Real GDP Per Capita Growth Rate } & 0.54 & 0.36 & 0.33 & 0.49 & \\
\hline & $(1.7)^{*}$ & $(0.53)$ & $(0.37)$ & $(0.95)$ & \\
\hline \multirow[t]{2}{*}{ Pension Parameters } & -0.03 & 0.28 & 0.27 & 0.14 & 0.23 \\
\hline & $(-0.71)$ & $(2.03)^{* *}$ & $(2.62)^{* *}$ & $(1.43)$ & $(2.64)^{* * *}$ \\
\hline \multirow{2}{*}{ Canadian Inflation Rate } & 0.00 & 0.00 & & 0.01 & \\
\hline & $(-2.12)^{* *}$ & $(0.55)$ & & $(1.76)^{*}$ & \\
\hline \multirow[t]{2}{*}{ Government Spending Growth Rate, T-1 } & -0.14 & -0.38 & -0.38 & & \\
\hline & $(-1.5)$ & $(-1.68)^{*}$ & $(-1.56)$ & & \\
\hline \multirow[t]{2}{*}{ Government Spending Growth Rate, T-2 } & -0.07 & 0.01 & & -0.12 & \\
\hline & $(-0.85)$ & $(0.03)$ & & $(-0.83)$ & \\
\hline \multirow[t]{2}{*}{ Percentage Turnout } & & & & -0.01 & \\
\hline & & & & $(-1.59)$ & \\
\hline \multirow[t]{2}{*}{ Average Electors } & 0.00 & 0.00 & & 0.00 & \\
\hline & $(3.34)^{* * *}$ & $(7.32)^{* * *}$ & & $(6.09)^{* * *}$ & \\
\hline \multirow{2}{*}{ Percent Voters Registered } & -0.01 & -0.02 & & -0.02 & \\
\hline & $(-2.65)^{* * *}$ & $(-3.41)^{* * *}$ & & $(-4.94) * * *$ & \\
\hline \multirow[t]{2}{*}{ Openness } & 0.00 & & & & \\
\hline & $(-1.05)$ & & & & \\
\hline \multirow{2}{*}{ Immigration Ratio } & 0.05 & & & & \\
\hline & $(1.57)$ & & & & \\
\hline \multicolumn{6}{|l|}{ Indicator Variables } \\
\hline Splinter Index, Historical & 1.00 & 1.00 & 1.00 & & 1.00 \\
\hline \multirow[t]{2}{*}{ Loss Probability Ratio, Kayser Lindstadt, T-1 } & & 0.73 & 0.86 & 1.00 & 1.06 \\
\hline & & $(5.48)^{* * *}$ & $(3.46)^{* * *}$ & $(10.51)^{* * *}$ & $(3.54)^{* * *}$ \\
\hline \multirow[t]{3}{*}{ Loss Probability Ratio, Kayser Lindstadt } & & & & 1.00 & \\
\hline & & & & 0.34 & 0.30 \\
\hline & & & & $(3.9)^{* * *}$ & $(2.83)^{* * *}$ \\
\hline \multirow[t]{2}{*}{ Swing Ratios, Dickson } & 1.51 & 1.13 & 1.26 & & 1.38 \\
\hline & $(2.36)^{* *}$ & $(3.81)^{* * *}$ & $(3.22)^{* * *}$ & & $(3.82)^{* * *}$ \\
\hline \multirow[t]{2}{*}{ Loss Probability Ratio, Historical } & & & & 1.04 & \\
\hline & & & & $(41.21)^{* * *}$ & \\
\hline \multirow[t]{2}{*}{ Pzeworski Sprague, Local Volatility } & 0.26 & & & 0.04 & \\
\hline & $(3.28)^{* * *}$ & & & $(1.42)$ & \\
\hline \multirow[t]{2}{*}{ ENP Ratio } & -0.47 & -0.15 & -0.11 & & \\
\hline & $(-3.63) * * *$ & $(-3.15) * * *$ & $(-2.54)^{* *}$ & & \\
\hline \multirow[t]{2}{*}{ Adjusted Marginal Seats } & 0.53 & & & & -0.05 \\
\hline & $(1.86)^{*}$ & & & & $(-0.77)$ \\
\hline \multicolumn{6}{|l|}{ Model Fit } \\
\hline Chi, P-Value & 0.00 & 0.00 & 0.0046 & 0.00 & 0.00 \\
\hline
\end{tabular}

